\title{
Architecture of Normal Villous Trees
}

\section{Classification of Villous Types}

The ramifications of the villous trees can be subdivided into segments that differ mainly as to caliber, stromal structure, vessel structure, and position within the villous tree (Fig. 7.1). Five villous types have been described (Kaufmann et al., 1979; Sen et al., 1979; Castellucci \& Kaufmann, 1982a,b; Kaufmann, 1982; Castellucci et al., 1984, 1990, 2000; Burton, 1987), some of which can be further subdivided. As will be discussed below, all villous types derive from single precursors, the mesenchymal villi, which correspond to the tertiary villi of the early stages of placentation.

The following villous types have been described (Fig. 7.2):

1. Stem villi are characterized by a condensed fibrous stroma, arteries and veins, or arterioles and venules with a media or adventitia identifiable by light microscopy (Fig. 7.2). They comprise the following structures (see Fig. 7.17A):

- The main stems (truncus chorii) of a villous tree, which connect the latter with the chorionic plate;

- Up to four generations of branchings (rami chorii of the first to fourth orders), which are short, thick branches derived from the truncus already in the vicinity of the chorionic plate;

- Two to 30 (mean, 10) more generations of unequal dichotomous branchings (ramuli chorii of the first to tenth orders), which are more slender branches that extend into the periphery of the villous trees;

- A special group of stem villi represented by the anchoring villi; these villi are ramuli chorii, which connect to the basal plate by a cell column. The proliferating trophoblast cells of the latter act as a growth zone for both, the anchoring villus as well as for the basal plate.
2. Immature intermediate villi (Fig. 7.2) are bulbous, peripheral, immature continuations of stem villi. They are in a position comparable to that of the mature intermediate villi, that is, interposed between stem villi and peripheral branches, and they prevail in immature placentas. Normally, this type persists in small groups within the centers of the villous trees (placentones) and represents the immature forerunners of stem villi.

3. Mature intermediate villi (Fig. 7.2) are long, slender, peripheral ramifications characterized by the absence of vessels with a light-microscopically identifiable media and/or adventitia.

4. Terminal villi (Fig. 7.2) are the final, grape-like ramifications of the mature intermediate villi, characterized by their high degree of capillarization and the presence of highly dilated sinusoids. They represent the main sites of fetomaternal exchange.

5. Mesenchymal villi (Fig. 7.2) are the most primitive. They prevail during the first stages of pregnancy, where they are the forerunners of immature intermediate villi. During later stages of pregnancy, these villi are inconspicuous, mostly small, slender structures that can be found along the surfaces of immature intermediate villi or at the tips of mature intermediate villi. At this stage they also act as zones of villous proliferation and further branching.

The principal morphometric data of the various villous types are shown in Chapter 28, Table 28.7, and in Fig. 7.15.

\section{Stem Villi}

Trunci chorii, rami chorii, ramuli chorii, and the anchoring villi are summarized as stem villi because they exhibit similar histologic features and differ from each other only in caliber and position within the hierarchy of villous branching (Demir et al., 1997). The calibers vary from 


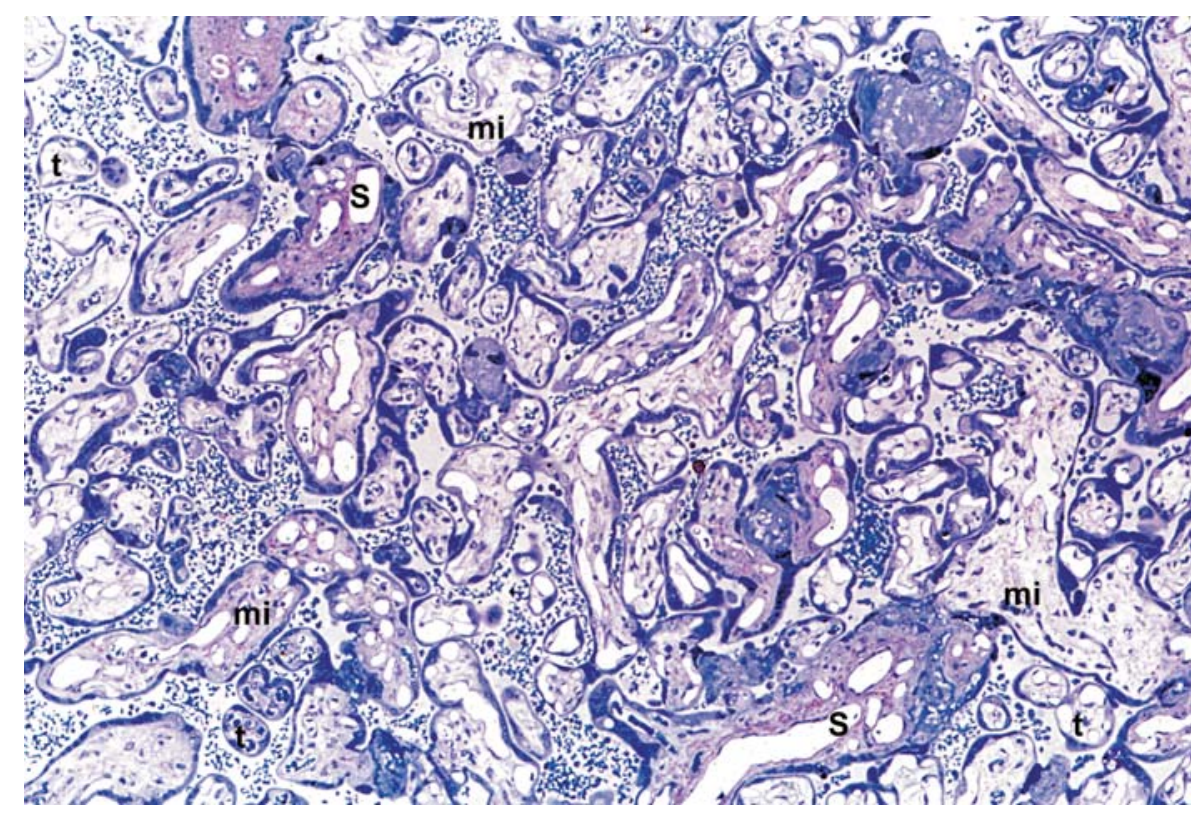

FIGURE 7.1. Semithin section from the 40th week postmenstruation (p.m.) to demonstrate the structural and staining variability of villous cross sections. Such pictures suggest that the villous tree is composed of several villous types that differ from each other regarding size, stromal fibrosis, and density of fetal vascularization. $s$, stem villi; mi, mature intermediate villi; $t$, terminal villi. $\times 140$.

7.3B). The adventitia of arteries and veins continues without sharp demarcation into the surrounding fibrous stroma of the villous core (Fig. 7.3A). The more centrally located connective tissue cells are myofibroblasts, whereas the more peripheral ones are noncontractile fibroblasts (Demir et al., 1992, 1997; Kohnen et al., 1995, 1996).

The central core of myofibroblasts is arranged around the stem vessels (Fig. 7.5) and has been called the perivascular sheath (Graf et al., 1994, 1995,1997). In stem villi that are not yet fully mature, an additional superficial rim of reticular stroma, composed of undifferentiated, proliferating connective tissue cells but deficient in fibers, may separate the fibrous stroma from the trophoblastic cover (see Chapter 8, Figs. 8.5 to 8.8). All three layers together represent a differentiation gradient; the most peripheral cells are the proliferating stem cells and the most central cells represent the highest degrees of differentiation. As soon as the trophoblastic cover is replaced by fibrinoid, the stromal stem cells stop proliferation and start differentiation, thus leading to a homogeneously fibrosed stem villus stroma (Demir et al., 1997). These data suggest paracrine interactions between trophoblastic epithelium and the stromal stem cells beneath. Macrophages are evenly distributed throughout the stroma (Demir et al., 1992, 1997). Occasionally mast cells are present in the vascular walls of the stem villi (see Chapter 6).

Function: Stem villi serve to mechanically support the structures of the villous trees. Considering the low degree of fetal capillarization and degenerative changes of the trophoblast, their share in fetomaternal exchange and and are accompanied by few paravascular capillaries (Fig. 

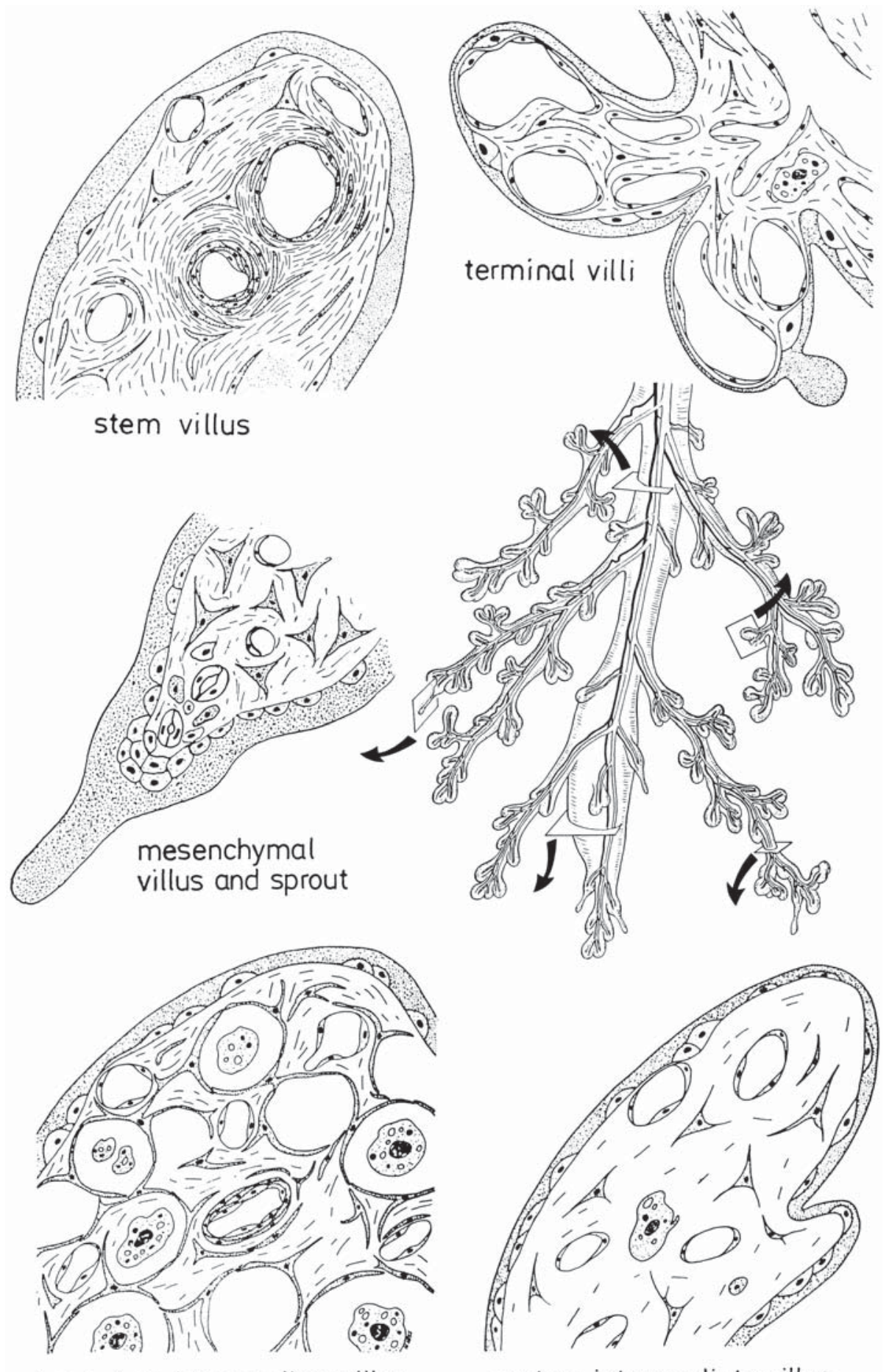

immature intermediate villus

mature intermediate villus

FIGURE 7.2. Simplified representation of the peripheral part of a mature placental villous tree, and typical cross sections of the various villous types. For further details see text. (Source: Kaufmann \& Scheffen, 1992, with permission.) 


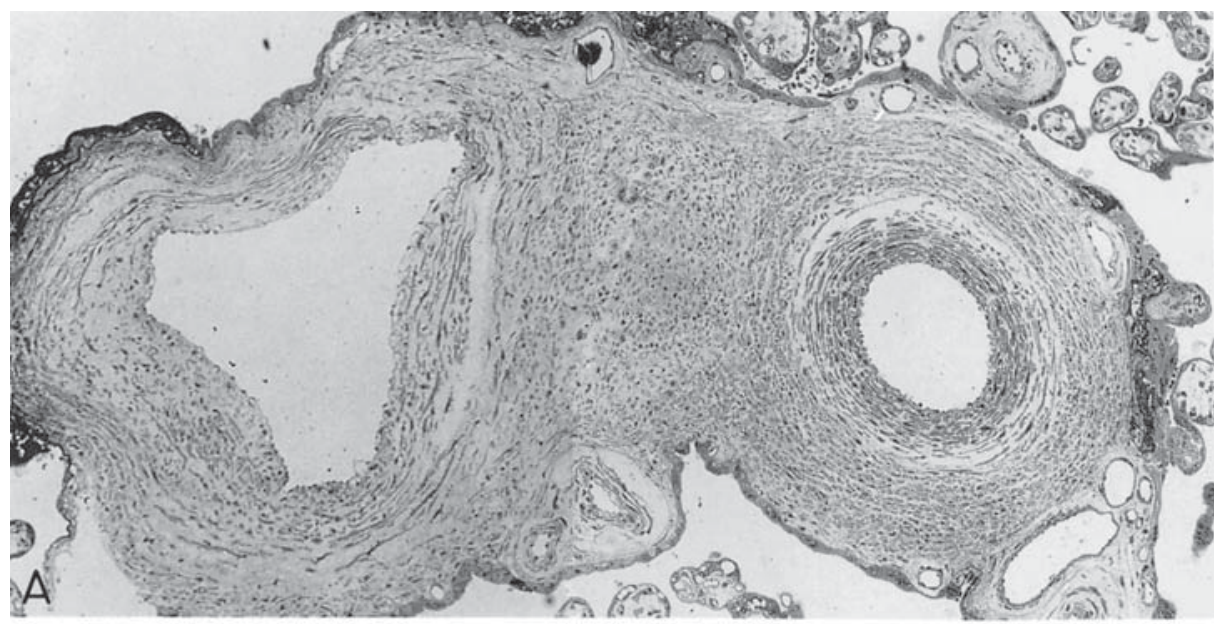

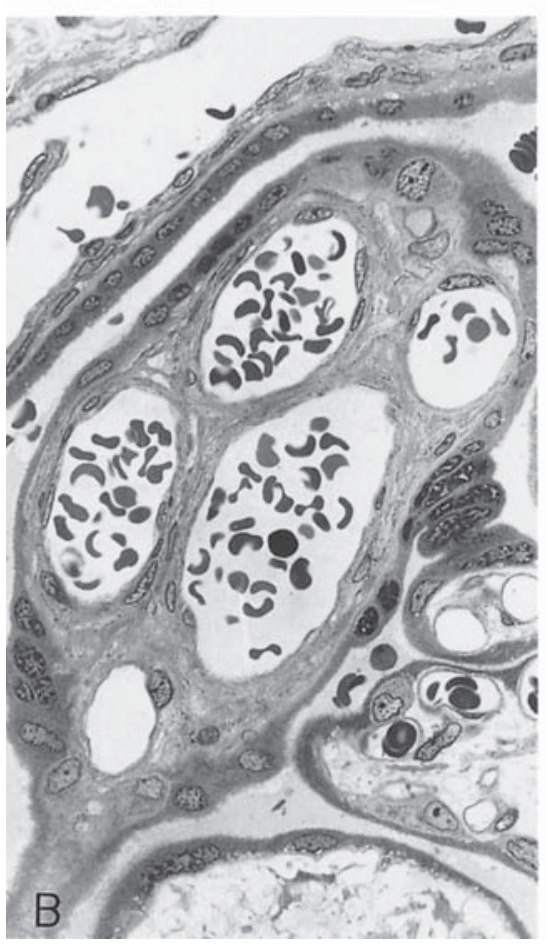

Figure 7.3. Structural features of stem villi. A: Semithin cross section of a large stem villus. Note that the adventitias of the artery (right) and vein (left) directly continue into the surrounding dense fibrous stroma of the villus. Superficially, numerous smaller vessels of the paravascular capillary net are seen. As is typical for stem villi of the mature placenta, the trophoblastic covering of this villus has been removed by fibrinoid in many places. $\times 115$. (Source: Leiser et al., 1985 , with permission.) B: More peripherally positioned stem villi of small caliber can

endocrine activity is presumably negligible. The presence of the large fetal vessels with thick muscular walls as well as the presence of extravascular myofibroblasts (Demir et al., 1992, 1997; Kohnen et al., 1996) makes their contribution to the autoregulation of the fetoplacental vascular system likely. Moreover, the myofibroblasts that are ori-

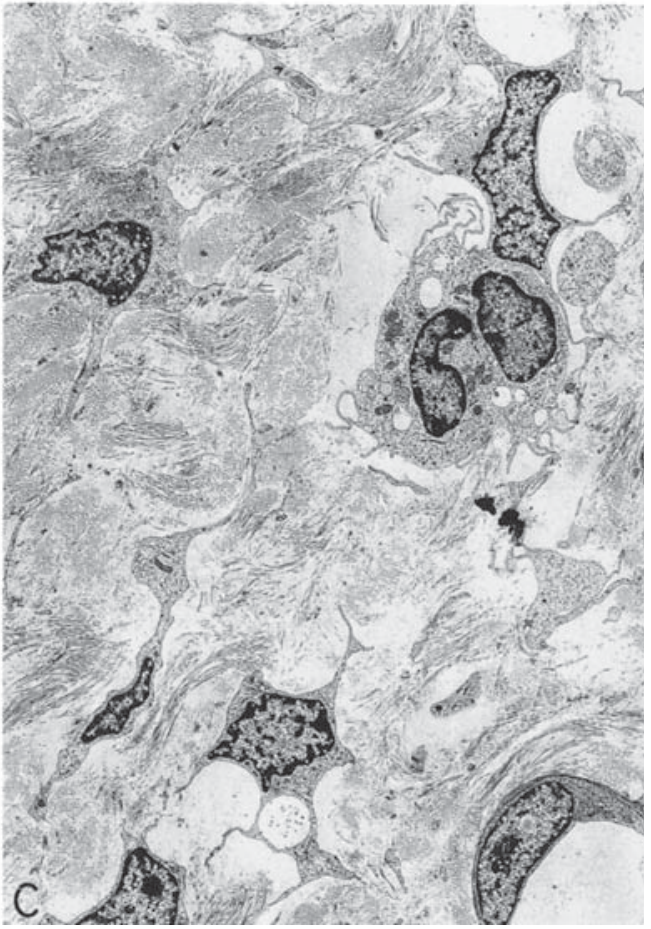

be identified by the condensed fibrous stroma, located between the fetal arterioles and venules (large lumens). Fetal capillaries are rare. $\times 430$. C: Transmission electron micrograph of the fibrous stroma of a stem villus. The interstitial space between the various types of connective tissue cells is mostly occupied by dense bundles of collagen fibers. Residual macrophages (upper right) partly surrounded by sail-like extensions of fibroblasts remind us that fibrous stroma is derived from reticular stroma. $\times 2400$.

ented in parallel to the longitudinal axis of the villous stems, the so-called perivascular sheath (Graf et al., 1994, 1995, 1997), may provide a regulating system for the maternal circulation in the intervillous space (Fig. 7.6). Because many of the larger villous stems are anchoring villi that connect the chorion and basal plate, their longi- 


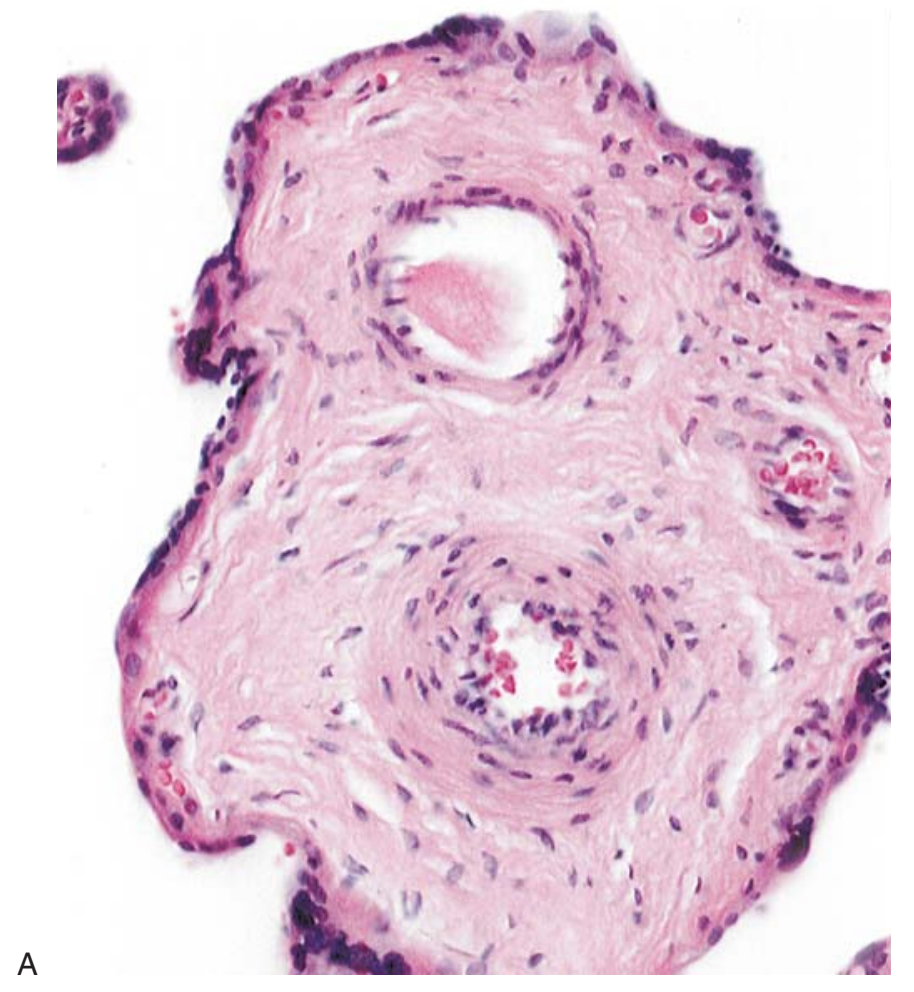

Figure 7.4. Peripheral stem villi. 40 weeks p.m. A: Structural features of a not yet fully matured stem villus from the center of a fetal cotyledon. The trophoblastic surface cover is still largely complete. Below the trophoblastic surface, locally paravascular capillaries can be seen, which are embedded in highly cellular connective tissue. B: In contrast, in a fully matured stem

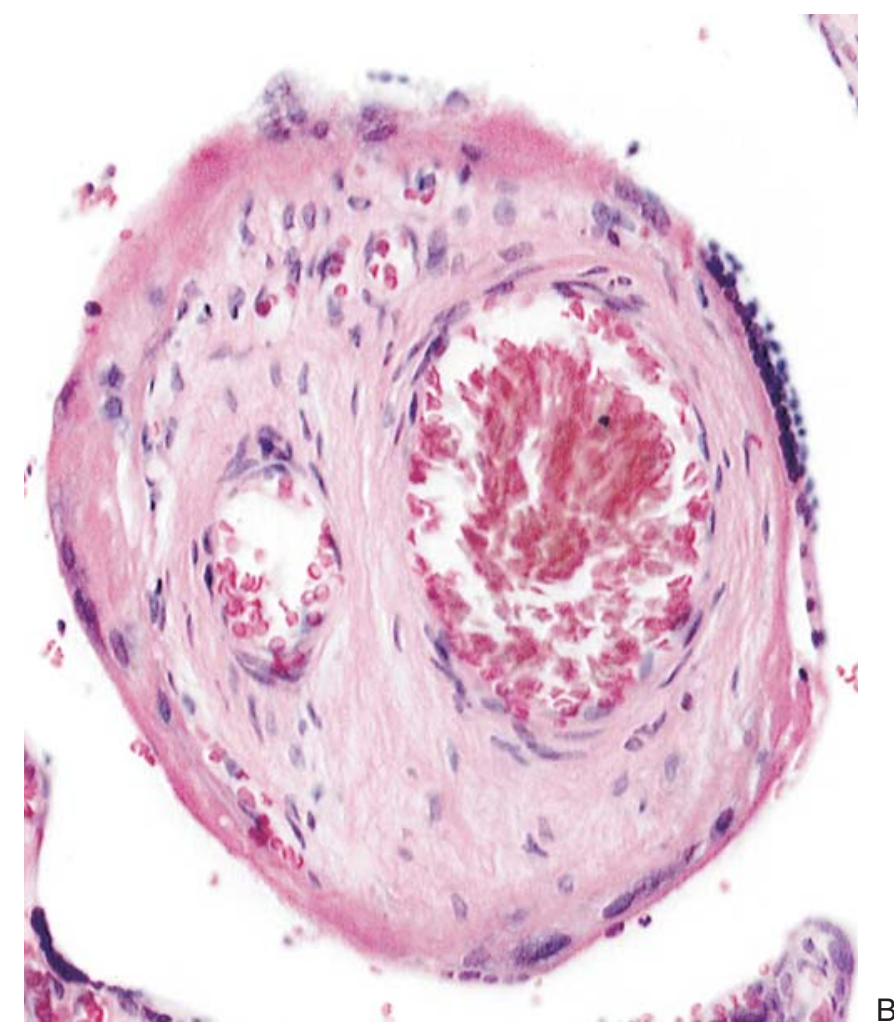

villus of the same size, derived from the peripheral parts of a fetal cotyledon of the identical placenta, the trophoblast is largely replaced by fibrinoid. The number of subtrophoblastic paravascular capillaries has decreased. Paraffin sections, hematoxylin and eosin $(\mathrm{H} \& \mathrm{E})$ stain. $\times 430$.

FIGURE 7.5. Mature placental villi immunostained with an antibody against $\gamma$ smooth muscle actin. This antibody stains both vascular smooth muscle cells and extravascular myofibroblasts. Nuclei counterstained with hematoxylin. Terminal villi and mature intermediate villi are immunonegative. Only stem villi are immunoreactive (brown). Cross sections of small-sized peripheral stem villi (upper and lower left) can be identified by immunoreactive smooth muscle cells concentrically surrounding villous arterioles and venules. In the centrally located longitudinally sectioned large-caliber stem villus between the immunopositive vessel walls (brown) and villous surface longitudinally sectioned, filiform, immunopositive myofibroblasts can be seen. $\times 100$.

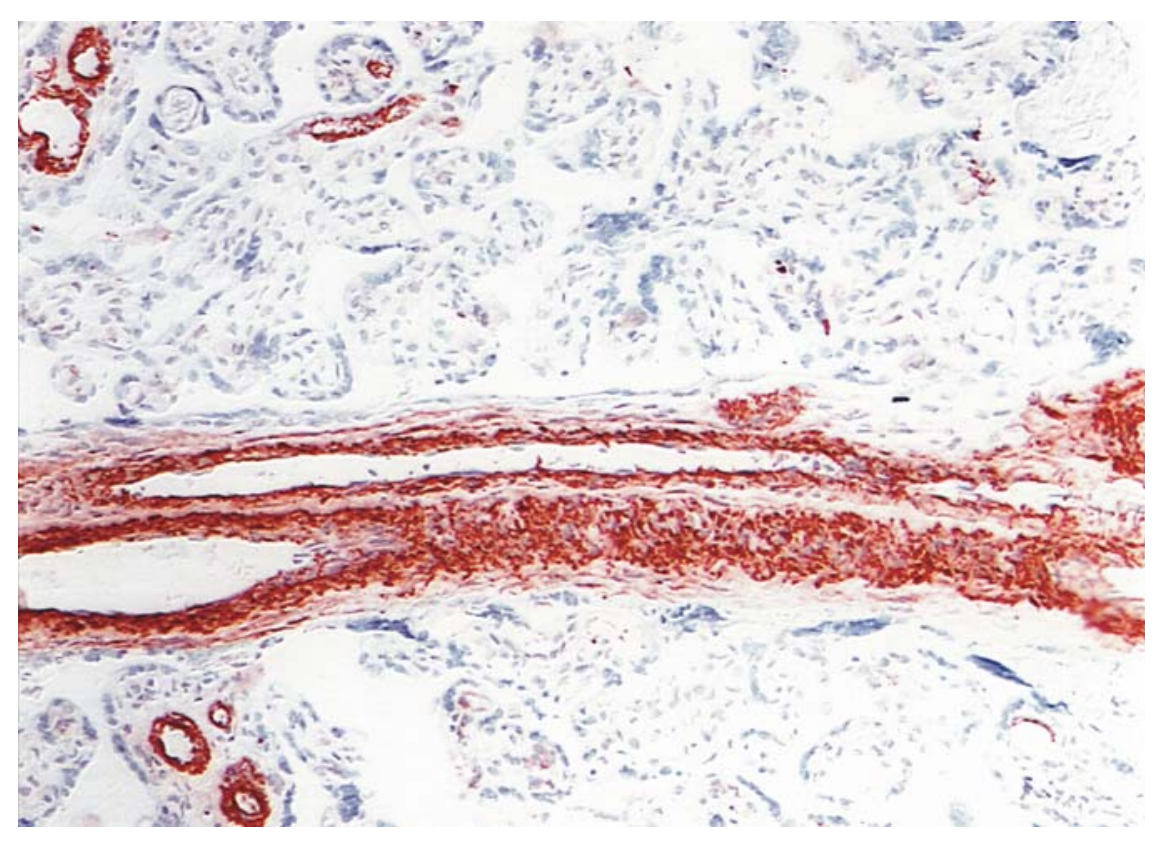




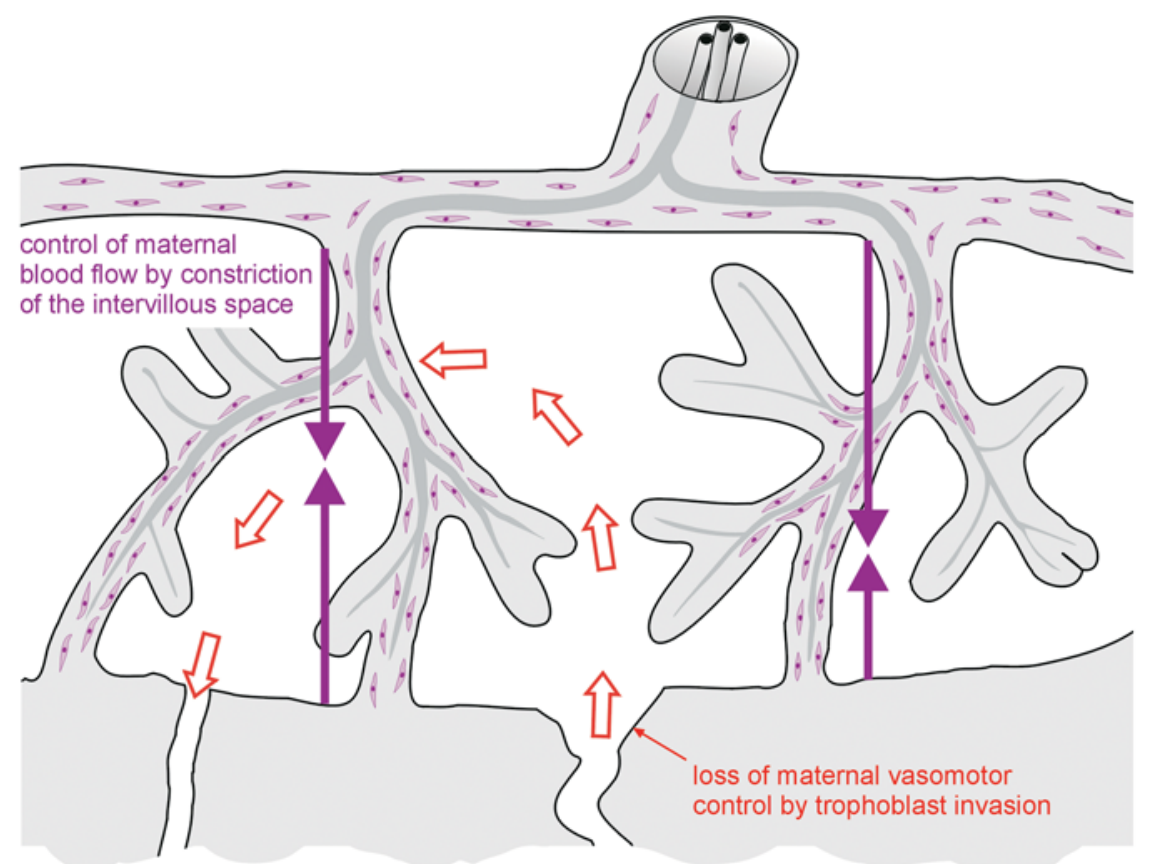

FIGURE 7.6. Schematic representation of the distribution of villous extravascular myofibroblasts (lilac) in large-caliber stem and anchoring villi. Upon contraction, these cells shorten the length of stem and anchoring villi, thereby reduce the width of the intervillous space, and increase the impedance of maternal intervillous blood flow (red arrows). In this way the fetus is thought to gain control over the maternal blood flow in the placenta, which the mother has lost as a consequence of trophoblast invasion of the uteroplacental arteries. tudinal contraction decreases intervillous volume (Krantz \& Parker, 1963; Kohnen et al., 1996; Demir et al., 1997; Farley et al., 2004) and very likely increases uteroplacental flow impedance. As was discussed in Chapter 6, in this way the fetus gains control over the maternal blood flow in the placenta, which the mother has lost as a consequence of trophoblast invasion of the uteroplacental arteries.

Blood flow and blood pressure control in the intervillous space are important, as has been demonstrated in vitro by Karimu and Burton (1994): pressure increases in the intervillous space reduce the width of the fetoplacental capillaries and thus increase fetoplacental impedance and reduce fetal perfusion of the placenta. Respective malregulation is thought to be a major mechanism in the pathogenesis of intrauterine growth restriction (IUGR) with absent or reversed end-diastolic (ARED) umbilical flow (Kingdom \& Kaufmann, 1997; Kingdom et al., 1997a). In conclusion, myofibroblasts may act as an important link adapting maternal and fetal perfusion of the placenta to each other. Increase in fetoplacental blood flow impedance caused by high pressure in the villous surrounding can be downregulated by relaxation of the myofibroblasts (Demir et al., 1997; Kohnen et al., 1995, 1996).

\section{Immature Intermediate Villi}

The immature intermediate villi have been known as immature villi or immature terminal villi. We have suggested that the term immature intermediate is more appropriate because these villi are not the only immature villous type, nor are they immature forerunners of later terminal villi (Kaufmann et al., 1979; Kaufmann, 1982). Rather, both types of intermediate villi (immature and mature intermediate villi) are differentiated successors of mesenchymal villi:

- The immature intermediate villi result from maturation of mesenchymal villi throughout the first two trimesters. Later they are transformed into stem villi.

- The mature intermediate villi, which derive from mesenchymal precursors during the last trimester, produce the terminal villi.

Thus, both "intermediate" villi are in an intermediate developmental position between mesenchymal and fully mature villi. Moreover, both are in an intermediate topographic position between stem villi and the most peripheral branches.

Histologically, immature intermediate villi have the same uniform, thick trophoblastic cover as stem villi (Figs. 7.2 and 7.7A,B). Epithelial plates are absent. During early pregnancy, Langhans' cells can be found below the syncytium on more than $50 \%$ of the villous surfaces. During late pregnancy, their prevalence is reduced to about $20 \%$.

The most characteristic feature of the immature intermediate villi is their reticular stroma, typified by numerous fluid-filled channels that are delimited by large, sail-like processes of the fixed stromal cells (Kaufmann et al., 1977b) (Fig. 7.7A-C). Hofbauer cells are inside the channels (Enders \& King, 1970; Castellucci \& Kaufmann, 1982a), suspended in some fluid.

Fetal vessels, such as the capillaries, arterioles, and venules, together with scarce bundles of collagen fibers, 

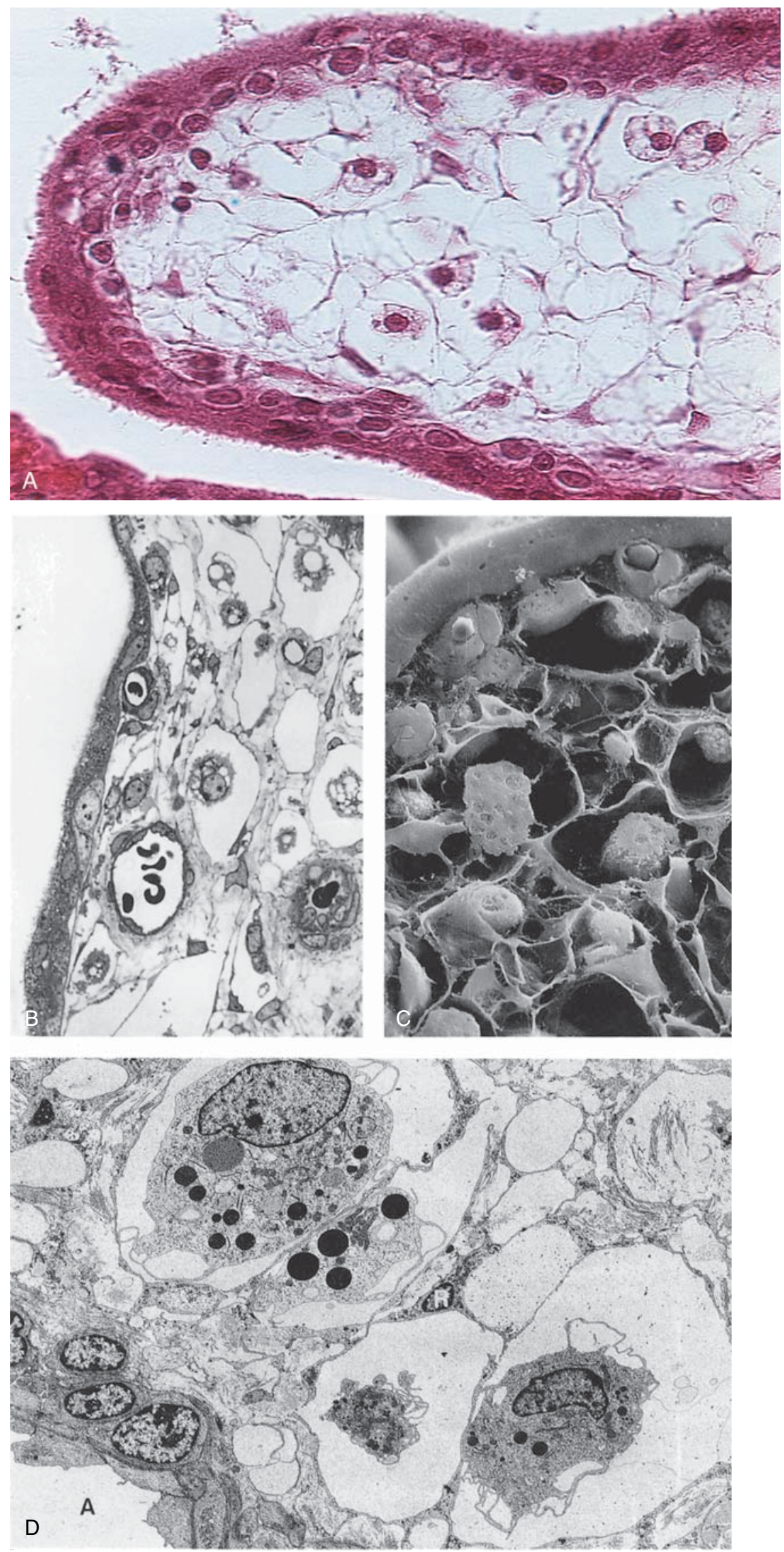

FIGURE 7.7. Typical structure of the immature intermediate villus. A: Paraffin section, 6th week p.m., H\&E. staining. Note the reticular appearance of the villous stroma with enmeshed highly vacuolated macrophages. $\times 400$. B: Semithin section of an immature intermediate villus from the 22nd week of pregnancy p.m. with its typical reticular stroma. The rounded, vacuolated macrophages (Hofbauer cells) are located in stromal channels, which are devoid of connective tissue fibers and therefore appear as empty holes. In faintly stained histologic sections, this feature can be misinterpreted as villous edema. $\times 520$. (Source: Kaufmann, 1981, with permission.) C: Scanning electron micrograph of a freeze-fractured immature intermediate villus shows the three-dimensional view of the reticular stroma with its characteristic stromal channels. $\times 1050$. (Courtesy of M. Castellucci.) D: Transmission electron micrograph of the reticular stroma of an immature intermediate villus at term. Several stromal channels, each containing a macrophage, can be identified. They are delimited from the surrounding connective tissue fibers by slender, sail-like extensions of fixed connective tissue cells (small reticulum cells, R). A small fetal arteriole (A) is seen in the lower left corner. $\times 2700$. (Source: Castellucci \& Kaufmann, 1982a, with permission.) 
are positioned between the stromal channels. Collagen bundles and vessel walls are separated from the lumina of the channels by the sail-like extensions of the connective tissue cells (Fig. 7.7B,D).

Transformation of immature intermediate villi into stem villi takes place during the first trimester. It is a gradual process that results in numerous intermediate steps. The starting point for the stromal fibrosis is the vascular wall. In the beginning, vessels acquire a distinct media and adventitia. The latter expands in later stages over the entire villous thickness. During this process the intercanalicular bundles of connective tissue fibers increase in diameter and thus compress the neighboring stromal channels. Eventually, they disappear. Residues can be found in all stem villi when one studies the stroma carefully for Hofbauer cells (Fig. 7.3C).

The first immature intermediate villi are formed around the 8 th week postmenstruation (p.m.) (compare Figs. 8.2 with 8.3; see Table 8.1). Between the 14th and 20th weeks (Figs. 8.3 to 8.5 ) they comprise most of the villous cross sections. At term, they may be completely absent; in most cases they can be found in small groups in the centers of the villous trees, the "placentones," where they still act as growth zones and produce new sprouts. At term, a volumetric share of $0 \%$ to $5 \%$ is normal for immature intermediate villi. This figure is applicable only when all parts of a placentone are equally represented in the histologic section. Sections restricted to the more central parts of a villous tree may show higher values and must thus be interpreted with care.

Function: The immature intermediate villi can be regarded as the growth centers of the villous trees. These produce the true sprouts (see hapter 15), which are transformed into mesenchymal villi as forerunners of all other villous types. Because of the long maternofetal diffusion distances, immature intermediate villi are the principal sites of exchange only during the first two trimesters, so long as other specialized villous types are not yet differentiated.

Immature intermediate villi may cause diagnostic problems, as their reticular stromal core has only a weak affinity for conventional stains because of the lack of collagen. Typical features are depicted in Figs. 7.7A,B and 8.3 through 8.5. The weaker staining, however, often results in the disappearance of the stromal channels so that the resulting histologic picture is that of a seemingly edematous villus that has accumulated much interstitial fluid. Such true edematous villi indeed exist. They are particularly impressive in hydatidiform moles but may also be found in maternal diabetes mellitus and some infections (e.g., syphilis, toxoplasmosis, cytomegalovirus infection). On the other hand, as experienced a pathologist as Harold Fox expressed some doubt when he wrote: "This has long been recognized as one of the characteristic features of placentae from diabetic women and from cases of materno-fetal rhesus incompatibility, though in fact only a proportion of such placentae are edematous." For other cases, he simply stated villous immaturity to be the correct designation (Fox, 1978, 1997). We believe that many villi referred to as "edematous villi" in the literature are in fact normal, immature intermediate villi (e.g., in most cases of rhesus incompatibility) (Pilz et al., 1980; Kaufmann et al., 1987). Naeye et al. (1983) have discussed in much detail the clinical significance of placental villous edema. We cannot exclude, based on their publication, that these changes represent true edematous alterations; however, at least one of the two examples they depicted, their Figure 2, is a normal, immature intermediate villus. They described it as follows: "Villous edema was recognized by the finding of open spaces in the interstitium of the villi," but they pointed to normal stromal channels.

This contradiction does not negate the existence of villous edema. It is probable that true generalized villous edema has functional significance, as it may compress the intervillous space and thus limit maternal blood flow (Alvarez et al., 1972; Fox, 1978); it also increases the maternofetal diffusion distances. Fox (1978) stated that "villous oedema is usually considered to be of no clinical significance," and that "there is, as yet, no clear evidence that villous oedema has, in itself, any effect on fetal growth or nutrition." Perhaps this negative conclusion is based on the interpretation that most cases of "villous edema" are misinterpretations of normal villous structures.

For further details regarding normal structure and function of immature intermediate villi, see the publications by Castellucci and Kaufmann (1982a,b), Castellucci et al. (1984), Highison and Tibbitts (1986), Kaufmann (1982), Kaufmann et al. (1977b, 1979), and Sen et al. (1979).

\section{Mature Intermediate Villi}

Mature intermediate villi are long slender villi with diameters of about 60 to $150 \mathrm{~mm}$. As soon as their surfaces bear terminal villi, their shape is characterized by numerous slight bends at points where the terminal villi branch off, resulting in a typical zigzag course (see Fig. 7.10A,D). This pattern is absent when terminal side branches are not present (see Chapter 15), features that may be of diagnostic importance. Mature intermediate villi have roughly the same diameters as terminal villi. Because of their zigzag courses, longitudinal histologic sections are rare. As long as mature intermediate villi do not produce terminal villi, they do not pursue the zigzag course but, rather, remain straight. This appearance, in sections of weeks 32 to 34 , is one of groups of cross sections that alternate with bundles of slender longitudinal sections (see Chapter 15, Fig. 15.9).

The trophoblast cover of mature intermediate villi is much thinner than those of stem and immature interme- 
diate villi. Where it covers capillaries, it often is reduced to epithelial plates of less than $1 \mu \mathrm{m}$ thickness. Also the rare cytotrophoblastic cells are mostly found close to the capillaries.

The stroma of mature intermediate villi is composed of seemingly unoriented, loose bundles of connective tissue fibers and fixed connective tissue cells. In some places it surrounds rudimentary narrow stromal channels that are usually devoid of macrophages (Figs. 7.8 and 7.9).

The vessels comprise numerous capillaries, small terminal arterioles, and collecting venules. The media of the latter is usually too thin for light microscopic identification. Because the terminal villi originate from the surface of the mature intermediate villi, there is a gradual transition. Cross sections are defined as mature intermediate villi, the stroma of which contains fewer than $50 \%$ vascular lumens (see Table 28.6). Roughly one fourth of the villous volume in the normal term placenta is composed of this villous type (see Table 28.7).

Function: The mature intermediate villi produce the terminal villi. The high degree of fetal vascularization and the large share in the exchange surface make them important for fetomaternal exchange. When studying the enzyme patterns and the immunolocalization of placental hormones, one gains the impression that they are prominent sites for hormone production. In analogy with the vascular bed of other organs, one may conclude that the presence of terminal arterioles allows participation in vasoregulation and thus intravillous blood distribution (Nikolov \& Schiebler, 1973).

\section{Terminal Villi}

Terminal villi are the final ramifications of the villous tree during the last trimester. They are grape-like outgrowths of the mature intermediate villi, where they appear as single or poorly branched side branches (Fig. 7.10). The peripheral end of the mature intermediate villus normally branches into a larger aggregate of such terminal villi (Fig. 7.10B). They usually connect to the mature intermediate villi by a narrow neck region (Fig. 7.10C,D; see also Fig. 7.20A). Only an extremely small proportion of the terminal villi are directly connected to stem villi or to immature intermediate villi.

Histologically, the trophoblast cover of terminal villi is thin and forms numerous epithelial plates. Depending on

FIGURE 7.8. Semithin section of the richly vascularized peripheral end of a mature intermediate villus (upper half), with a terminal villus (lower half) arising at a narrow neck region (center). The fetal vessels show the typical composition of narrow capillaries and dilated sinusoids. The latter are closely related to the trophoblastic surface, forming thin epithelial plates. $\times$ 430. (Source: Kaufmann et al., 1979, with permission.)

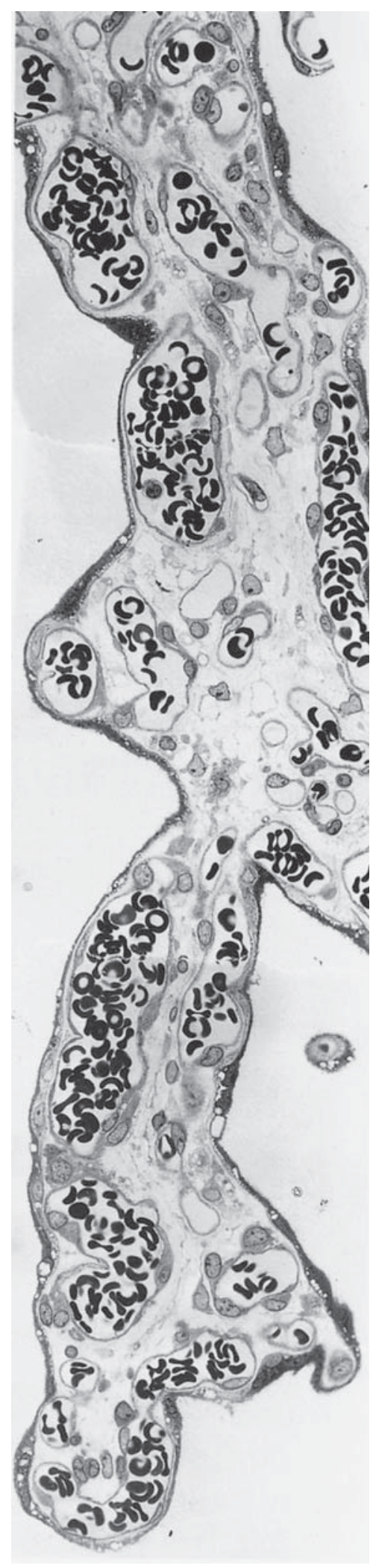



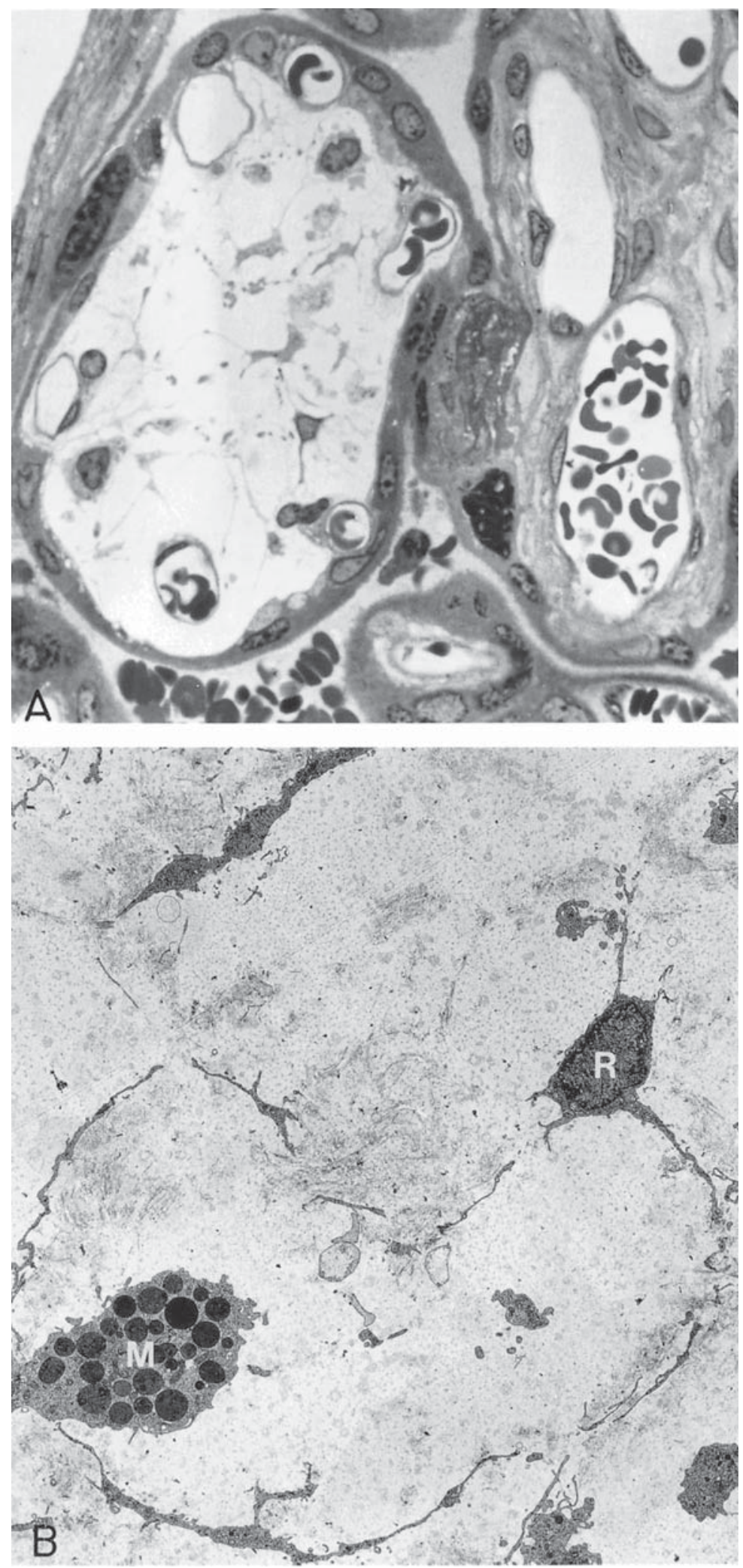

FIGURE 7.9. Typical structure of mature intermediate villi. Semithin cross section of the poorly vascularized, more central portion of a mature intermediate villus. Note the peripheral position of the small fetal capillaries and the ample connective tissue, deficient in cells and fibers. The syncytiotrophoblastic covering of the villus is more uniform in structure than that of the terminal villi. $\times 730$. B: Transmission electron micrograph of the typical loose connective tissue of a mature intermediate villus. The seemingly unoriented mixture of small reticulum cells (R) with long processes, macrophages $(\mathrm{M})$, and loosely arranged connective tissue fibers is highly characteristic for this villous type. $\times 2150$. 

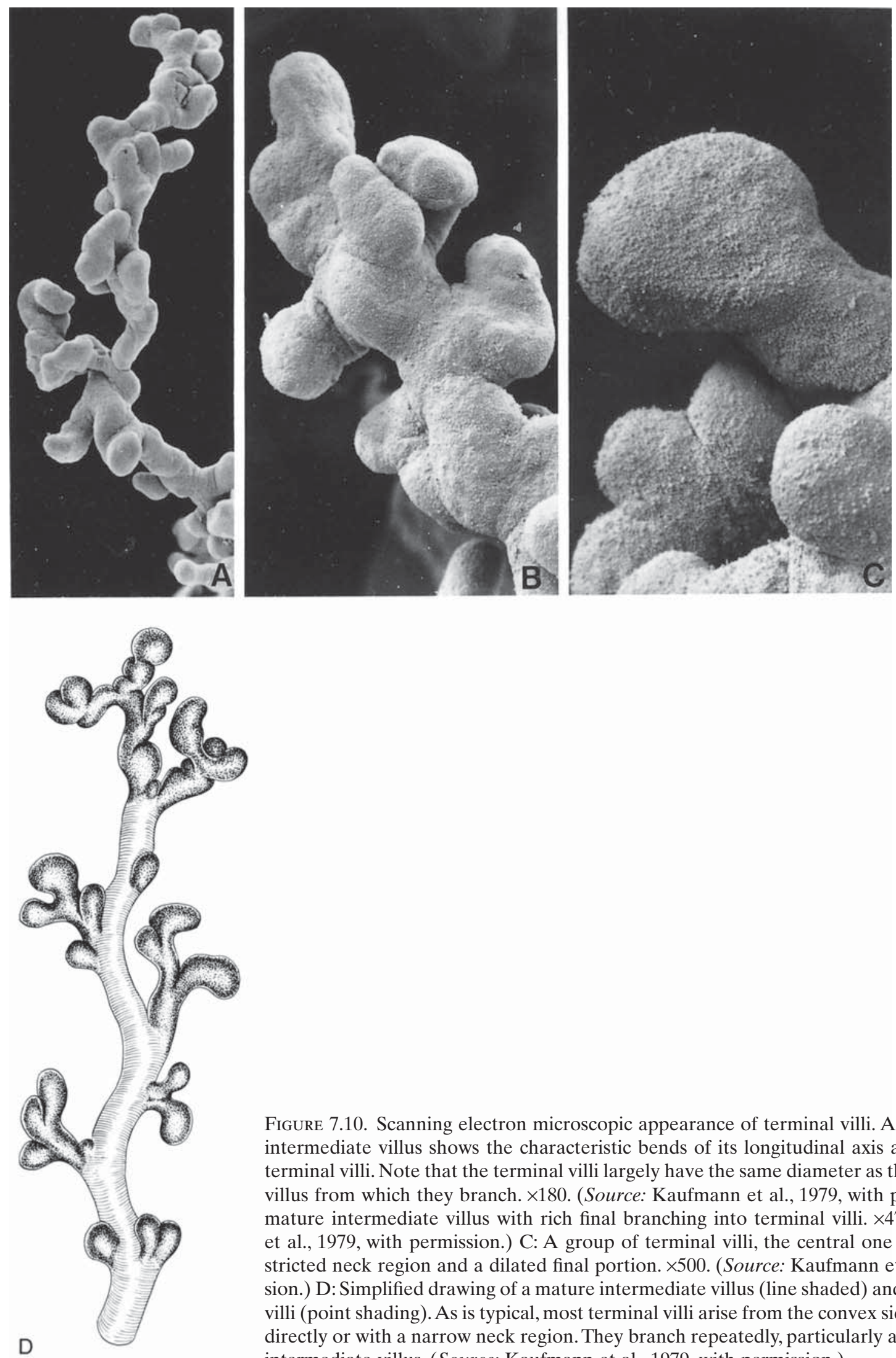

FIGURE 7.10. Scanning electron microscopic appearance of terminal villi. A: A single, long, mature intermediate villus shows the characteristic bends of its longitudinal axis and multiple grape-like terminal villi. Note that the terminal villi largely have the same diameter as the mature intermediate villus from which they branch. $\times 180$. (Source: Kaufmann et al., 1979, with permission.) B: Tip of a mature intermediate villus with rich final branching into terminal villi. $\times 470$. (Source: Kaufmann et al., 1979, with permission.) C: A group of terminal villi, the central one showing a typical constricted neck region and a dilated final portion. $\times 500$. (Source: Kaufmann et al., 1979, with permission.) D: Simplified drawing of a mature intermediate villus (line shaded) and its branching terminal villi (point shading). As is typical, most terminal villi arise from the convex sides of each bend, either directly or with a narrow neck region. They branch repeatedly, particularly at the end of the mature intermediate villus. (Source: Kaufmann et al., 1979, with permission.) 
the quality of tissue preservation, they amount to $30 \%$ to $40 \%$ of the villous surface (see Table 28.6 and Fig. 7.20).

Fetal vessels are represented by sinusoidally dilated capillaries. The latter occupy more than $50 \%$ of the stromal volume and more than $35 \%$ of the villous volume (see Table 28.6) (Figs. 7.8 and 7.11; also see Fig. 7.20) (Kaufmann et al., 1979; Sen et al., 1979). The fetal sinusoids are in intimate contact with the trophoblastic surface and form the epithelial plates.

The remaining connective tissue has scant fibers and cells. Macrophages are rare (Fig. 7.11). The average diameter of terminal villi ranges from 30 to $80 \mu \mathrm{m}$. Their histologic appearance differs, depending on where they are sectioned. The slender neck region, containing mostly undilated capillaries, is easily differentiated from the bulbous tip containing mostly sinusoids and from flat sections across tips (see Fig. 7.20).

It must be pointed out that the light microscopic appearance is heavily influenced by the mode of tissue preservation. Delayed fixation (see Tables 28.6 and 28.9), inappropriate osmolarity of the fixative (see Table 28.10), and time and mode of cord clamping (see Table 28.9) influence the villous structure. In particular, the highly dilated sinusoids respond to postpartal changes of fetal blood pressure. They tend to collapse within minutes, thus dramatically changing the villous proportions (Voigt et al., 1978; Burton \& Palmer, 1988). An increase in pressure in the peripheral fetal vessels, as during cord compression (knots, torsion, nuchal cord), leads to congestion in the terminal capillaries and results in seemingly "hyper-

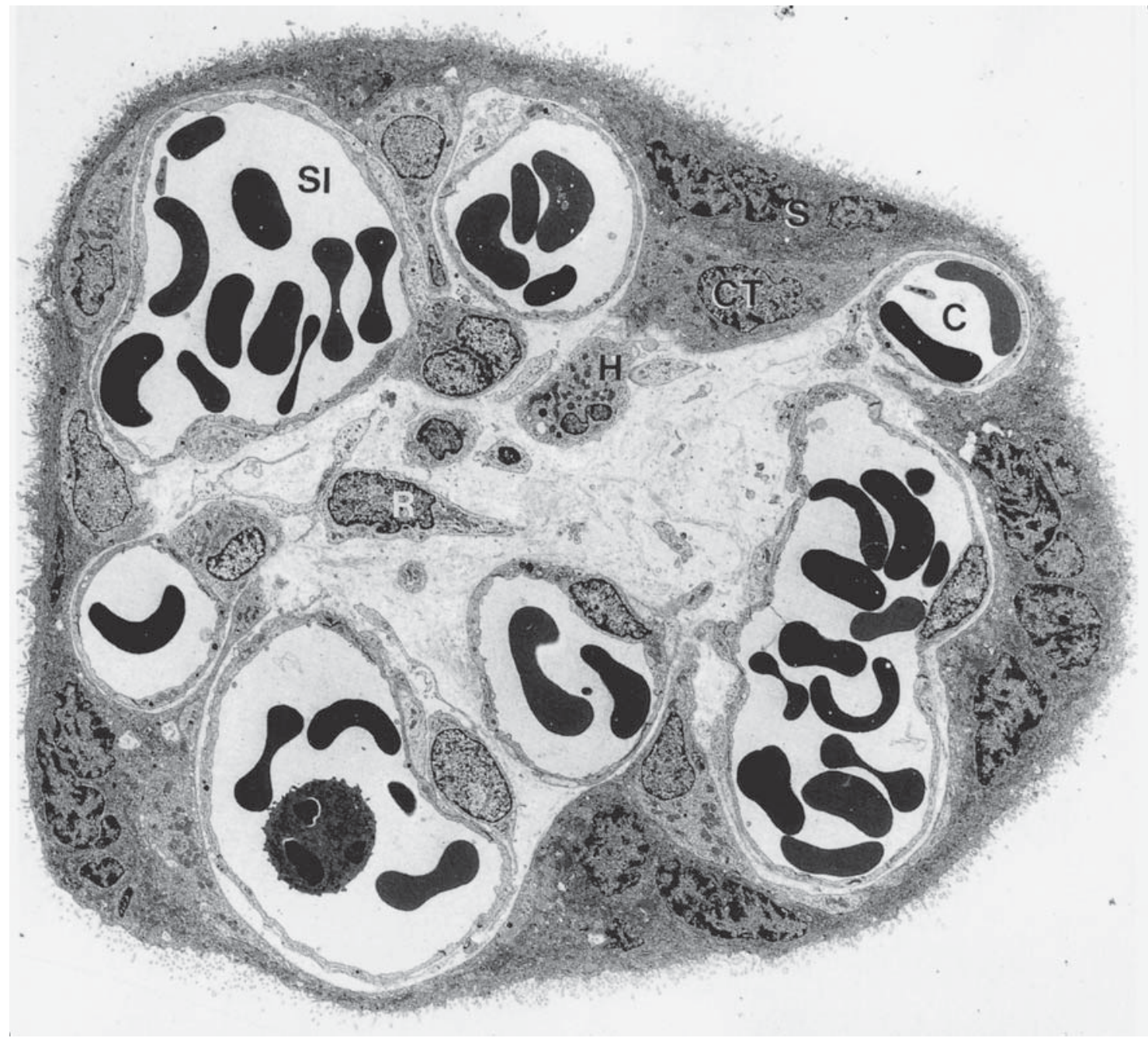

FIGURE 7.11. Survey electron micrograph of a typical, well-fixed terminal villus illustrates the high degree of fetal capillarization, with some of the capillaries (C) being narrow and others dilated, forming sinusoids (SI). The sparse connective tissue is composed of macrophages $(\mathrm{H})$, fibroblasts or small reticulum cells
(R), and a loose meshwork of connective tissue fibers. The stroma is surrounded by a structurally highly variable layer of syncytiotrophoblast (S) below which a few cytotrophoblastic cells (CT) can be seen. $\times 2000$. (Source: Schiebler \& Kaufmann, 1981, with permission.) 
capillarized" villi ("chorangiosis"). We found this feature frequently with preterm rupture of membranes, and the correlation is highly significant. There was also an increase in villous blood volume, sometimes of more than $50 \%$. It may be speculated that loss of amnionic fluid predisposes to compression of the umbilical veins and thus inhibits placental venous backflow (Paprocki, 1992).

Function: The high degree of vascularization and minimal mean maternofetal diffusion distance of about $3.7 \mu \mathrm{m}$ (Voigt et al., 1978; Sen et al., 1979; Feneley \& Burton, 1991) (see Table 28.6) make this villous type the most appropriate place for diffusional exchange (e.g., transfer of oxygen, carbon dioxide, and water). In the normal mature placenta, the terminal villi comprise nearly $40 \%$ of the villous volume. Because of their small diameters, the sum of their surfaces amounts to $50 \%$ of the total villous surface. They comprise about $60 \%$ of villous cross sections. These figures explain why a remarkable reduction of terminal villi (as in IUGR with ARED umbilical flow) (Macara et al., 1996; Kingdom et al., 1997b) may lead to fetal hypoxia. Also, according to Fox (1978), there is a clear-cut inverse relation between the incidence of villous vasculosyncytial membranes and fetal hypoxia.

\section{Mesenchymal Villi}

The term mesenchymal villi has been proposed for the first generation of tertiary villi, which are characterized by a seemingly primitive stromal core resembling fetal mesenchyme (Castellucci \& Kaufmann, 1982a). From the 5th (onset of villous vascularization) to the 7th week p.m., this is the only vascularized villous type. At later stages, their number continuously decreases. Some of these villi are still found at term, indicating that expansion of the villous trees in normal pregnancies never comes to a standstill.

These villi comprise the first generation of newly formed villi, not only during the first trimester but also at later stages. Differentiation of every new villus starts in the mesenchymal stage. It is derived from trophoblastic sprouts by mesenchymal invasion and vascularization and precedes the formation of new intermediate villi (Figs. 7.12 to 7.14). In accordance with their role as proliferating segments, the mesenchymal villi decrease in number as pregnancy advances. At term, they are primarily found in small numbers on the surfaces of immature intermediate villi. They are located in the centers of the villous trees.

Mesenchymal villi have thick trophoblast surfaces with large numbers of Langhans' cells, which are interposed between syncytium and the trophoblastic basal lamina on $50 \%$ to $100 \%$ of the villous surfaces (Castellucci et al., 1990, 2000).

The stroma is characterized by loosely arranged collagen fibers that enmesh mesenchymal and some Hofbauer cells (Fig. 7.14). Condensed collagen is sometimes observed.

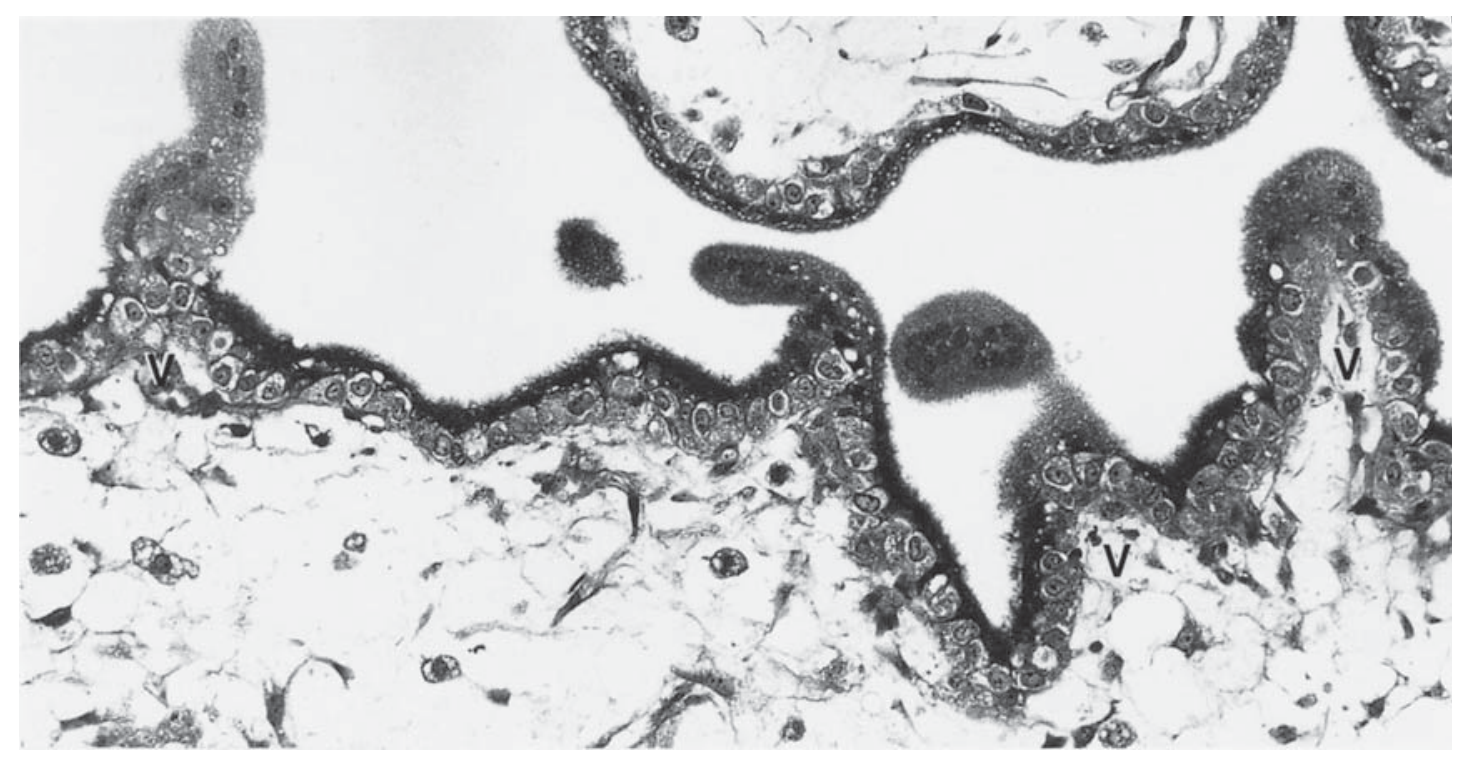

Figure 7.12. Structural features of villous sprouts and mesenchymal villi in a methacrylate section of placental villi from the 6th week p.m. From a larger mesenchymal villus (below), several true sprouts protrude into the intervillous space. At their tips, the latter consist merely of syncytiotrophoblast. Nearer the base they are invaded by cytotrophoblast and finally by loose connective tissue (villous sprout, V). The latter is the forerunner of a new mesenchymal villus, which becomes established as soon as the sprout is invaded by fetal vessels. $\times 390$. 


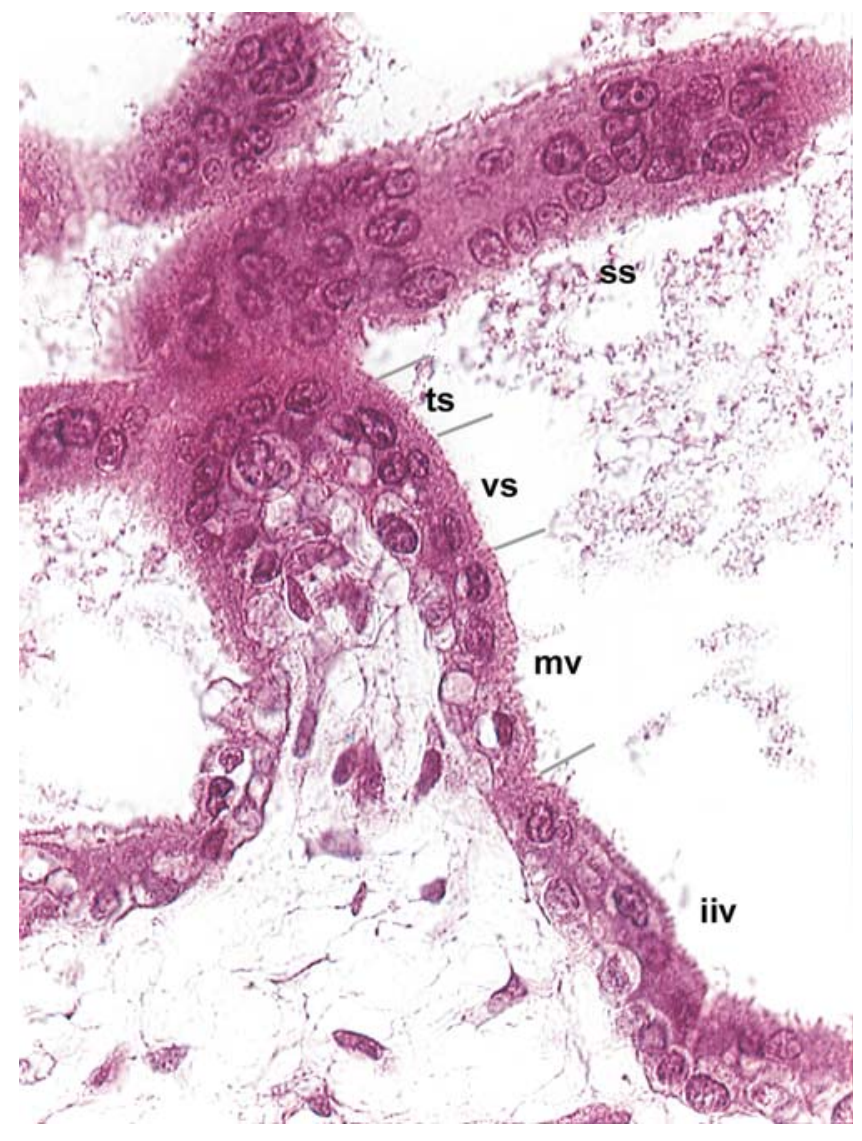

FIGURE 7.13. This longitudinal section of a newly sprouting villus demonstrates the various stages of the sprouting process: as the first step, a group of syncytial sprouts (upper third, ss) is formed; these become invaded by cytotrophoblast (trophoblastic sprout, ts), followed by invasion by dense, avascular cellular stroma (villous sprout, vs). Development of fetal capillaries marks the transition into a mesenchymal villus (mv). The latter branches from an immature intermediate villus (iiv), which was the starting point of the sprouting process. Paraffin section, H\&E. staining, $\times 560$.
Fetal capillaries are poorly developed and never show sinusoidal dilatation. Near the villous tips, capillary lumens may still be occluded and are made up of a string of endothelium (Figs. 7.13 and 7.14); several steps in the formation of lumens can be observed.

The still unvascularized tips of mesenchymal villi are referred to as villous sprouts. At their tips, the villous sprouts continue into trophoblastic sprouts (Figs. 7.2, 7.12, and 7.13). In summary, the typical sequence of structures representing the process of villous sprouting is as follows: syncytial sprout, trophoblastic sprout with a central core of cytotrophoblast, villous sprout with some connective tissue, and mesenchymal villus with fetal capillaries (Fig. 7.13).

Function: During the first weeks of pregnancy, mesenchymal villi are not only the places of villous proliferation but also the sites of maternofetal exchange and nearly all endocrine activity. With advancing pregnancy and development of more advanced villous types, their functional importance is reduced to villous growth. At term, their share in total villous volume is far below $1 \%$ (Fig. 7.15) (Castellucci et al., 1990, 2000).

\section{Immunohistochemistry of Villous Types}

Villous classification is based on two parameters (Kaufmann et al., 1979; Kohnen et al., 1996; see also foregoing text):

- Differences in stromal structure (mesenchymal, reticular, or fibrous);

- Distribution of the various segments of the fetal vessel system: (1) capillaries without media and adventitia; (2) arterioles and venules with thin media and nonfibrous adventitia; or (3) arteries and veins with thick muscular media and fibrous adventitia.

Consequently, immunohistochemistry of cytoskeletal proteins within the villous stroma and the vessel walls provides a useful tool for the identification of various villous types. The above-mentioned differences in stromal structure as well as the differences in vascular wall structure are reflected by different degrees of cytoskeletal differentiation. According to Kohnen et al. (1995, 1996) and Demir et al. (1997), the following mesenchymal derivatives show a highly specific distribution pattern 


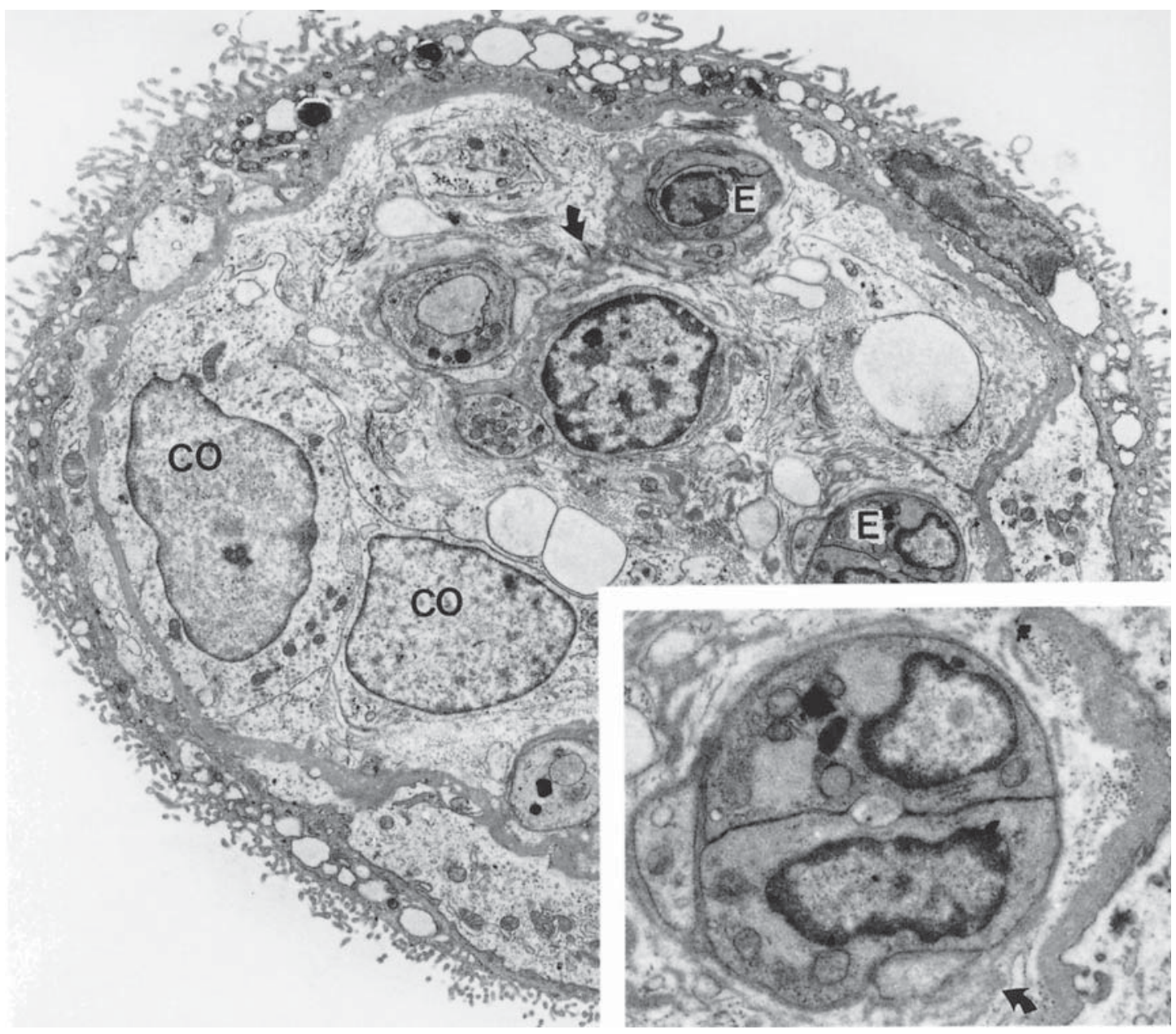

FIgURE 7.14. Transmission electron microscopic cross section of a transitional stage between a villous sprout and a mesenchymal villus from the term placenta. This villus is characterized by large, epithelioid connective tissue cells (CO) and capillary sprouts. The latter consist of densely packed endothelial cells (E) connected to each other by tight junctions, showing no or only minimal lumens (inset), and surrounded by basal laminas. The latter form sometimes thick convolutions (arrow). It is interesting to note that many of the villous sprouts and mesenchymal villi observed exhibit degenerative signs (compare the highly vacuolated syncytiotrophoblast), which can be explained by the fact that not all syncytial sprouts survive, depending on the local circulatory conditions in the intervillous space. By this selection, the shape of the villous tree is adapted to the intervillous hemodynamics. $\times 5200$; inset $\times 13,000$. (Source: Demir et al., 1989, with permission.) 


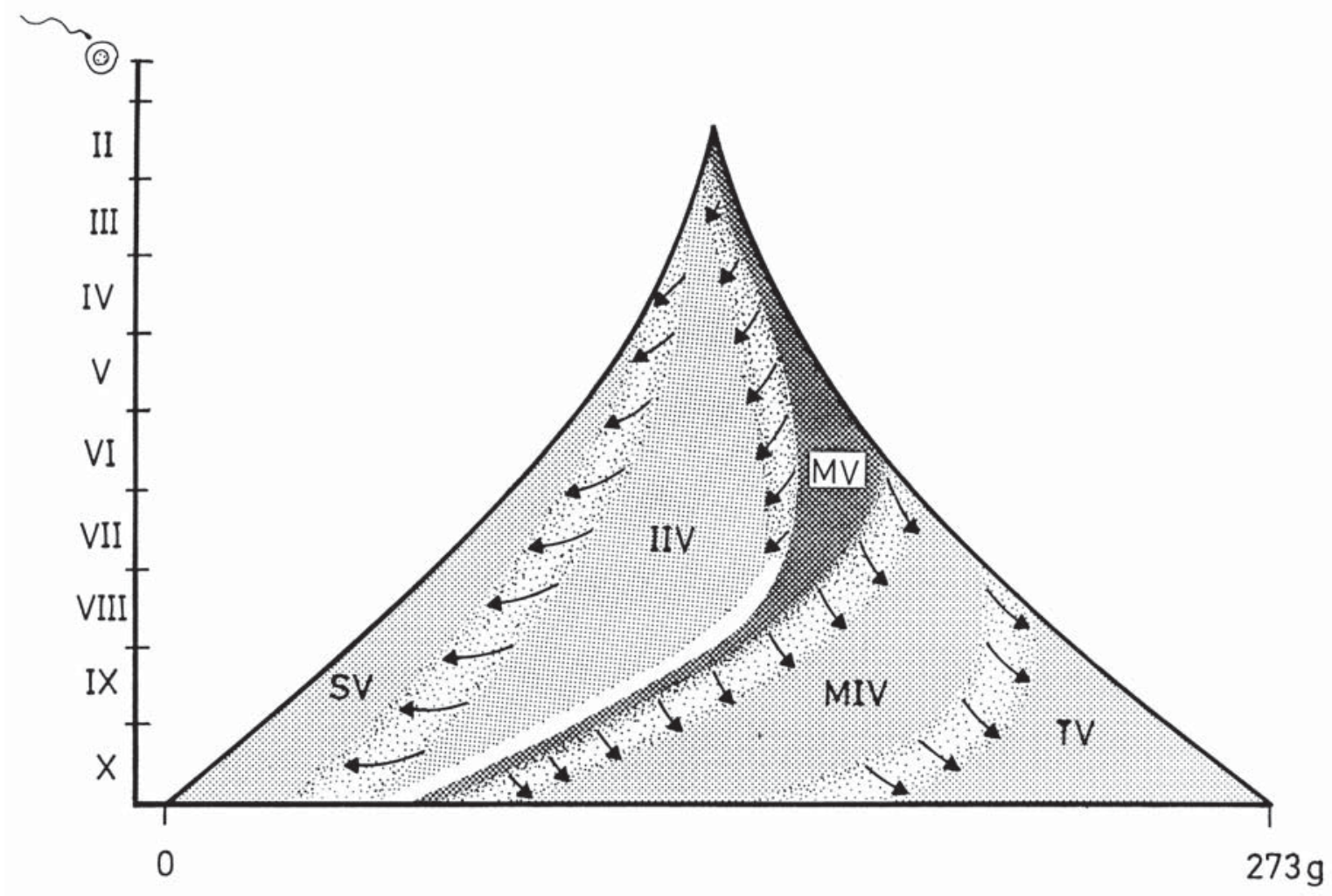

FIGURE 7.15. Development of total villous weight and the weight of the various villous types (in grams), from the 2nd month p.m. until term. Abscissa, villous weight in grams per placenta; ordinate, gestational age p.m. in months. The arrows demonstrate the routes of transformation or formation of villi. The lightly stippled areas around the arrows symbolize transitional stages between closely related villous types. At term, the mean villous weight per placenta amounts to $273 \mathrm{~g}$. After morphometric evaluation of representative histologic sections, this weight can be assigned to the various villous types at term as follows: stem villi (SV), $31 \mathrm{~g}, 11 \%$; transitional stages to immature intermediate villi, $24 \mathrm{~g}, 9 \%$; immature intermediate villi (IIV), 9g, 3\%; mesenchymal villi (MV), less than 1\%; transi- tional stages to mature intermediate villi, $3 \mathrm{~g}, 1 \%$; mature intermediate villi (MIV), $77 \mathrm{~g}, 28 \%$; transitional stages to terminal villi, 31g, 11\%; terminal villi (TV), 95g, 35\%. Rough data for earlier stages of pregnancy can be deduced from the diagram. It must be pointed out that these data are preliminary, obtained from only a few placentas. There is a considerable local and interindividual variation. It becomes evident that the sum of stem villi (SV) plus immature intermediate villi (IIV) decreases throughout the last 3 months of pregnancy; the decrease can be explained by a massive transformation of stem villi into fibrinoid. (Source: Modified from Castellucci et al., 1990, with permission.) within the various villous types and can be identified immunohistochemically by the expression of the cytoskeletal proteins listed (Table 7.1):

1. Undifferentiated mesenchymal cells express only vimentin (V cells). They are the only fixed connective tissue cells in undifferentiated mesenchymal villi.

2. Fibroblasts express vimentin and desmin (VD cells), and partly even $\alpha$-smooth muscle actin (VDA cells). Together with the former cell type they make up the stromal core in mesenchymal villi in later pregnancy as well as in mature intermediate and terminal villi.
3. Myofibroblasts in addition to vimentin and desmin are characterized by the expression of $\alpha$ - and $\gamma$-smooth muscle actin (VDAG cells). These are the typical representatives of immature intermediate villi.

4. The highest stages of myofibroblast differentiation are characterized by the additional expression of smooth muscle myosin (VDAGM cells). These latter cells share most but not all structural features with smooth muscle cells (see Chapter 6). Their appearance characterizes the transformation of an immature intermediate villus into a stem villus. 
TABLE 7.1. Immunohistochemical classification of villous types using monoclonal antibodies directed against various cytoskeletal filaments

\begin{tabular}{|c|c|c|c|c|c|c|c|}
\hline Villous type & Stroma & Vimentin & Desmin & $\alpha$-sm-Actin & $\gamma$-sm-Actin & sm-Myosin & Ultrastructure \\
\hline $\begin{array}{l}\text { Undifferentiated } \\
\text { mesenchymal } \\
\text { villi }\end{array}$ & & + & 0 & 0 & 0 & 0 & Mesenchymal cells \\
\hline $\begin{array}{l}\text { Differentiated } \\
\text { mesenchymal } \\
\text { villi }\end{array}$ & & + & + & 0 & 0 & 0 & $\begin{array}{l}\text { Mesenchymal and } \\
\text { reticulum cells }\end{array}$ \\
\hline \multirow{3}{*}{$\begin{array}{l}\text { Immature } \\
\text { intermediate } \\
\text { villi }\end{array}$} & Reticular stroma & + & + & 0 & 0 & 0 & Reticulum cells \\
\hline & $\begin{array}{l}\text { Fibrosed } \\
\text { surrounding of } \\
\text { larger vessels }\end{array}$ & + & + & + & 0 & 0 & $\begin{array}{l}\text { Fibroblasts or } \\
\text { myofibroblasts }\end{array}$ \\
\hline & $\begin{array}{l}\text { Inner adventitia of } \\
\text { larger vessels }\end{array}$ & + & + & + & + & 0 & Myofibroblasts \\
\hline \multirow[t]{3}{*}{$\begin{array}{l}\text { Stem villi } \\
\quad \text { (in general) }\end{array}$} & $\begin{array}{l}\text { Superficial cellular } \\
\text { rim }\end{array}$ & + & + & 0 & 0 & 0 & $\begin{array}{l}\text { Reticulum cells or } \\
\text { fibroblasts }\end{array}$ \\
\hline & Fibrous stroma & + & + & + & 0 & 0 & $\begin{array}{l}\text { Fibroblasts or } \\
\text { Myofibroblasts }\end{array}$ \\
\hline & $\begin{array}{l}\text { Adventitia of larger } \\
\text { vessels }\end{array}$ & + & + & + & + & Partly + & Myofibroblasts \\
\hline $\begin{array}{l}\text { Type I stem } \\
\text { villi (caliber } \\
>250 \mathrm{~mm})\end{array}$ & $\begin{array}{l}\text { Adventitia and } \\
\text { media of arteries } \\
\text { and veins }\end{array}$ & + & + & + & $\begin{array}{l}+ \text { in adventitia } \\
\text { and media of } \\
\text { arteries and } \\
\text { veins }\end{array}$ & $\begin{array}{l}\text { Partly }+ \text { in } \\
\text { adventitia }\end{array}$ & $\begin{array}{l}\text { Myofibroblasts } \\
\text { and smooth } \\
\text { muscle cells }\end{array}$ \\
\hline $\begin{array}{l}\text { Type II stem } \\
\text { villi (caliber } \\
120-300 \mathrm{~mm})\end{array}$ & $\begin{array}{l}\text { Adventitia and } \\
\text { media of arterioles } \\
\text { and venules }\end{array}$ & + & + & + & $\begin{array}{l}+ \text { only in media } \\
\text { of arterioles and } \\
\text { venules }\end{array}$ & + in media & $\begin{array}{l}\text { Smooth muscle } \\
\text { cells }\end{array}$ \\
\hline $\begin{array}{l}\text { Type III stem } \\
\text { villi (caliber } \\
<150 \mathrm{mmh})\end{array}$ & $\begin{array}{l}\text { Adventitia and } \\
\text { media of arterioles } \\
\text { and venules }\end{array}$ & + & + & + & $\begin{array}{l}+ \text { only in media } \\
\text { of arterioles }\end{array}$ & + in media & $\begin{array}{l}\text { Smooth muscle } \\
\text { cells }\end{array}$ \\
\hline $\begin{array}{l}\text { Mature } \\
\text { intermediate villi }\end{array}$ & & + & + & 0 & 0 & 0 & $\begin{array}{l}\text { Fibroblasts or } \\
\text { reticulum cells }\end{array}$ \\
\hline Terminal villi & & + & + & 0 & 0 & 0 & $\begin{array}{l}\text { Fibroblasts or } \\
\text { reticulum cells }\end{array}$ \\
\hline
\end{tabular}

Source: Based on findings by Kohnen et al., 1996; Demir et al., 1997. Positive immune reaction (+), no immune reaction (0). For details see text.

\section{Differentiation and Maturation of Villous Types}

The mechanisms of villous maturation have attracted little attention, perhaps because they may seem to be unimportant for the understanding of placental pathology. This notion is supported by the experience that, with conventional paraffin histology, it is difficult to identify the various villous types and stages of villous differentiation. Direct structural evidence of villous differentiation and maturation are usually lacking. Only if one compares the villous trees of a mature placenta (see Fig. 8.12) with early villous trees (see Fig. 8.1) does one realize that important developmental steps must have occurred.

Immunohistochemistry and availability of human material from most stages of pregnancy enabled us to consider the mechanism of villous maturation and differentiation in some detail (Kaufmann, 1982; Castellucci et al., 1990, 2000; Kohnen et al., 1996; Demir et al., 1997). Further insights into the dynamics of the growth of the villous trees can be obtained from their topologic analysis of the branching patterns and their later comparison with theoretical branching models (Kosanke et al., 1993). Our insight is still superficial, and our conclusions are accordingly preliminary. We believe, however, that we must discuss this concern because clinical methods (e.g., chorion biopsy and Doppler studies) have caused renewed interest; moreover, our understanding of the pathogenetic mechanisms of IUGR depends on an understanding of villous development.

\section{Development of the Mesenchymal Villi}

The first tertiary villi recognizable are represented by mesenchymal villi (Castellucci \& Kaufmann,1982a). They are derived from the following sources (Castellucci et al., 1990, 2000): 
- Up to the 6th week p.m., the mesenchymal villi are formed from primary villi via secondary villi (Boyd \& Hamilton, 1970). The numerous trophoblastic primary villi are transformed into secondary villi by invagination of extraembryonic mesenchyme. Immediately thereafter, the first capillaries form, giving rise to tertiary villi, the mesenchymal villi considered here.

- Beginning from the 6th week p.m., the supply of primary and secondary villi is exhausted and new mesenchymal villi are henceforth formed by vascularization of trophoblastic sprouts. These structures are trophoblastic outgrowths of the surfaces of mesenchymal and immature intermediate villi and result from trophoblastic proliferation (Figs. 7.12, 7.13, and 7.16).

Not all sprouts (i.e., fungiform outgrowths from the villous surface) are signs of trophoblastic sprouting. Some represent stages of expulsion of apoptotic syncytial nuclei (see Chapters 6 and 15), and others are simply flat sections of villous surfaces (see Chapter 15) (Cantle et al., 1987). The true trophoblastic sprouts correspond to the primary villi of the early stages of placentation; the latter sprouts are invaded by mesenchyme and transformed into villous sprouts. These sprouts then correspond to secondary villi of early development. The first signs of capillary formation mark the transformation into mesenchymal villi.

The concentration of Langhans' cells is greater in mesenchymal villi than in all other villi. In addition, the mitotic index of villous cytotrophoblast, counted from autoradiographs following ${ }^{3} \mathrm{H}$-thymidine incorporation and from immunohistochemical preparations using the antibodies Ki-67, MIB-1, or proliferating-cell nuclear antigen (PCNA) (Kohnen et al., 1993; Kosanke et al., 1998), considerably exceeds that of all other villi. This fact was not evident in previous publications (Moe, 1971; Tedde \& Tedde-Piras, 1978; Kaufmann et al., 1983; Arnholdt et al., 1991) because the authors did not differentiate among the various villous types.

\section{Development and Fate of Immature Intermediate Villi}

Beginning between the 7th and 8th weeks p.m., mesenchymal villi transform to immature intermediate villi. This process is characterized by (1) an increase in villous diameter; (2) the formation of the stromal channels (Fig. 7.7) containing numerous macrophages (Enders \& King, 1970; Kaufmann et al., 1979; Castellucci \& Kaufmann, 1982a,b; Castellucci et al., 1984; King, 1987); (3) the transformation of mesenchymal cells in structurally and immunohistochemically different reticulum cells and fibroblasts (Kohnen et al., 1996); and (4) a decrease in thickness of syncytiotrophoblast and in the number of Langhans' cells.

The reticular stroma is the most characteristic feature of immature intermediate villi. It seems to play an important role during transformation of these villi into fibrosed stem villi. According to G. Petry (personal communication, 1981), the accumulation of connective tissue fibers is preceded by a similar reticular architecture of connective tissue cells during the course of early scar formation in the skin. The significance of this stromal type appears to be defined by the role of macrophages (Hofbauer cells), which are involved in the remodeling of the connective tissue (Scott \& Cohn, 1982; Werb, 1983; Castellucci et al., 1984; Takemura \& Werb, 1984). There is presently no specific function for the immature intermediate villi, other than being a quickly growing developmental precursor for stem villi (Fig. 7.16).

Development of additional immature intermediate villi from mesenchymal villi gradually ceases at the end of the second trimester (Castellucci et al., 1990, 2000; Bukovsky et al., 1999). Their transformation into stem villi, however, continues to term. Therefore, the number of immature intermediate villi decreases steeply (Fig. 7.15). Sometimes they completely disappear before term. It is common, however, that small numbers persist in the centers of the villous trees and serve as growth zones.

\section{Development of Stem Villi}

The development of stem villi is closely related to the formation of the immature intermediate villi. As early as in the 8th week p.m., the central vessels of the proximal segments of immature intermediate villi, near the chorionic plate, commence constructing a compact adventitia. They thus slowly transform into arteries and veins. Centrifugal expansion of the adventitia, paralleled by transformation of reticulum cells and fibroblasts into myofibroblasts, leads to a reduction of the adjacent reticular connective tissue (see Chapter 8, Figs. 8.4 to 8.8).

The transition of immature intermediate villi into stem villi is a gradual process. According to our definition, stem villi are established as soon as the superficial sheet of reticular connective tissue beneath the trophoblast is thinner than the fibrous center surrounding stem vessels (Figs. 8.5, 8.6) (Castellucci et al., 1990, 2000). Stem vessels have then been transformed into arteries and veins or arterioles and venules. The persistence of a small rim of reticular connective tissue beneath the trophoblast in the term placenta can be regarded as a reliable sign of placental immaturity (Kaufmann, 1981).

The formation of additional stem villi depends on the availability of immature intermediate villi. Therefore, the expansion of villous stems gradually ceases during the course of the last trimester, as soon as most of the immature intermediate villi have been transformed and new ones are no longer produced.

Increased stromal fibrosis outside stem villi is considered to be a pathologic phenomenon. Such villi are usually referred to as being fibrotic. Fox (1978) reported several conditions that are commonly associated with fibrotic villi: 

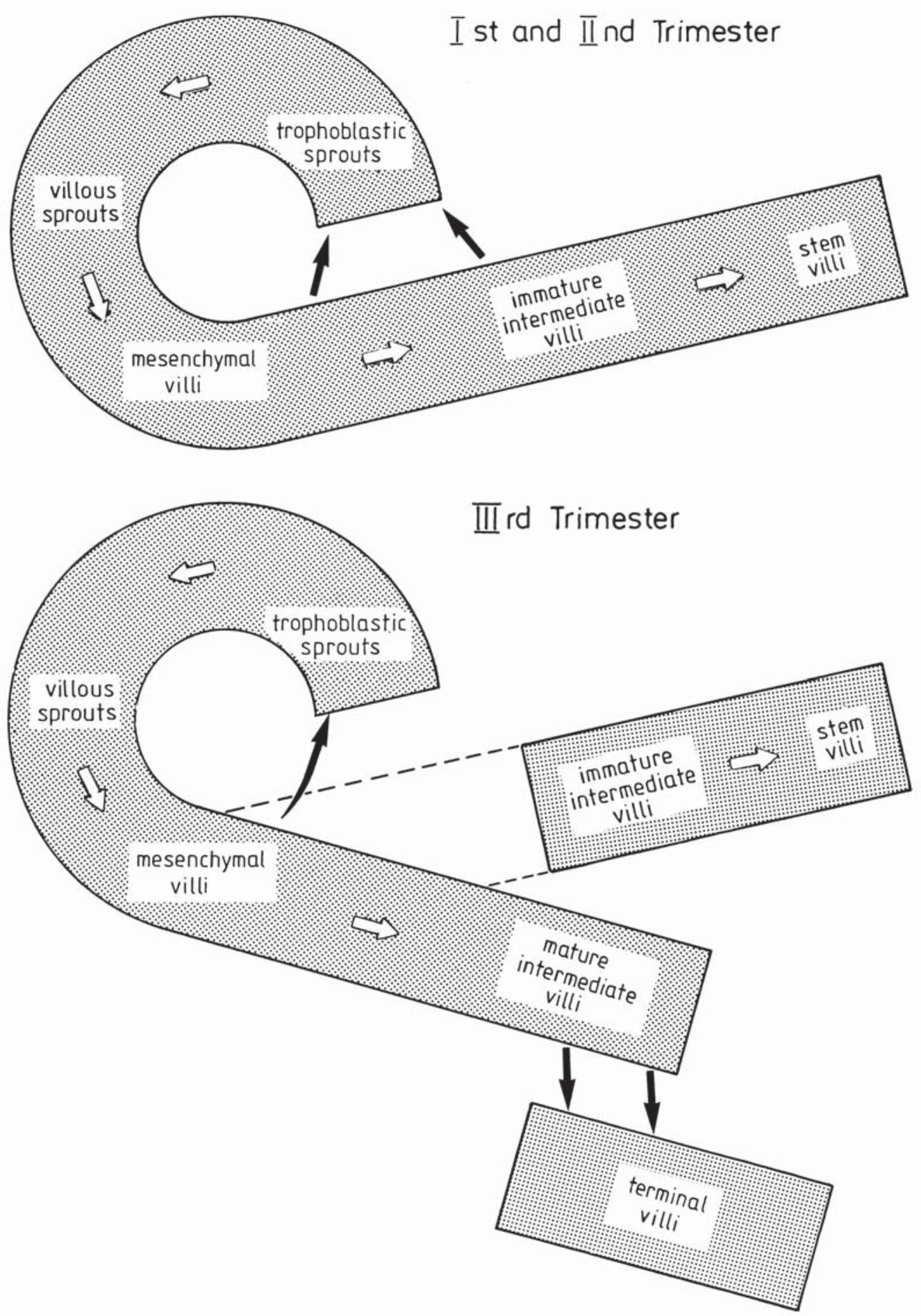

Figure 7.16. Routes of villous development during early and late pregnancy. White arrows, transformation of one villous type into another; black arrows, new production of villi or sprouts along the surface of other villi. Upper half: First and second trimester. Trophoblastic sprouts are produced along the surfaces of mesenchymal and immature intermediate villi. Via villous sprouts, they are transformed into mesenchymal villi. The latter differentiate into immature intermediate villi, which produce new sprouts before they are transformed into stem villi. Lower half: Throughout the third trimester, the mesenchymal villi become transformed into mature intermediate villi, which later produce terminal villi along their surfaces. There is no longer transformation of mesenchymal into immature intermediate villi. The remaining immature intermediate villi differentiate into stem villi. Thus, their number steeply decreases toward term. Thus, the base for the formation of new sprouts is also reduced, and the growth capacity of the villous trees gradually slows. 
1. Stromal fibrosis is a regular finding of peripheral villi following fetal artery thrombosis.

2. It may also be found in inadequately vascularized villi adjacent to areas of infarction.

3. In placentas from macerated stillbirths, increased numbers of fibrotic villi have also been observed. Fox (1978) concluded that this must be a postmortem change because this feature is absent in placentas from fresh stillbirths. This issue, however, is still debated and probably depends on the causes of fetal demise.

4. A marked increase of fibrosed villi may be found in placentas of prolonged pregnancy.

Contrary to many other reports, Fox (1978) was unable to show an association between villous fibrosis and fetal complications, such as hypoxia or low birth weight. He thus refutes the theory that increased stromal fibrosis is a response to uteroplacental ischemia. In his opinion, it is more likely a result of reduced intravillous blood flow. This situation may result in intravillous hyperoxic conditions as oxygen transfer from the villi to the fetus is impaired (Macara et al., 1996; Kingdom \& Kaufmann, 1997; see following).

\section{Development of the Mature Intermediate Villi}

One of the most important steps for an understanding of villous development occurs at the beginning of the last trimester. At this time, the transformation of newly formed mesenchymal villi into immature intermediate villi switches to a transformation into mature intermediate villi (Figs. 7.15 and 7.16; also see Figs. 8.7 and 8.8) (Castellucci et al., 1990, 2000). Little is known about the factors causing this switch. The structurally most striking event at this developmental stage (Kaufmann \& Kingdom, 2000; Kaufmann et al., 2004) is the switch

- from branching angiogenesis, which is responsible for the development of immature intermediate villi out of mesenchymal ones,

- to nonbranching angiogenesis, which is necessary for the growth of the long, poorly branched capillary loops characteristic for mature intermediate villi developing out of mesenchymal ones.

As will be dealt with later in this chapter, this switch from branching to nonbranching angiogenesis is modulated by a downregulation of vascular endothelial growth factor (VEGF) and an upregulation of placental growth factor (PlGF), as well as by respective changes of their receptors KDR and flt-1 (for review see Kingdom \& Kaufmann, 1997; Charnock-Jones et al., 2004; Kaufmann et al., 2004; Mayhew et al., 2004). The factors, however, that trigger this switch in growth factor expression still remain unknown (see below).

Differing in two respects from immature intermediate villi, the mature intermediate villi provide the matrix out of which terminal villi develop, but they do not transform into stem villi.

\section{Development of the Terminal Villi}

The first terminal villi, as defined in the past (Kaufmann et al., 1979; Sen et al., 1979), are produced soon after the first mature intermediate villi are formed (Fig. 7.15; see Table 8.1). The formation of terminal villi is closely related to the longitudinal growth of capillaries within the mature intermediate villi (see Figs. 7.19 and 7.23). As soon as longitudinal capillary growth exceeds longitudinal villous growth, the capillaries become coiled and form loops (Kaufmann et al., 1985, 1988). Because of the slender shape of these villi, the loops bulge on the trophoblastic surface and finally protrude as grape-like outgrowths into the intervillous space. This process is not accompanied by trophoblastic proliferation and, therefore, leads to considerable stretching of trophoblast. This process results in numerous vasculosyncytial membranes of terminal villi.

It follows that, in contrast to the development of other villous types, the terminal villi are not active outgrowths induced by proliferation; rather, they represent passive formations caused by capillary coiling. Accordingly, maldevelopment of terminal villi is always an immediate consequence of abnormal fetoplacental angiogenesis.

- Impaired angiogenesis results in deficiency of terminal villi (see Fig. 15.17).

- Overstimulated angiogenesis leads to the development of large conglomerates of terminal villi (see Fig. 15.16).

The slight bends of the mature intermediate villi, at points where terminal villi branch off (see Fig. 7.10A,D), illustrate the mechanical forces that have been active during capillary growth and coiling. Terminal villi, at the surfaces of stem villi and immature intermediate villi and derived from coiling of paravascular capillaries, are the exceptions because these particular capillaries show less impressive longitudinal growth (Leiser et al., 1985).

\section{Angioarchitecture of Villi}

\section{Vascular Arrangement in Immature Villi}

The first vascular nets formed in early placental villi show no differentiation into arteries, veins, or capillaries (Demir et al., 1989), a picture that changes around the 8th week p.m. (cf. Fig. 7.23, stage III). As a consequence of fusion of locally developed intravillous vascular nets with the fetal vessels that invade the villous trees via the connective stalk (the forerunner of the umbilical cord), the fetoplacental circulation becomes established. Because of pressure gradients between arterial and venous limbs, differently structured vessel walls appear (see Fig. 8.3). Connective tissue cells that aggregate around the endothelial tubes in a circular fashion are the first steps in the 
formation of the walls of future arteries and veins. Normally, one artery and one vein are formed. The remaining capillary net that surrounds the larger vessels is referred to as the paravascular net. An example of this phenomenon has been illustrated by Boe (1969) (see Fig. 7.18). When he traced single vessels, he found numerous capillaries that formed shortcuts between arteries and veins but also between neighboring arteries (arterioarterial anastomoses). Because of the low blood pressure in the vascular system, effective arteriovenous shunting is unlikely.

The villus depicted by Boe (see Fig. 7.18) is consistent with what we described as an immature intermediate villus. It is an undifferentiated, still growing villous type that can even be found in the mature placenta, although in only small restricted groups. The small branching-off villi described by Boe as "terminal villi" are likely newly formed mesenchymal villi (see Figs. 7.12 and 7.18). As it is typical for newly formed villi, their richly branched capillary nets are connected only with the paravascular net, rather than directly with arteries and veins. Only after further development, as soon as some of their capillaries have been transformed to arterioles and venules, are direct connections to the fetal stem vessel established.

\section{Larger Vessels of Stem Villi}

Large stem villi normally contain one artery in a nearly central position. If not constricted or collapsed, the lumen accounts for about one third of the villous caliber (see Fig. 7.3A). The endothelium is surrounded by a few layers of smooth muscle cells. The adventitia is continuous with the surrounding connective tissue without a sharp line of demarcation. The artery is normally accompanied by a corresponding vein. Its luminal width does not much exceed that of the artery in most preparations owing to the collapse occurring after delivery. In addition to the two main vessels, varying numbers of smaller arterioles and venules exist (Leiser et al., 1985; Kaufmann et al., 1988).

The most peripheral generations of stem villi branch or continue into mature intermediate villi and have diameters ranging from 80 to $150 \mu \mathrm{m}$ (Fig. $7.3 \mathrm{~B}$ ). The stem vessels are represented by arterioles and venules (Fig. 7.17; also see Fig. 7.19) that are surrounded by one or two layers of smooth muscle cells. The inconspicuous venules have one, usually incomplete, layer of muscle cells. Some are surrounded only by pericytes and correspond to the collecting venules of Rhodin (1968), despite their different diameter. Frequently, arterioles and venules of these segments are so similar that they cannot be identified on cross sectioning but only from reconstructions. For quantitative estimations of stem vessels, we refer to a survey by Leiser et al. (1991).

\section{Paravascular Capillary Net of Stem Villi}

Beneath the trophoblast, numerous cross sections of capillaries with small calibers appear (Fig. 7.17; also see Figs. 7.19 and 7.24D). They belong to the paravascular net (Boe, 1953). This system is derived from the subtrophoblastic capillary net of the earlier immature villi. Because of vascular obstruction during transformation of the immature intermediate villi into stem villi, a rarefied and poorly branching system of slender capillary loops develops. It can be seen in most stem villi depicted in the literature (Arts, 1961; Thiriot \& Panigel, 1978; Habashi et al., 1983; Leiser et al., 1985; Kaufmann et al., 1988). The paravascular capillaries follow a straight course, mostly parallel to the longitudinal axis of the villus. In our material of mature stem villi, net-like connections have been uncommon. We have seen such richly branched and dense paravascular capillary nets as depicted by Burton (1987) only in immature intermediate villi (Fig. 7.18) and in not yet fully matured stem villi. We concede, however, that our impression may be incomplete. The paravascular capillaries are connected to the arteries and veins by short arteriolar and venular segments, measuring up to $100 \mu \mathrm{m}$ in length.

Only in rare cases do the paravascular capillaries show focal sinusoidal dilatations. If this happens, the dilated and coiling segments bulge on the stem villus surface and form a terminal villus that arises from the stem villus (Kaufmann et al., 1979; Burton, 1987) (Fig. 7.17C, upper half). Such terminal villi are serially intercalated into the paravascular net. According to our experience, this occurrence is rare (less than $5 \%$ of all terminal villi), whereas Burton (1987) described it to be a regular finding.

When we traced individual paravascular capillaries from their arteriolar beginnings to their venular ends, we found an average length of 1000 to $2000 \mu \mathrm{m}$. Arteriovenous and arterioarterial shortcuts, as described by Boe $(1953,1969)$ for the earlier stages of development, could no longer be detected in mature stem villi. There is therefore no real basis for speculations that the paravascular net participates in the regulation of fetal blood flow impedance as an arteriovenous shunting system.

The functional relevance of the paravascular capillary net is still uncertain. Thiriot and Panigel (1978) suggested that this was the site for effective fetomaternal exchange. The long diffusion distances in these places make this interpretation implausible. Moreover, the assumption by Arts (1961) that the paravascular net may be of nutritional importance for the stem villi, acting as a kind of vasa vasorum, seems unlikely to us. The concentration of oxygen and most nutrients in the surrounding intervillous space considerably exceeds that in the fetal vessels. Thus, the nutrition by direct diffusion from the maternal blood is probably more effective. This finding is in agreement with those of Zeek and Assali (1950) as well as Fox (1978), 

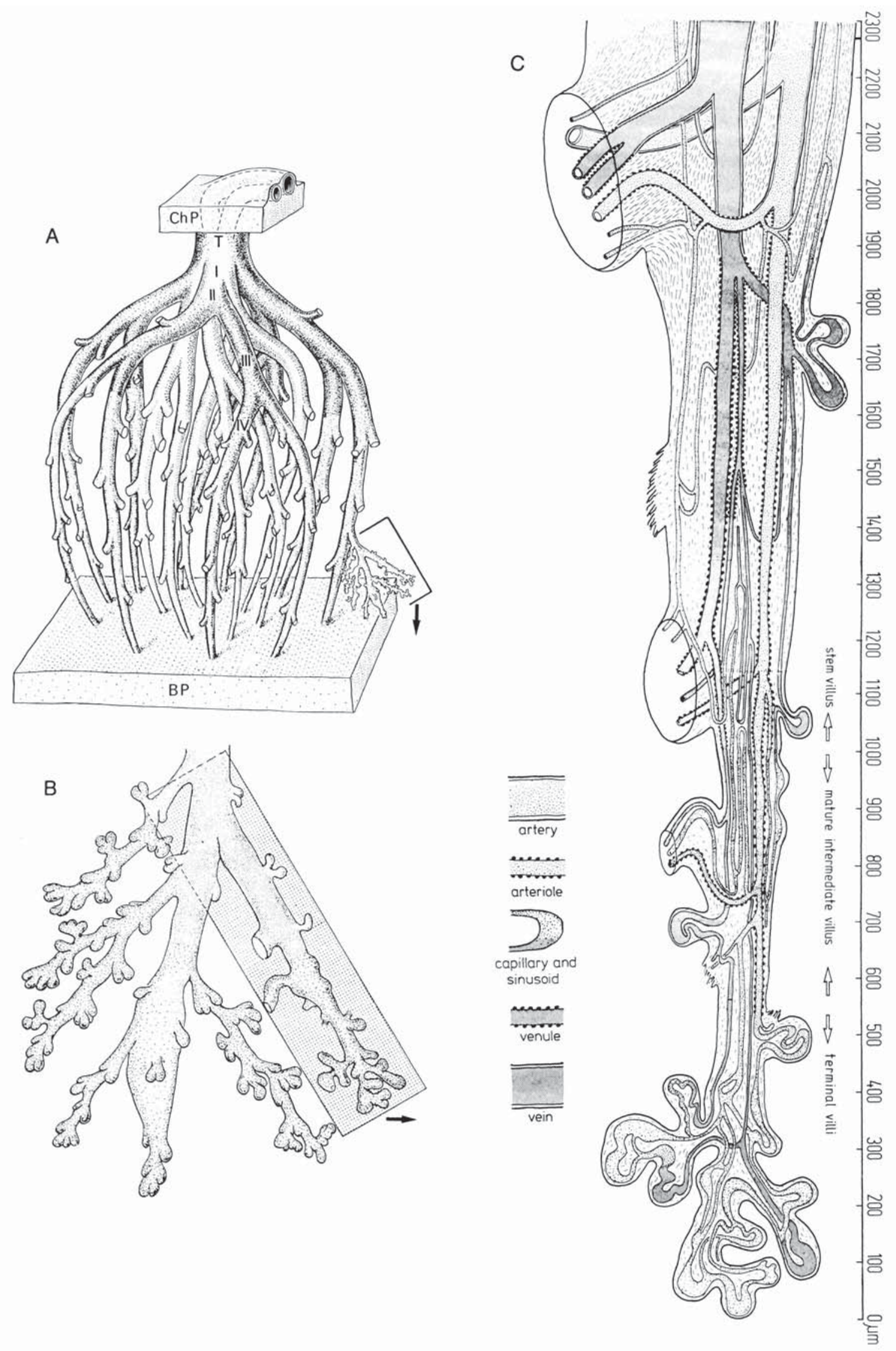


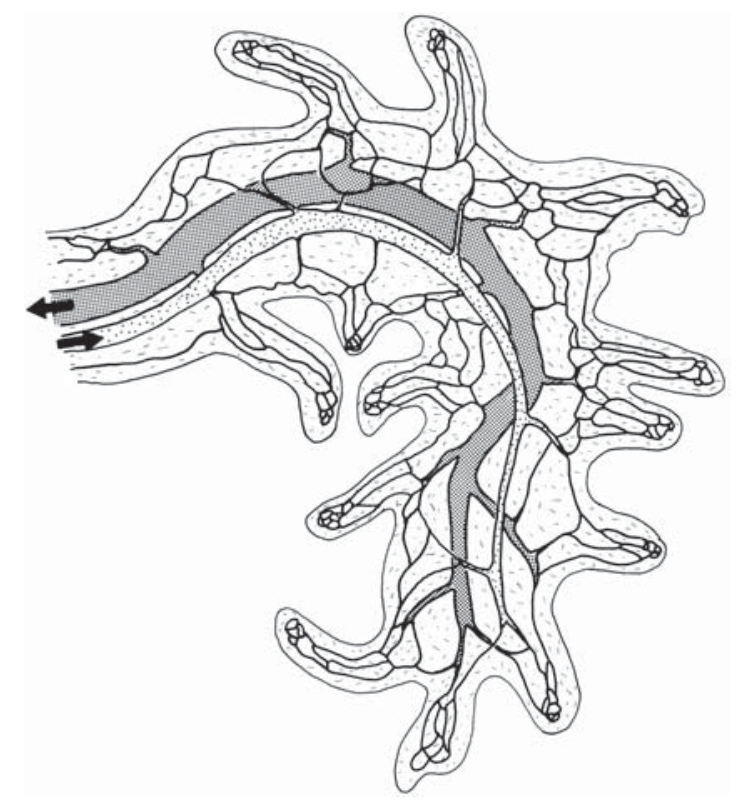

Figure 7.18. Classical representation of the villous vascularization by Boe (1969) represents an immature intermediate villus with numerous mesenchymal side branches. The web-like arrangement of the fetal capillaries protruding from the paravascular net of the immature intermediate villus into its sprouting side branches is highly characteristic, not only for early placentas but also for villous sprouting patterns in the term placenta. As depicted in the foregoing pictures, it is normally absent in the mature villous types. (Source: Based on findings of Boe, 1969.)

who found not only survival of stroma but also increased fibroblast proliferation and collagen production within stem villi after fetal death.

Boyd and Hamilton (1970) described the paravascular net to be simply a residual indication of better vascularization during early stages of development. Keeping in mind that the developmental forerunners of the stem villi were immature intermediate villi with a well-developed paravascular net (Kaufmann et al., 1988), the respective capillaries of the mature stem villi probably represent the remains of the immature state where terminal villi with their effective exchange system were absent and the paravascular net had to sustain maternofetal exchange. The development of better-vascularized terminal villi during the course of the last trimester renders the paravascular capillaries largely nonfunctional.

\section{Arrangement of Vessels in Mature Intermediate and Terminal Villi}

The mature intermediate villi serve as junctional segments between the most peripheral stem villi and most of the terminal villi. Their vessels are direct continuations of the smallest stem villous vessels (Figs. 7.17C and 7.19). One or two small arterioles, with luminal diameters ranging from 20 to $40 \mu \mathrm{m}$, appear histologically as bare endothelial tubes, accompanied by occasional muscle cells. Precapillary sphincters, or comparable narrow segments with complete muscular coats as described for other vascular beds (Rhodin, 1967), have not been identified. Rather, the terminal ends of arterioles continue directly into one or two capillaries by a gradual reduction of their diameters and loss of smooth muscle (Kaufmann et al., 1985; Leiser et al., 1991).

Although the arterioles occupy a more central position in the villous stroma, one or two venules can be found more superficially. Surprisingly, their diameter usually appears to be considerably smaller than that of the arterioles, usually 15 to $20 \mu \mathrm{m}$. In agreement with the classification of Rhodin (1968), the term postcapillary venule seems to be most appropriate because of the absence of muscle cells and the existence of a nearly complete sheet of pericytes. The most peripheral loops of the paravascular capillaries of the stem villi surround the terminal arterioles and postcapillary venules. They extend to about the middle of the mature intermediate villi (Figs. 7.17C and 7.19).

In the distal half of the mature intermediate villi, the paravascular capillaries are absent. Histologically, the
FigURE 7.17. Fetal vascularization of term placental villi based on the spatial reconstruction of serial sections. A: Large stem villi of the villous tree. $\mathrm{ChP}$, chorionic plate; $\mathrm{BP}$, basal plate; $\mathrm{T}$, truncus; I, II, III, IV, rami chorii of the first to the fourth order. The more peripheral branches depicted in this drawing are ramuli chorii of the first to the tenth order. The marked peripheral ramulus with its terminal branches refers to part B. B: Higher magnification of peripheral branches of the villous tree. A peripheral stem branches into several mature intermediated villi (slender) and one immature intermediate villus (thick). The shaded rectangular area corresponds to the reconstructed branches depicted in part C. C: Fetal vascular branching patterns of a peripheral stem villus (above), continuing into a mature intermediate villus, extending into several terminal villi, reconstructed from a series of 2300 semithin sections. Length and caliber of the villi are drawn on the same scale, whereas the diameter of the vessels is reduced to two thirds (necessary because of two-dimensional representation of a threedimensional system). Occasional spots of fibrinoid necrosis on the villous surface are marked by hatching. Note that the capillary loops of neighboring terminal villi are serially connected. These are normally not continuous with the straight paravascular capillaries of the stem and mature intermediate villi, but form a second independent capillary bed. (Source: Modified from Kaufmann et al., 1988, with permission.) 


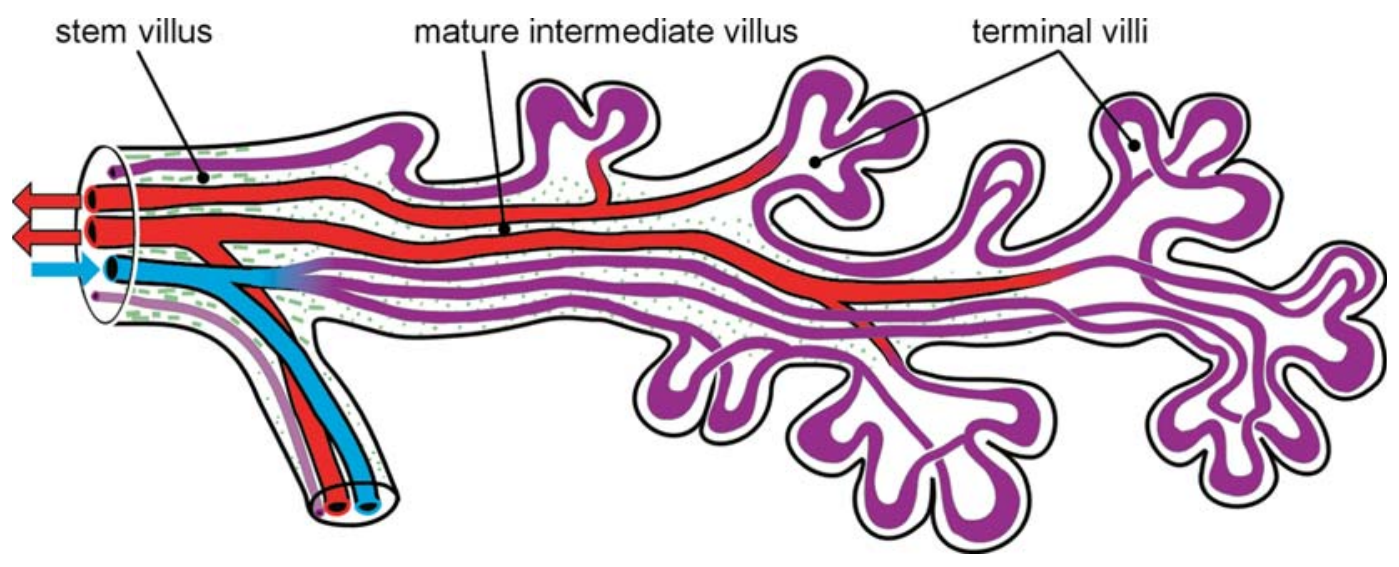

Figure 7.19. Arrangement of the fetal vessels in a group of terminal villi (stroma unstained) derived from one mature intermediate villus (green dotted stroma). Based on a threedimensional reconstruction of the peripheral branches of a mature villous tree. Note the highly complex loop formation of the terminal fetal capillaries. Branching is usually followed

distal segment can easily be differentiated from the more proximal segments by the absence of larger vessel cross sections and the absence of vessels in the center of the stromal core; most capillaries are located directly beneath the trophoblast. In most cases, the abrupt end of the paravascular "net" causes a sharp line of demarcation between the more proximal segments, which are rich in capillaries, and the distal, less vascularized part (Figs. 7.17C and 7.19).

The terminal capillaries are different from the mostly straight paravascular capillaries and are characterized by the formation of loops and coilings. Focally dilated segments may bulge against the trophoblast and thus form vasculosyncytial membranes, knob-like protrusions, or even terminal villi. As one approaches the peripheral end of the mature intermediate villus, the number and extent of capillary coilings increases and so does the number of terminal outgrowths that cover the surface of the mature intermediate villus (Figs. 7.17, 7.19, and 7.20). At its end, the mature intermediate villus regularly branches into a cluster of terminal villi (Fig. 7.20).

There is no sharp demarcation between mature intermediate and terminal villi. Increased capillary coiling, accompanied by increased sinusoidal dilatation and reduced stromal connective tissue, is responsible for the structural differences. The descriptive name "terminal villus" is used for those villi

1. that contain no vessels other than capillaries and sinusoids, and

2. in which the vascular lumens comprise at least one half of the stromal volume (Kaufmann et al., 1979, 1985). shortly later by refusion of the two capillary branches. Such a branching pattern avoids basal shortcuts. Each erythrocyte must pass the terminal capillaries of several terminal villi in their full length. Local dilatations, so-called sinusoids, reduce blood flow impedance. Blue, fetal arteries and arterioles; lilac fetal villous capillaries and sinusoids; red, fetal villous venules and veins.

Depending on the level at which such terminal villi are sectioned, their histologic appearance is highly variable. An example is depicted in Fig. 7.20. The capillary loops of the peripheral terminal villi are direct continuations of terminal arterioles. According to our experience, they show only on occasion cross-connections to peripheral loops of the paravascular capillaries, described as a regular feature by Arts (1961). It is of particular importance to note that the capillary loops of neighboring terminal villi are serially connected to each other (Figs. 7.17C, 7.19, and 7.20A). Fetal blood leaving a terminal arteriole and entering the terminal capillaries normally passes through the capillary loops of three to five terminal villi in series before entering a postcapillary venule. This passage is responsible for the length of terminal capillaries, which we measured as ranging from 3000 to $5000 \mu \mathrm{m}$ (Kaufmann et al., 1985). Shortcuts at the base of terminal capillary loops are the exception, so that each erythrocyte has to pass the full length of the capillaries. As reported earlier, the paravascular capillary loops measure only 1000 to $2000 \mu \mathrm{m}$ in length.

When one looks at casts of vessels such as those depicted in Figure 7.20, it seems that the terminal capillary bed is made up of a highly branching network, and it has usually been described as such (Boe, 1953, 1968; Arts, 1961; Boyd \& Hamilton, 1970; Thiriot \& Panigel, 1978; Habashi et al., 1983; Burton, 1987). In contrast, our reconstructions of terminal vessel beds revealed only a low degree of branching. When discussing this discrepancy, Burton (1987) stated that "the superimposition of SEM [scanning electron microscopy] images can lead to mistaken estimates of the incidence of vessels joining, but it cannot be denied that branching and union 


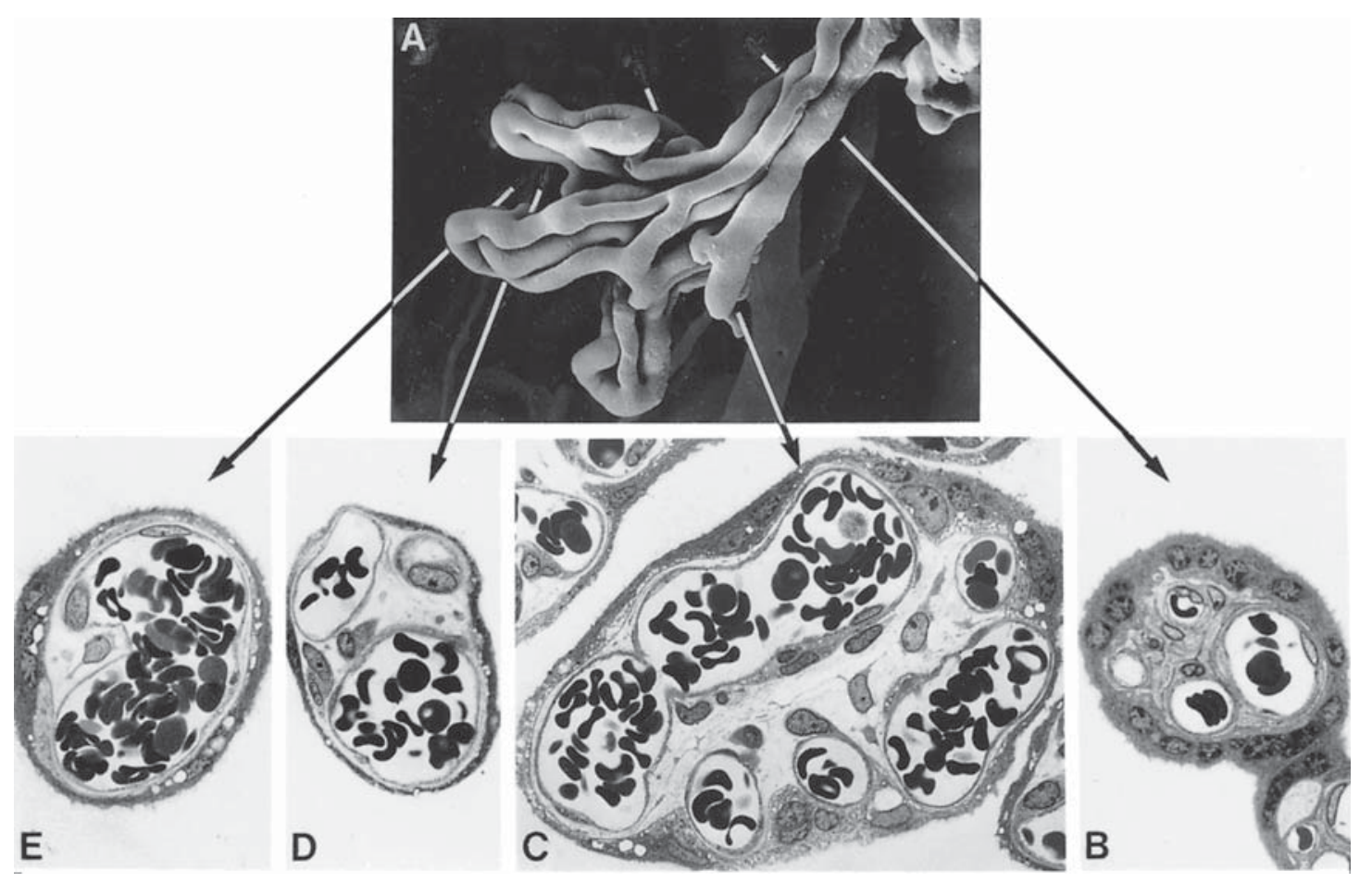

FIGURE 7.20. Fetal vascularization of terminal villi. A: Cast of vessels from a neck region (right) branching into three terminal villi. Comparable to mature intermediate villi, the capillaries of the neck region are strikingly straight and arranged in parallel; however, the diameter of the villus is much smaller. $\times 520$. Corresponding semithin sections of the neck region (B), the basis of the branching terminal villi (C), a single terminal villus near its tip (D), and a flat section of the terminal villous tip (E). The fetal capillaries and the highly dilated sinusoids amount to more than $50 \%$ of the stromal volume as long as postpartal collapse can be avoided by early fixation. $\times 630$. (Source: From Kaufmann et al., 1988, with permission.) between capillaries does occur within terminal villi. The problem may be only one of degree...." We admit that our results were obtained from the reconstruction of only a few cases (Kaufmann et al., 1985); it is our opinion, however, that the more likely explanation for the discrepancy is one of definition. Branching, with directly subsequent union, is indeed a frequent feature (Fig. 7.19). It must not be confused with the establishment of true, complex intravillous capillary nets, which offer the possibility of basal shortcuts. The latter arrangement might considerably shorten the individual capillary length. On the other hand, a high degree of coiling with serially intercalated branching and direct fusion has no influence on the mean capillary length. This difference may have physiologic importance for fetal blood flow impedance. Jirkovska and coworkers (1998) have shown that threedimensional reconstructions of terminal villi using confocal microscopy are a useful approach to solve these questions. This is particularly valid if sophisticated methods of tissue preparation are applied such as dual perfusion fixation (Larsen et al., 1995).

\section{Sinusoids of Terminal Villi}

Sinusoids are focal capillary enlargements that attain diameters to about $50 \mathrm{~mm}$ (Figs. 7.11 and 7.20). They are thought to be typical features of the mature placenta and are not comparable to the sinusoids of liver, spleen, and bone marrow, as the former possess a continuous endothelium and complete basal lamina. Sinusoids thus differ from conventional capillaries only by their increased diameters.

In semithin sections, the sinusoids are normally positioned near the villous tips. Vascular casts, however, reveal that they are randomly scattered over the full length of the terminal capillaries, rather than dilatations of defined segments (Kaufmann et al., 1985). They may narrow and dilate serially several times (Fig. 7.19). Statistically, they can be found more frequently near the villous tips and along the venous limbs, as well as at points of branching and fusion. The grade of dilatation and the degree of tortuosity of the capillary loops seem to depend on each other. 
We have measured the diameters of capillaries and sinusoids in semithin sections and compared them to casts of vessels (Kaufmann et al., 1985). The results, obtained with both methods, were largely consistent. The mean diameters of capillaries and sinusoids of the mature placenta varied from $12.2 \mu \mathrm{m}( \pm 0.58 \mu \mathrm{m})$ in vessel casts to $14.4 \mu \mathrm{m}( \pm 1.94 \mu \mathrm{m})$ in semithin sections. The difference can be explained by different degrees of shrinkage of the resins used for preparation. In our experience, the higher values seem to be more appropriate. The maximum values were $39 \mu \mathrm{m}$ in casts of vessels and $45 \mu \mathrm{m}$ in semithin sections. Depending on the method applied, $60 \%$ to $80 \%$ of the vessel lumens had diameters larger than $10 \mathrm{~mm}$. Our data are largely consistent with those reported by Becker (1962a), Becker and Seifert (1965), and Boyd and Hamilton (1970).

The smaller diameters reported by Habashi et al. (1983) and O'Neill (1983), the latter author giving a range of only 4 to $7 \mu \mathrm{m}$, are probably the result of incomplete filling of vessels of their casts and resin shrinkage. Even more contradictory are the physiologic results published by Penfold et al. (1981). These authors perfused capillaries with microspheres of varying diameters and concluded that as many as $25 \%$ of capillaries measure less than $4 \mu \mathrm{m}$ in diameter and virtually no capillary exceeds $11 \mu \mathrm{m}$ in diameter. Their results were based on the erroneous assumption that narrow and dilated capillary loops are arranged in parallel; their results must be refuted (Habashi et al., 1983). In fact, the capillaries become narrow and dilate serially. Thus, when using microsphere perfusion, the diameter for the narrowest segment of each capillary loop can only be estimated. Even so, the value of $4 \mathrm{~mm}$ for $25 \%$ of the capillary loops cannot be accepted.

Function: The functional relevance of the sinusoids has caused much speculation. It is evident from the foregoing description that the sinusoidal dilatation cannot be regarded as dilated venous limbs of the capillary loops that allow retarded venous backflow, as was discussed by Nikolov and Schiebler (1973). The localization of most sinusoids near the villous tips supports the conclusion of Arts (1961) that the sinusoids locally decelerate blood flow, thus providing ample opportunity for fetomaternal exchange. This assumption is in agreement with the finding that the sinusoids are regularly situated in contiguity with the epithelial plates (Boyd \& Hamilton, 1970; Nikolov \& Schiebler, 1973, 1981; Schiebler \& Kaufmann, 1981). These plates are thought to represent areas of maximal diffusional exchange (Amstutz, 1960; Kaufmann et al., 1974).

It is still a matter of dispute whether the reduced blood flow velocity facilitates the maternofetal exchange or whether the increased diffusion distance from the center of sinusoids to villous surface negatively influences the diffusion capacity. Another explanation for the existence of sinusoids has been that they serve as functionally specialized segments devoted to specific transport processes. Nikolov and Schiebler (1981) described two types of endothelial cells. These findings, however, cannot serve as arguments for a functional specialization of sinusoids compared to narrow capillaries, as they seem to be evenly distributed in both vessel segments.

We have discussed another explanation for the function of the sinusoids elsewhere (Kaufmann et al., 1985, 1987, 1988). It is remarkable that the sinusoids are pro- duced at the end of pregnancy (Becker, 1981), as soon as the terminal villi achieve the highest degree of branching and twisting and as the terminal capillary loops reach their maximal length of 3000 to $5000 \mu \mathrm{m}$. On the other hand, sinusoids are largely absent in the shorter terminal capillary loops of immature placentas and in the shorter paravascular capillaries. Moreover, they are not found in labyrinthine placentas such as those of the guinea pig (Kaufmann \& Davidoff, 1977) and chinchilla (Dantzer et al.,1988), both of which are characterized by short fetal capillaries, ranging from 500 to $1000 \mu \mathrm{m}$. We have also studied some capybara placentas (Kaufmann, 2004). This species is of the same suborder of caviomorph rodents as the guinea pig and chinchilla but it has a much larger placenta with fetal capillaries of about twice their lengths. Its placenta shows fetal sinusoids. The same is true for the goat placenta, which has long capillary loops comparable to those of the human placenta (Leiser, 1987; Dantzer et al., 1988).

According to the law of Hagen-Poiseuille, blood flow resistance is reduced by the fourth power of the vascular radius. It can be concluded that even limited and focal sinusoidal dilatation of the long terminal capillary loops may considerably decrease blood flow impedance to such a degree that it no longer exceeds that in the shorter paravascular capillaries. In this way, an even blood flow distribution is guaranteed for all capillaries, independent of their length and diameter. In addition, for this low-pressure fetal circulatory system, the perfusion of the huge extracorporeal organ becomes much easier.

\section{Fetoplacental Angiogenesis as the Driving Force for Villous Development}

As already noted before, the structural comparison of (1) villous development with (2) vascular development within the villi suggests that both processes depend on each other. This impression is further substantiated by the analysis of normally as compared to abnormally matured terminal villous ramifications:

- More than $95 \%$ of terminal villi arise from the surfaces of mature intermediate villi by simple bulging of coiled capillaries (Kaufmann et al., 1985) (Fig. 7.19).

- "Hypermature villi" (Salvatore, 1968; Kaufmann, 1982; Kaufmann et al., 1987), villi in maternal anemia (Kingdom \& Kaufmann, 1997; Kosanke et al., 1998), and villi in IUGR with abnormal but still preserved end-diastolic (PED) flow in the umbilical arteries (IUGR with PED) (Todros et al., 1999) show an increased number of highly branched terminal villi, together with highly branched capillary networks (see Fig. 7.23). 
- In contrast, placentas from IUGR with ARED umbilical flow exhibit nearly naked, unbranched mature intermediate villi that continue in one single terminal villus (Krebs et al., 1996; Macara et al., 1996; Kingdom et al., 1997a,b). The terminal capillaries are much shorter, and uncoiled, with only a few sinusoidal dilatations (see Fig. 7.23).

We conclude from these observations that the development of terminal villi is influenced by the balance of longitudinal growth of mature intermediate villi with that of their capillary loops. The more capillary growth exceeds the longitudinal villous growth, the more do the capillaries become coiled. The single coils bulge against the surfaces of the mature intermediate villi and thus produce the terminal villi. We interpret the terminal villi as passive outpocketings, rather than the result of trophoblastic proliferation.

Even more simplified, one can say that the placental villous trees are fetoplacental vascular trees covered by a flexible wrapping of trophoblast. The latter does not shape the villi but rather follows the vascular shapes.

\section{General Aspects of Placental Vasculogenesis and Angiogenesis}

Because of the obvious importance of formation of vessels for the understanding of decisive steps of villus development, some general principles of vasculogenesis and angiogenesis (Fig. 7.21) as well as the respective findings in the placenta shall be summarized here (for review see also Breier, 2000).

According to Folkman and Shing (1992), Risau and Flamme (1995), and Risau (1997), formation of vessels can be subdivided in two processes that differ regarding mechanisms and control:

- Vasculogenesis involves de novo formation of blood vessels from mesodermally derived precursor cells. Throughout placentation, it takes place during the development of the first villous vessels at the transition from secondary to the tertiary villous stage (from day 18 through about day 35), and later in pregnancy during formation of mesenchymal villi out of immature intermediate ones.

- Angiogenesis is the expansion of a preexisting vessel bed and involves creation of new vessel branches from preexisting ones as well as longitudinal growth of vessels. Throughout placentation it is the principal mechanism for the development of the vascular supply of immature intermediate villi, stem villi, mature intermediate villi, and terminal villi.

Placental angiogenesis must be further subdivided regarding its mechanisms and the geometry of the resulting vascular bed (Kingdom \& Kaufmann, 1997; Kaufmann \& Kingdom, 2000; Charnock-Jones et al., 2004) into of the following categories:

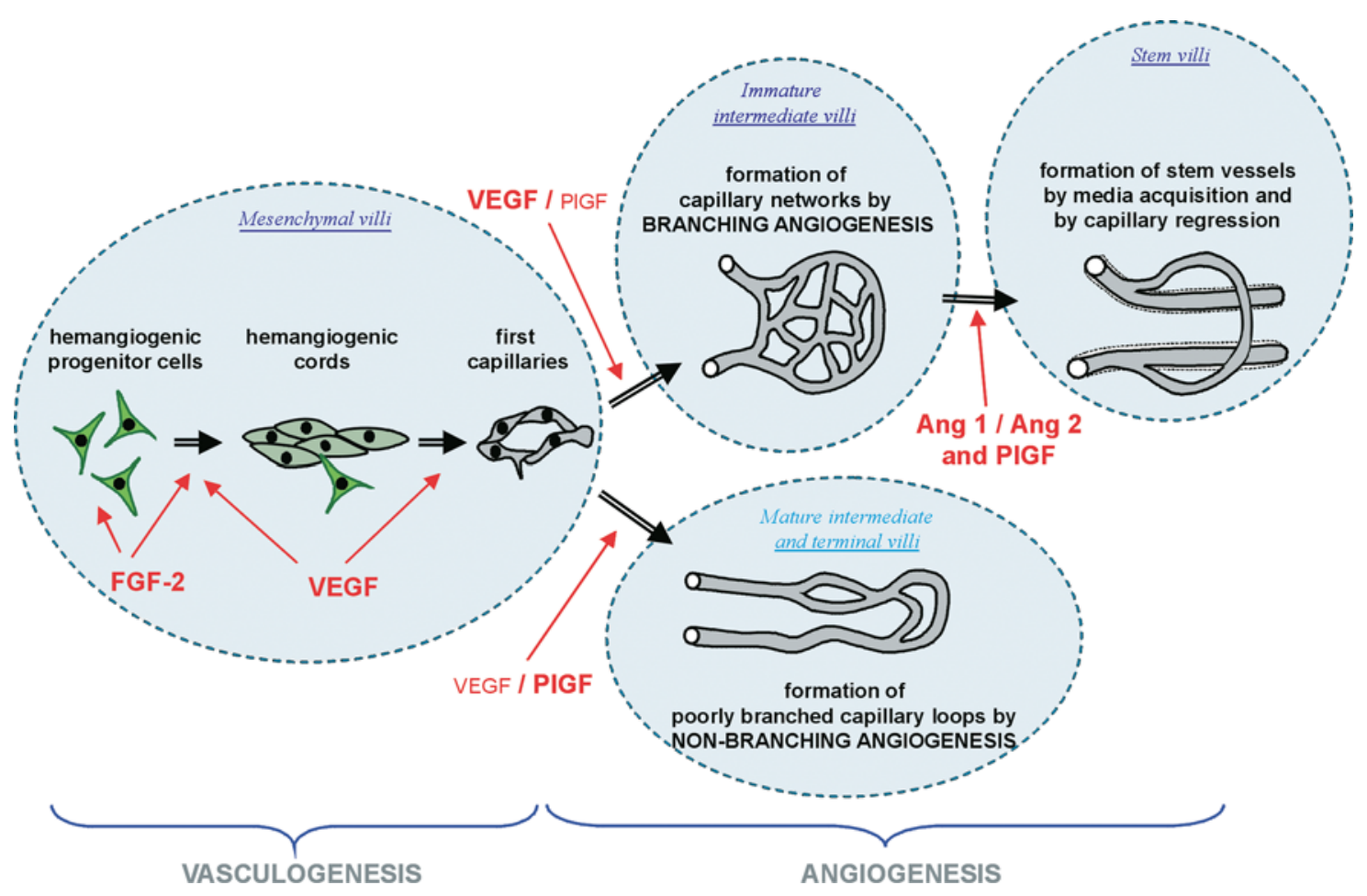

Figure 7.21. Diagrammatic survey of basic mechanisms of vasculogenesis and angiogenesis, their attribution to villous development and their presumed paracrine control (red). For details see text. 
- Branching angiogenesis: This term describes a pattern in which multiple sprouting of microvessels produces a complex, multiply branched capillary web. This is the principal type of angiogenesis from day 32 until about week 24 during development of mesenchymal and immature intermediate villi.

- Nonbranching angiogenesis: In this type of angiogenesis branching by sprouting is the exception. Rather, the vascular bed expands by elongation of existing capillary loops. This mode of angiogenesis starts at about week 24 when mesenchymal villi start developing into mature intermediate villi and the latter start producing terminal villi. It lasts until term. Under pathologic conditions it may become the only mode of angiogenesis. Under normal conditions it takes place in combination with branching angiogenesis.

\section{Vasculogenesis 1: Origin of Hemangiogenic Progenitor Cells (Days 15 to 21)}

The first generations of placental villi develop by local de novo formation of capillaries (vasculogenesis) rather than protrusion of embryonic vessels via the umbilical cord into the placenta. In the rhesus monkey (gestation 166 days), the onset of vasculogenesis is around day 19 postconception (King, 1987). The few existing respective data in the human (Knoth, 1968; Demir et al., 1989) suggest a slightly later date, at about 21 days postconception, in four-somite embryos. At this stage, the villous trees comprise solid trophoblastic primary villi and secondary villi containing a villous core of loose mesenchymal stroma invading from the exocoelomic cavity.

Hertig (1935) formulated the classic theory that villous mesenchymal cells and hemangioblastic cells are derived from villous cytotrophoblast by in situ delamination. This view has been refuted by all subsequent authors (Dempsey, 1972; Luckett, 1978; King, 1987; Demir et al., 1989), who found that the villous mesenchyme is directly derived from the fetus and invades the villi. The hemangiogenic progenitor cells differentiate locally in the villi from the fetally derived mesenchymal cells. The two cell types are structurally similar.

Using the monoclonal antibody QBend10, which detects the endothelial cell surface marker CD34, the endothelial precursor cells (hemangiogenic progenitor cells) can be demonstrated already from day 15 postconception onwards (Figs. 7.22, 7.23, and 7.24A). Within a short period of time the originally dispersed hemangiogenic progenitor cells form string-like aggregates of polygonal cells (hemangiogenic cords), which differ from their mesenchymal precursors by the absence of cellular extensions and the presence of fewer organelles. The narrow intercellular spaces between these cells are bridged by desmosomes and primitive tight junctions (Fig. 7.22c). Extensions of surrounding mesenchymal cells are often integrated into these clusters.

A variety of angiogenic growth factors are involved in angiogenesis and vasculogenesis (Table 7.2). Basic fibroblast growth factor (FGF-2 or bFGF) and its receptor FGFR are thought to be involved in recruitment of hemangiogenic progenitor cells. Its expression in human placental villi has been described repeatedly (Ferriani et al., 1994; Shams \& Ahmed, 1994; Crescimanno et al., 1995) but, due to shortage of respective material, never at this early stage of pregnancy. Vascular endothelial growth factor A (VEGF-A) and its receptor VEGFR-2 (KDR/ flk-1), which were found to be responsible for recruitment, growth, and aggregation of the hemangiogenic progenitor cells in other organs, are highly expressed in early placental specimens (Sharkey et al., 1993; Ahmed et al., 1995, 1997; Wheeler et al., 1995; Shore et al., 1997; Vuorela et al., 1997; Demir et al., 2004). In situ hybridization and immunohistochemistry revealed that villous trophoblast and villous stromal macrophages are the main sources of this cytokine (Sharkey et al., 1993; Ahmed et al.,1995; Vuorela et al.,1997; Demir et al.,2004). VEGFA secretion by human trophoblast was also demonstrated in vitro by Shore et al. (1997). The assumption that macrophages and their cytokines are involved in these first steps of capillary formation is in line with the finding that macrophages differentiate locally in villous stroma even prior to the development of hemangiogenic cords (Demir et al., 1989). Knockout experiments in mice have also highlighted the importance of VEGFR-2 for specification and early differentiation of hemangioblastic precursors of fetoplacental capillaries (Shalaby et al., 1995).

\section{Vasculogenesis 2: Formation of Endothelial Tubes (Days 21 to 32)}

Lumen formation within the hemangiogenic cords and thus formation of short segments of endothelial tubes starts at day 21 postconception. This occurs by enlargement of the centrally located intercellular clefts that fuse to become a larger lumen (Fig. 7.22c,d). We have never observed lumen formation by fusion of intraendothelial vacuoles, as this has been described in other organs (Folkman \& Haudenschild, 1980; Bär et al., 1984). Rather, the fetoplacental capillary lumen in the human, as in placentas of other mammals, always seems to form by acquisition of a junctionally defined extracellular compartment within the hemangioblastic cords (guinea pig: Davidoff \& Schiebler, 1970; rhesus monkey: King, 1987; human: Demir et al., 1989). The acquisition of such still unconnected, isolated segments of capillaries (Fig. 7.23, stage I) defines the transition from secondary to tertiary villi. 

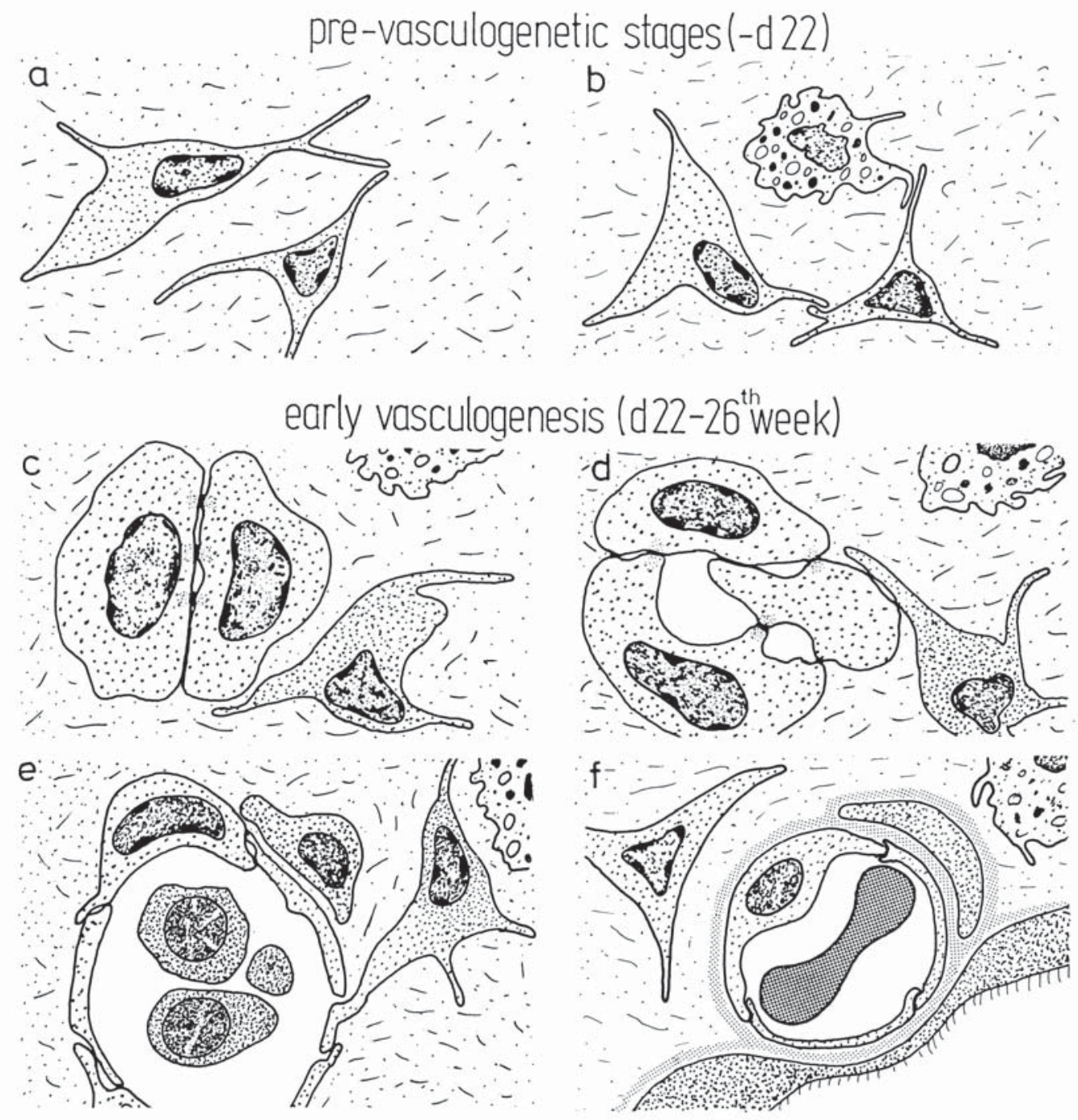

late extension of the vessel bed (angiogenesis) $\left(26^{\text {th }}-40^{\text {th }}\right.$ week)
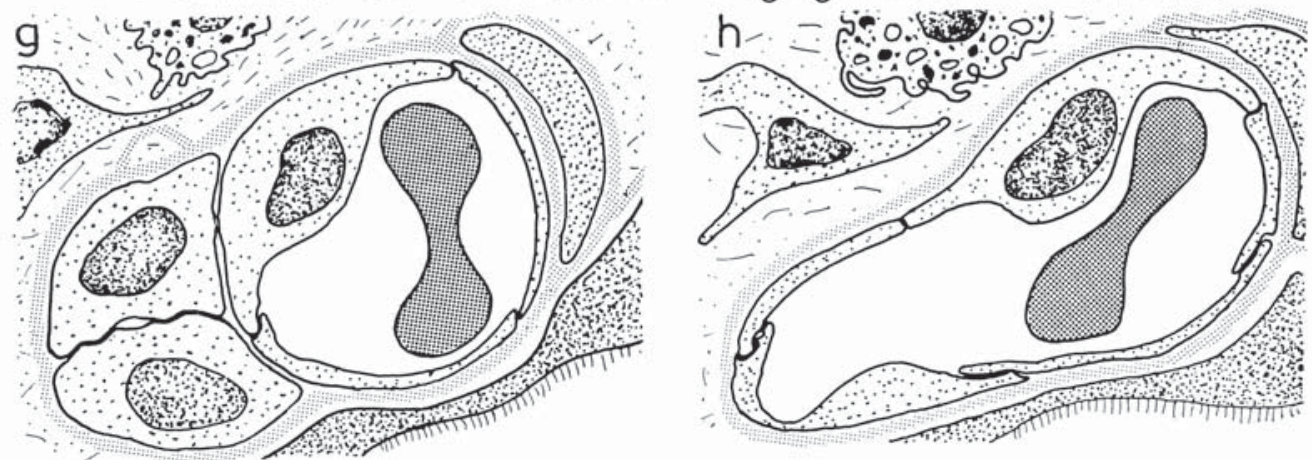

FIGURE 7.22. Vasculogenesis and angiogenesis in early and late placental villi. For further details, see text. (Source: Demir et al., 1989, with permission.) 


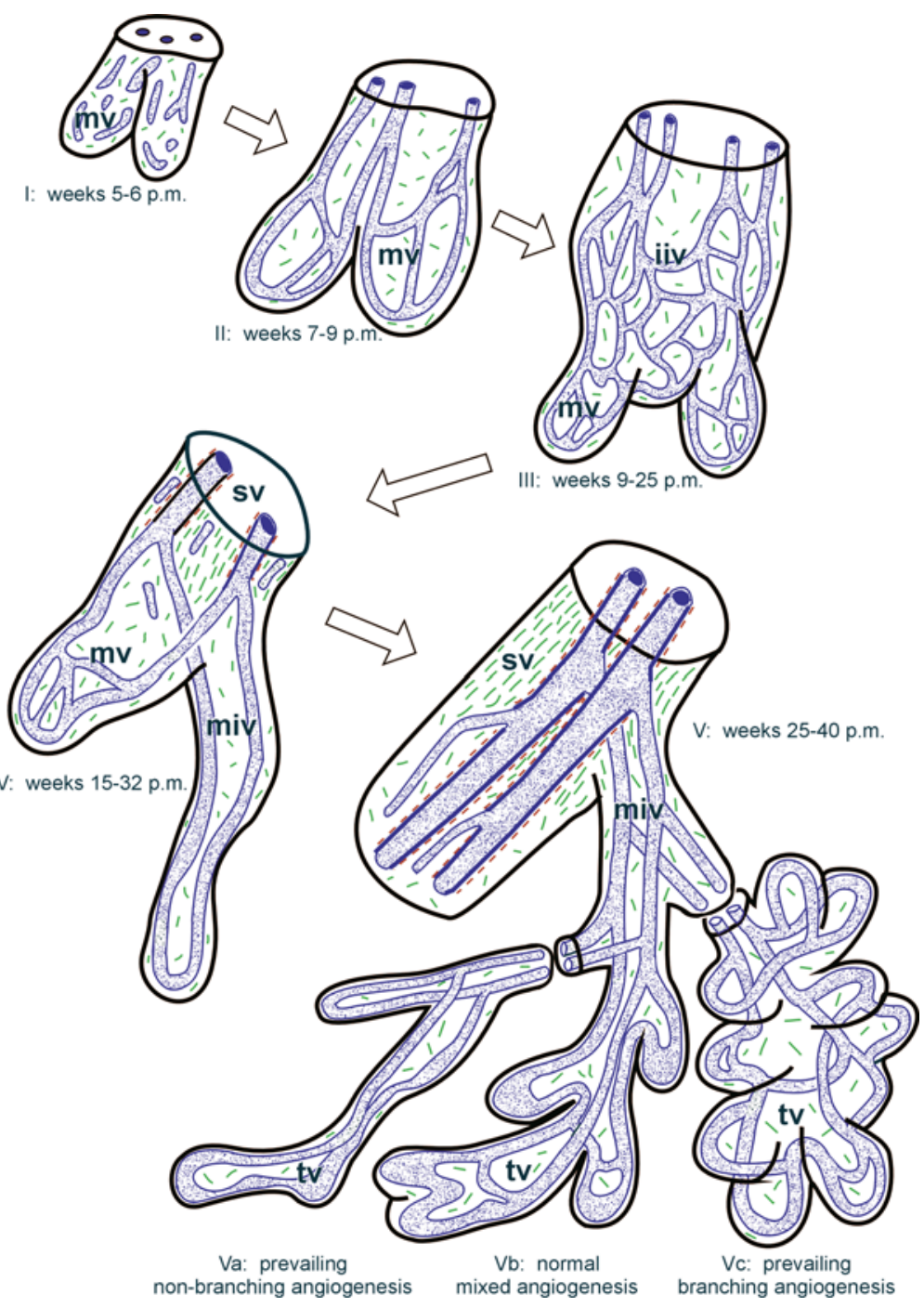

FIgURE 7.23. Villous development in relation to fetal vascular development. Stage I: In the first stage (weeks 5 to 6 p.m.), within mesenchymal villi (mv) fetal capillary segments are formed by vasculogenesis (see Fig. 7.18). Stage II: In weeks 7 to 8 p.m. the primitive vessel segments fuse to form a simple netlike capillary bed. Stage III: During development of immature intermediate villi (iiv) from mesenchymal villi (mv) between weeks 9 and 25 p.m., the preexisting capillary bed enormously expands by branching angiogenesis. This process is likely to be driven predominantly by vascular endothelial growth factor (VEGF). Stage IV: During weeks 15 to 32 p.m., most of the older immature intermediate villi are transformed into highly fibrosed stem villi. In the course of this process, the centrally located capillaries become transformed into stem vessels (arteries and veins), whereas most of the peripheral capillaries undergo regression. In the periphery of these primitive stem villi, mesenchymal villi (mv) are transformed into mature intermediate villi (miv) by nonbranching angiogenesis, resulting in considerable elongation of preexisting capillary loops. The switch from branching angiogenesis toward capillary regression and nonbranching angiogenesis, respectively, is likely to be controlled by increasing levels of placental growth factor (PlGF) and decreasing levels of VEGF. Stage V: Throughout the last

trimester (weeks 25 to 40 p.m.), generally increasing levels of angiogenetic growth factors stimulate longitudinal capillary growth within the mature intermediate villi; as a consequence, elongation of capillary loops exceeds elongation of the villi themselves. This difference results in coiling of the capillaries, the coils bulging against the surface, thereby causing the development of terminal villi (tv). Different types of terminal villous development result from varying degrees of imbalance between villous and capillary growth in context with prevalence of branching or nonbranching angiogenesis (compare Fig. 15.5). Prevalence of PlGF is responsible for predominance of nonbranching angiogenesis, resulting in long, filiform terminal villi (stage Va), typical for postplacental hypoxia. The prevalence of VEGF stimulates terminal branching angiogenesis, resulting in highly branched convolutes of short and multiply notched terminal villi (stage $\mathrm{Vc}$ ), typical for preplacental and uteroplacental hypoxia. Well-balanced secretory levels of VEGF and PIGF are responsible for a balance of branching and nonbranching angiogenesis; thus, evenly formed grape-like terminal villi represent the dominating features in normal term pregnancy. Green, collagen fibers; brown, vascular smooth muscle cells; blue, endothelial tubes. 


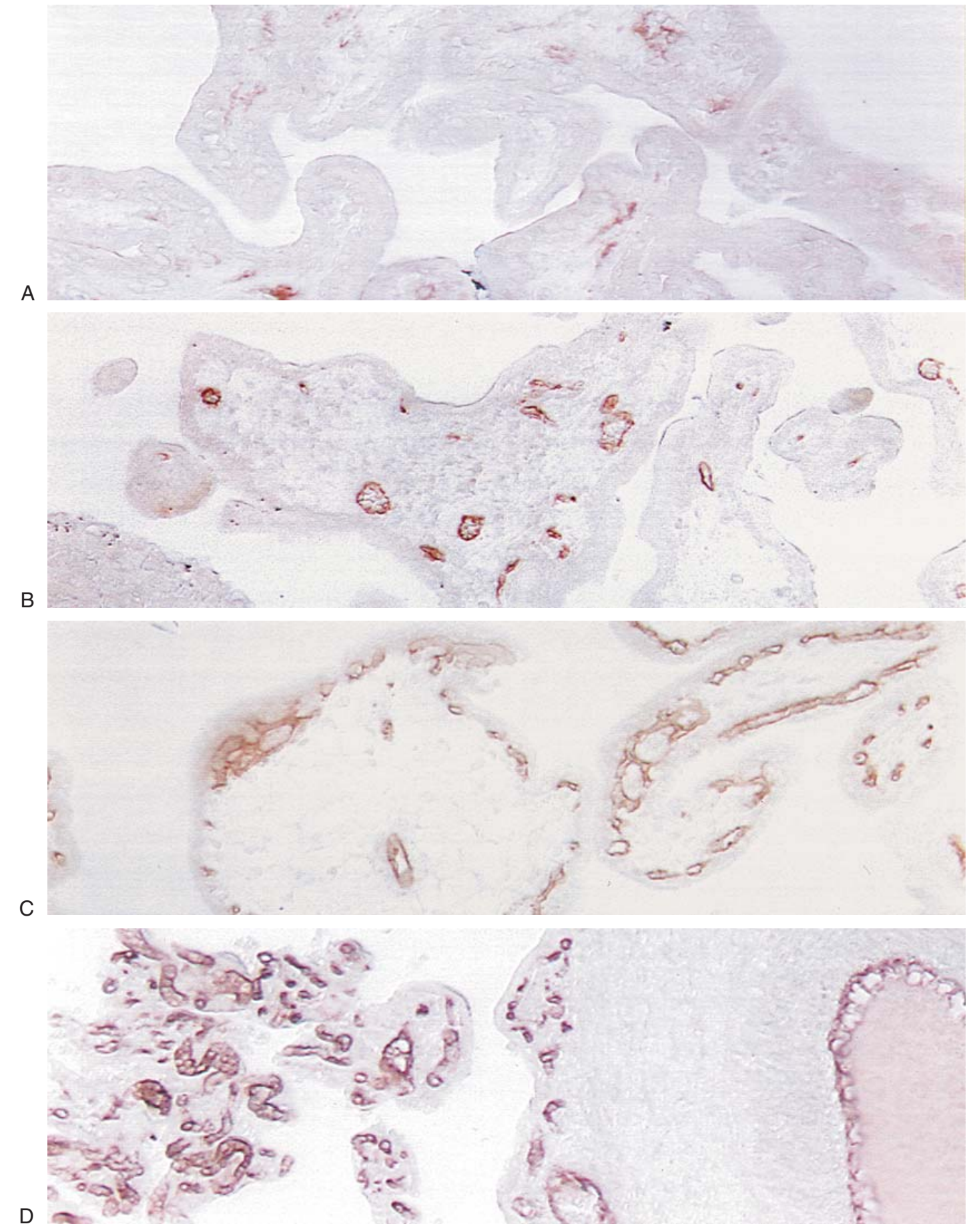

FIGURE 7.24. Stages of villous vasculogenesis and angiogenesis, immunostained with the endothelial marker antibody Qbend10. A: Day 15 to day 20 postconception. The antibody stains weakly hemangiogenic cell cords (light brown). True capillaries are still missing. $\times 650$. (Source: From Kaufmann \& Kingdom, 2000, with permission). B: Mesenchymal villi in week 7 p.m. The majority of capillary cross sections have developed lumens. The capillaries are still evenly distributed across the villous stroma. $\times 320$. C: Immature intermediate villi at the end of the first trimester.

Note the subtrophoblastic localization of richly developed capillary nets. The remaining central vessels are the precursors of arterioles and venules. $\times 320$. D: Terminal and mature intermediate villi (left) and a large-caliber stem villus (right) in week 20 p.m. Note the dense capillarization of the peripheral villous branches, as opposed to the scarce capillarization of the stem villus, largely consisting of superficially located paravascular capillaries. $\times 320$. (Source: Kaufmann \& Kingdom, 2000, with permission). 
TABLE 7.2. Expression of angiogenic growth factors and their receptors in normal and pathologic pregnancies

\begin{tabular}{|c|c|c|c|}
\hline $\begin{array}{l}\text { Growth factors and } \\
\text { their receptors }\end{array}$ & Placental site of expression & $\begin{array}{l}\text { Serum levels throughout } \\
\text { pregnancy }\end{array}$ & $\begin{array}{l}\text { Data from pathologic } \\
\text { pregnancies }\end{array}$ \\
\hline VEGF-A & $\begin{array}{l}\text { Trophoblast, Hofbauer cells, } \\
\text { vascular smooth muscle (1-5) }\end{array}$ & $\begin{array}{l}\text { Moderate increase of total } \\
\text { VEGF serum levels } \\
\text { throughout pregnancy } \\
\text { (including VEGF bound to } \\
\text { its antagonist sflt-1) }(6,34)\end{array}$ & $\begin{array}{l}\text { Total is increased in } \\
\text { preeclampsia; free VEGF-A } \\
\text { may be lower. Placental } \\
\text { VEGF-A immunostaining lower } \\
(6-10)\end{array}$ \\
\hline VEGF-B & None detected (2) & " & $\%$ \\
\hline VEGF-C & Decidual NK cells (11) & $"$ & $\%$ \\
\hline VEGF-D & None detected & " & $\%$ \\
\hline PlGF & Trophoblast $(2,12)$ & $\begin{array}{l}\text { Marked increase of PlGF } \\
\text { serum levels throughout } \\
\text { pregnancy, peaking at } \\
\text { weeks } 28-32(13,15)\end{array}$ & $\begin{array}{l}\text { Reduced in maternal plasma in } \\
\text { preeclampsia }(13-15)\end{array}$ \\
\hline VEGFR-1 (flt-1) & $\begin{array}{l}\text { Trophoblast, endothelial cells } \\
\quad(1,5,10,27)\end{array}$ & $\%$ & $\%$ \\
\hline VEGFR-2 (kdr) & $\begin{array}{l}\text { Villous endothelial cells } \\
(1,5,10,28)\end{array}$ & $\%$ & $\%$ \\
\hline VEGFR-3 (flt-4) & $\begin{array}{l}\text { Trophoblast ( } 29 \text { and S. } \\
\text { Charnock-Jones, unpublished) }\end{array}$ & $\%$ & $\%$ \\
\hline Soluble VEGFR-1 (sflt-1) & Trophoblast (30-33) & $\%$ & $\begin{array}{l}\text { Increased in maternal plasma in } \\
\text { preeclampsia (10 and S. } \\
\text { Charnock-Jones, unpublished) }\end{array}$ \\
\hline FGF-1 & $\begin{array}{l}\text { Trophoblast and vascular } \\
\text { smooth muscle }(16,17)\end{array}$ & $\%$ & $\%$ \\
\hline FGF-2 & $\begin{array}{l}\text { Trophoblast and vascular } \\
\text { smooth muscle }(16,17)\end{array}$ & $\%$ & $\%$ \\
\hline Ang-1 & $(5,19-21)$ & $\%$ & $\%$ \\
\hline Ang-2 & Villous trophoblast $(5,19-21)$ & $\%$ & $\%$ \\
\hline Tie-2 (Tek) & $\begin{array}{l}\text { Villous endothelial cells and } \\
\text { trophoblast }(5,19-21)\end{array}$ & $\%$ & $\%$ \\
\hline $\mathrm{HGF}$ & Villous core $(22-24)$ & $\%$ & $\begin{array}{l}\text { Placental HGF mRNA reduced in } \\
\text { IUGR; circulating HGF } \\
\text { unchanged }(25,26)\end{array}$ \\
\hline Met (HGF receptor) & Trophoblast (22-24) & $\%$ & $\begin{array}{l}\text { No change in mRNA in IUGR } \\
\text { (25) }\end{array}$ \\
\hline
\end{tabular}

(1) Clark et al., 1996a; (2) Clark et al., 1998c; (3) Sharkey et al., 1993; (4) Shore et al., 1997; (5) Wulff et al., 2002; (6) Sharkey et al., 1996; (7) Lyall et al., 1997; (8) Kupferminc et al., 1997; (9) Baker et al., 1995; (10) Zhou et al., 2002; (11) Li et al., 2001; (12) Khaliq et al., 1996; (13) Torry et al., 1998; (14) Reuvekamp et al., 1999; (15) Chappell et al., 2002; (16) Shams \& Ahmed, 1994; (17) Ferriani et al., 1994; (18) Di Blasio et al., 1997; (19) Dunk et al., 2000; (20) Ahmed \& Perkins, 2000; (21) Zhang et al., 2001; (22) Clark et al., 1996b; (23) Kilby et al., 1996; (24) Uehara et al., 1995; (25) Somerset et al., 1998; (26) Clark et al., 1998a; (27) Ahmed et al., 1995; (28) Vuckovic et al., 1996; (29) Helske et al., 2001; (30) Banks et al., 1998; (31) Hornig et al., 2000; (32) He et al., 1999; (33) Clark et al., 1998b; (34) Evans et al., 1998.

Ang, angiotensin; FGF, fibroblast growth factor; HGF, hepatocyte growth factor; IUGR, intrauterine growth restriction; PIGF, placental growth factor; VEGF, vascular endothelial growth factor; \%, no data available; ", identical as above.

Extended and modified after Charnock-Jones et al., 2004.

Immunohistochemical studies have found that the receptor VEGFR-1 (flt-1) is expressed on human villous endothelium (Crescimanno et al., 1995; Clark et al., 1996a; Vuckovic et al., 1996; Demir et al., 2004) but also in villous macrophages and trophoblast (Ahmed et al., 1995; Clark et al., 1996a). Analysis of knockout animals by Fong et al. (1995, 1999) has suggested that VEGFR-1 mediates the action of VEGF-A on endothelial precursors. Interestingly, deletion of the tyrosine kinase encoding intracellular portion of the VEGFR-1 gene has no effect on vascular structures (Hiratsuka et al., 1998), suggesting that it is the extracellular portion of the molecule (i.e., the soluble VEGF antagonist, sflt-1) that is required for placental vascular development.

By day 28 postconception, most villi show clearly defined, long, polygonal capillary lumens with surrounding endothelial cells becoming considerably flattened (Fig. 7.22D,E). Additional mesenchymal cells are integrated by their extensions into both the mesenchymal network and the endothelial tubes (Fig. 7.22E). These "juxta-hemangiogenic" cells are characterized by richly developed rough endoplasmic reticulum and are considered to become pericytes (Dempsey, 1972; King, 1987). Also their inclusion into the endothelial lining has been discussed, since focal extension of these cells may even 
protrude between endothelial cells (Dempsey, 1972; Challier et al., 1999).

As soon as capillary lumens have been formed, around day 28 postconception, the first hematopoietic stem cells develop by delamination from the primitive vessel walls into the early lumens and start further differentiation (Fig. 7.22E). These cells are not yet circulating since most of the endothelial tubes are still isolated. Also an anatomic connection via the cord to the embryonic circulation does not exist yet. The latter is established a few days later (between days 32 and 35 postconception) by fusion of villous capillaries with each other (Fig. 7.23, stage II) and with the larger, allantoic vessels. The latter are formed by vasculogenesis within the allantois (Downs et al.,1998) and thereafter spread in both embryonic and placental directions and finally establish the connection between intraembryonic and placental vascular beds.

\section{Angiogenesis 1: Branching Angiogenesis (Day 32 to Week 25)}

At around day 32 postconception many villous endothelial tubes have created contact among each other (Fig. 7.23 , stage II) and with the fetal allantoic vessels in the presumptive umbilical cord. A primitive fetoplacental circulation is established. From this data onward, vasculogenetic de novo formation of capillaries out of mesenchymal precursors is an exception that usually can only be found at the tips of newly sprouting mesenchymal villi. Rather, further expansion of the villous vascular system until term mainly takes place by angiogenesis.

The angiogenic processes from day 32 until term can be divided into three periods that partly overlap:

1. Formation of capillary networks from day 32 to 25 weeks post conception by prevalence of branching angiogenesis (Fig. 7.23, stage III)

2. Regression of peripheral capillary webs and formation of central stem vessels mainly through weeks 15 to 32 postconception (Fig. 7.23, stage IV)

3. Formation of terminal capillary loops by prevalence of nonbranching angiogenesis (25 weeks postconception until term) (Fig. 7.23, stage V)

From day 32 postconception until the end of the first trimester, the endothelial tube segments formed by vasculogenesis are transformed into primitive capillary networks by the interaction of two mechanisms: (1) elongation of preexisting tubes by nonbranching angiogenesis, and (2) ramification of these tubes by lateral sprouting (sprouting angiogenesis; Carmeliet, 2003) and possibly also by intussusceptive microvascular growth (branching of a preexisting vessel by formation of an endothelial pillar along the vessel lumen (Burri \& Tarek, 1990).
In the first generation of small-caliber villi (mesenchymal villi), branching angiogenesis is less expressed and the resulting capillary webs are only poorly developed (Fig. 7.23, stage II; Fig. 7.24B). With increasing diameter of the immature intermediate villi differentiating out of the mesenchymal villi, branching angiogenesis is stimulated and results in a dense two-dimensional network which is located just below the villous surface (Fig. 7.23, stage III; Fig. 7.24C).

Around the capillaries differentiation processes occur. The endothelial tubes acquire an incomplete layer of pericytes. First spots of basal lamina material are deposited around the endothelial tubes and around the pericytes from about 6 weeks postconception. Complete wrapping of capillaries by basal lamina has been observed only in the last 10 weeks of pregnancy (Fig. 7.22; Demir et al., 1989).

In vitro experiments on the chorioallantoic membrane of the chicken (Wilting et al., 1995,1996) have shown that binding of VEGF to both of its receptors (VEGFR-1 and -2) stimulates branching angiogenesis and results in highly branched capillary webs. Expression of VEGF-A and VEGFR-2 are most intense in these early stages of pregnancy. Whether they decline or moderately increase as pregnancy advances is still a matter of controversy (Jackson et al., 1994; Cooper et al., 1996; Sharkey et al., 1996; Shiraishi et al., 1996; Vuckovic et al., 1996; Evans et al., 1998; Kumazaki et al., 2002). By contrast, expression of PlGF and the soluble form of VEGFR-1 (Crescimanno et al., 1995; Clark et al., 1998b,c; He et al., 1999; Kumazaki et al., 2002) have been found steeply to increase toward term when branching angiogenesis is increasingly replaced by nonbranching angiogenic mechanisms. Placental growth factor binds selectively to VEGFR-1 and, in some systems, appears to suppress sprouting angiogenesis (chorioallantoic membrane of the chicken; Wilting, personal communication). However, in other systems (rabbit cornea and mouse skin), PlGF stimulates formation of highly branched capillary networks (Ziche et al., 1997; Odorisio, 2002).

\section{Angiogenesis 2: Formation of Stem Vessels and Regression of Capillaries in Stem Villi (Weeks 15 to 32 )}

In the third month of pregnancy differentiation of stem villi out of immature intermediate villi is started: some of the centrally located endothelial tubes of immature intermediate villi achieve larger diameters of $100 \mu \mathrm{m}$ and more. Within a short period of time, they establish thin sheaths of contractile cells expressing $\alpha$ - and $\gamma$-smooth (sm) actins in addition to vimentin and desmin. This is followed soon afterward by the expression of sm-myosin (Kohnen et al., 1996; Demir et al., 1997). The surrounding stroma shows concentric, centrifugally spreading fibrosis. 
These vessels are forerunners of villous arteries and veins. In larger immature intermediate villi, the adventitia of arteries and veins fuse, thereby forming a fibrosed stromal core within the villus. As soon as more than $50 \%$ of the reticular stroma of the former immature intermediate villi is replaced by fibrosed stroma, this type of villus is called a stem villus.

Establishment of the outer parts of vessel walls is thought to be controlled by the balance of angiopoietin-1 (Ang-1), and angiopoietin-2 (Ang-2), interacting at their receptor Tie-2 (Tek) (Hanahan, 1997). Accordingly, Ang1 and Ang-2 protein and messenger RNA (mRNA) have been detected in perivascular cells of immature intermediate villi (Geva et al., 2002) where differentiation of stem vessels takes place.

In the course of pregnancy, fibrosis of the stroma of the stem villi advances in a centrifugal manner toward the villous trophoblast (Fig. 7.24D). In parallel, the superficial, subtrophoblastic capillary net become rarified into few largely unbranched paravascular capillaries (Fig. 7.23, stage IV) (Arts, 1961; Leiser et al., 1985). The mechanisms by which capillary regression occurs in stem villi are unstudied, nor is it known whether Ang-2 and its receptor Tie-2 (Hanahan, 1997), the lack of VEGF-A, or the increase of PIGF is involved. The latter is under discussion since Cao et al. (1996) and Khaliq et al. (1999) reported that PIGF may antagonize VEGF action and thus suppresses angiogenesis. Interestingly, regression of capillary nets in developing stem villi is contemporaneous with loss of trophoblast at the villous surface and reduction of macrophages in the fibrosing stroma (own data; Demir et al., 1997), both known to be rich sources of VEGF-A (Sharkey et al., 1993, Ahmed et al., 1995, Vuorela et al., 1997).

\section{Angiogenesis 3: Prevailing Nonbranching Angiogenesis (Week 25 to Term)}

From about 25 weeks postconception until term, mesenchymal villi transform no longer into immature intermediate villi but rather into a new villous types, the mature intermediate villi. These are slender (80 to $120 \mu \mathrm{m}$ diameter), elongated villi ( $>1000 \mu \mathrm{m}$ long) containing one or two long, poorly branched capillary loops. Differentiation of this new villous type out of mesenchymal precursors becomes possible since the pattern of villous vascular growth switches from prevailing branching angiogenesis (leading to immature intermediate villi) to the prevalence of nonbranching angiogenesis (Kaufmann \& Kingdom, 2000).

Analysis of proliferation markers at this stage reveals a relative reduction of trophoblast proliferation and an increase in endothelial proliferation along the entire length of the mature intermediate villi, resulting in nonsprouting angiogenesis by proliferative elongation. An alternative mechanism of capillary elongation would be intercalation (Rafii et al., 2002), that is, by recruitment of circulating endothelial progenitor cells into existing vascular endothelium; but currently there is no evidence to support this.

The final length of these peripheral capillary loops exceeds $4000 \mu \mathrm{m}$ (Kaufmann et al., 1985, 1988). Most importantly, they grow at a rate that exceeds that of the mature intermediate villi themselves, resulting in coiling of the capillaries (Fig. 7.23, stage V). The looping capillaries bulge toward the trophoblastic surface and thereby contribute to formation of the terminal villi, the number of terminal villi depending on the degree of capillary elongation and the resulting degree of coiling (Fig. 7.23, stage Va-c; Fig. 7.24D). Each of the terminal villi is supplied by one or two capillary coils and is covered by an extremely thin $(<2 \mu \mathrm{m})$ layer of trophoblast that contributes to the so-called vasculosyncytial membranes. Normally, the capillary loops of five to 10 such terminal villi are connected to each other in series by the slender, elongated capillaries of the central mature intermediate villus (Figs. 7.19 and 7.24D).

Immunohistochemical studies on the expression patterns of VEGF-A, PlGF, and their receptors give hints as to their importance in villous angiogenesis. Expression of VEGF-A and VEGFR-2 are intense early in pregnancy and decline as pregnancy advances (Jackson et al., 1994, Cooper et al., 1996, Shiraishi et al., 1996, Vuckovic et al., 1996; Kumazaki et al., 2002) or at least increase much less than placental weight does (Sharkey et al., 1996; Evans et al., 1998). By contrast, expression of VEGFR-1 and PlGF steeply increase toward term (Crescimanno et al., 1995; Clark et al., 1996a; Kumazaki et al., 2002). Placental growth factor is expressed in both villous syncytiotrophoblast (Shore et al., 1997, Vuorela et al., 1997) and the media of larger stem vessels (Khaliq et al., 1996, 1999). Experiments on the avian chorioallantoic membrane (Wilting et al., 1995, 1996) have shown that binding of VEGF-A to its receptors results in sprouting angiogenesis and a highly branched capillary web. In contrast, PIGF (which binds selectively to VEGFR-1) is reported to suppress angiogenesis (Cao et al., 1996).

As already indicated above, the role of PlGF may be very complex. Initially, it was reported that this factor had little potency in vitro to stimulate endothelial cell proliferation. Therefore, it was suggested that PIGF functioned either as a weak stimulator or, more likely, as an antagonist of the proangiogenic actions of VEGF-A (Cao et al., 1996; Khaliq et al., 1999). However, Lang et al. (2003) showed that PlGF in vivo stimulates proliferation of microvascular endothelial cells in human term placenta, and Ziche et al. (1997) showed that PlGF in vivo is a potent stimulator of angiogenesis. Overexpression of PlGF in mouse skin leads to a substantial increase in vessel growth, and ischemic tissues can revascularize 
following PIGF treatment (Luttun et al., 2002; Odorisio et al., 2002).

In spite of these contradictions, correlation of growth factor data (Jackson et al., 1994, Cooper et al., 1996, Sharkey et al., 1996; Shiraishi et al., 1996, Vuckovic et al., 1996; Evans et al., 1998; Torry et al., 1998; Chappell et al., 2002; Kumazaki et al., 2002) with development of the villous angioarchitecture (Kaufmann et al., 1985, 1988, Leiser et al., 1985; Kaufmann \& Kingdom, 2000) suggests that the final geometry of villous vascular bed is defined, at least to some degree, by the balance of VEGF-A and PIGF together with their receptors.

- Total circulating VEGF is high in early pregnancy (Jackson et al., 1994, Cooper et al., 1996, Sharkey et al., 1996; Shiraishi et al., 1996, Vuckovic et al., 1996; Evans et al., 1998; Kumazaki et al., 2002), whereas circulating PlGF is low (Torry et al., 1998; Chappell et al., 2002). The predominance of VEGF in this period promotes establishment of richly branched, low-resistance capillary beds within mesenchymal and immature intermediate villi, both of which prevail during the first two trimesters of pregnancy.

- By contrast, in the second half of pregnancy VEGF either decreases (Jackson et al., 1994, Cooper et al., 1996; Shiraishi et al., 1996; Vuckovic et al., 1996; Kumazaki et al.,2002) or shows only a moderate further increase (Sharkey et al., 1996; Evans et al., 1998), whereas PlGF levels steeply increase and peak between weeks 28 and 32, the period of the most dramatic nonbranching angiogenesis. The balanced secretion of both cytokines in this period or even the predominance of PIGF and its receptor VEGFR-1 seems to block the development of complex capillary beds to the benefit of poorly branched terminal capillary loops in the last trimester.

\section{Oxygen and Oxygen-Controlled Growth Factors as Regulators of Villous and Vascular Development}

Only a little is known concerning the control of villous development. On the other hand, a broad variety of pathologic conditions, such as genetic abnormalities but also such as diabetes mellitus, maternal hypertension, maternal anemia or pregnancy in high altitude, rhesus incompatibility, and smoking during pregnancy, severely affect villous and fetoplacental vascular development. This list suggests that the villous and vascular maturational processes are influenced not only by genes but also by endocrine, metabolic, and environmental parameters. From these, only the role of oxygen has been studied in some more detail.

\section{The Special Role of Oxygen in the Placenta}

When discussing effects of oxygen in the placenta, one should be aware of the special role of this gas in the placenta.

First, transplacental oxygen transfer is only one of many villous functions; however, its particular importance becomes evident from the fact that it is nearly the only villous function that, upon disturbance, within a short period of time may cause fetal death. Because of this, it is not surprising that the maternal oxygen supply to the placenta has a stronger impact on villous growth and differentiation than any other known parameter.

Second and even more importantly, in most organs the interactions among density of vascularization, tissue oxygenation, and capillary growth follow the same pattern: a low degree of local vascularization results in insufficient oxygen delivery to this tissue. The resulting tissue hypoxia stimulates capillary growth and thus improves capillary density and local tissue oxygenation. On the other hand, optimum capillarization of a tissue under otherwise normal conditions guarantees a high tissue oxygenation and this, in turn, will block further angiogenesis.

By contrast, in placental villi tissue oxygenation appears to be inversely related to the numerical density of fetal capillaries since, rather than delivering oxygen to the surrounding tissue, the latter extract it from the villi (Kingdom \& Kaufmann, 1997).

- Consequently, a low numerical density of fetal capillaries because of reduced oxygen extraction by the fetal circulation, results in increasing intraplacental oxygen levels (Todros et al., 1999; Sibley et al., 2002), which, in turn, may negatively impact on the already poor vascularization (Charnock-Jones et al, 2004).

- And under otherwise constant conditions, high numerical densities of capillaries, resulting in high oxygen extraction by the fetal circulation, would lower intraplacental oxygen tensions (Todros et al., 1999; Sibley et al., 2002) and thus further stimulate growth of the already well-developed capillary bed (Charnock-Jones et al., 2004).

It is evident that, when exceeding certain limits, both situations are predetermined to develop vicious circles.

\section{Types of Hypoxia and Its Effects on Villous Development}

Because of the above-mentioned inverse relationship between the degree of capillarization and the level of tissue oxygenation, the term hypoxia in pregnancy often causes confusion. This is particularly true when the hypoxic compartment is not exactly defined. Does the hypoxia relate 
Figure 7.25. Depending on the origins of fetal hypoxia, placental oxygenation and placental structural reaction patterns to oxygenation are different. In preplacental hypoxia the hypoxic mother (anemia, cyanotic heart disease, high altitude, etc.) causes hypoxia of placenta and fetus. In uteroplacental hypoxia the mother is normoxic, whereas placenta and fetus are hypoxic as the result of uteroplacental malperfusion. In both these conditions, placental hypoxia stimulates angiogenesis and villous proliferation, which may partly compensate for the hypoxic effects. By contrast, in postplacental hypoxia mother and placenta are normoxic and only the fetus is hypoxic from fetoplacental malperfusion; reduced oxygen extraction from the placenta typically results in an intraplacental $\mathrm{pO}_{2}$ exceeding normal values. This high $\mathrm{pO}_{2}$ inhibits villous growth and accordingly causes the most severe degrees of intrauterine growth restriction. Red point shading: oxygenation of maternal blood. Blue point shading, oxygenation of fetal blood. Dense point shading, oxygen partial pressure shows normal values for that particular tissue; light point shading, oxygen partial pressure is below normal. (Source: Kingdom \& Kaufmann, 1997, with permission.)

- to mother, uterus, placenta, and the fetus, or

- to uterus, placenta, and fetus, or

- only to the fetus?

Based on a respective international symposium 1996 in Banff, the following types of hypoxia in the fetoplacental unit have been defined (Kingdom \& Kaufmann, 1997):

1. In preplacental hypoxia, the mother, the placenta, and the fetus are hypoxic (Fig. 7.25). Underlying pathologies include pregnancy at high altitude (Jackson et al., 1987; Reshetnikova et al.,1993), maternal anemia (Piotrowicz et al., 1969; Beischer et al., 1970; Kadyrov et al., 1998), and cyanotic maternal cardiac diseases. In this condition, the peripheral placental villi show increased branching angiogenesis with formation of richly branched but shorter terminal capillary loops (Fig. 7.23, stage Vc). These human data are consistent with animal experiments in chronically hypoxic guinea pigs (Scheffen et al., 1990) and chronically hypoxic sheep (Krebs et al., 1997), in which both demonstrated increased branching angiogenesis. Interestingly, in the guinea pig, capillary diameters were reduced under these conditions (Bacon et al., 1984; Scheffen et al., 1990), whereas they were increased in the sheep (Krebs et al., 1997). At the present time, however, we do not understand which factors are responsible for controlling capillary diameter in the human placenta.

2. In uteroplacental hypoxia (e.g., preeclampsia with preserved umbilical end-diastolic flow), maternal oxygenation is normal, but because of impaired uteroplacental circulation (Alvarez et al., 1970; for review, see Brosens, 1988), the placenta and fetus are both hypoxic (Fig. 7.25). In this situation, peripheral placental villi similarly show the formation of richly branching capillary networks
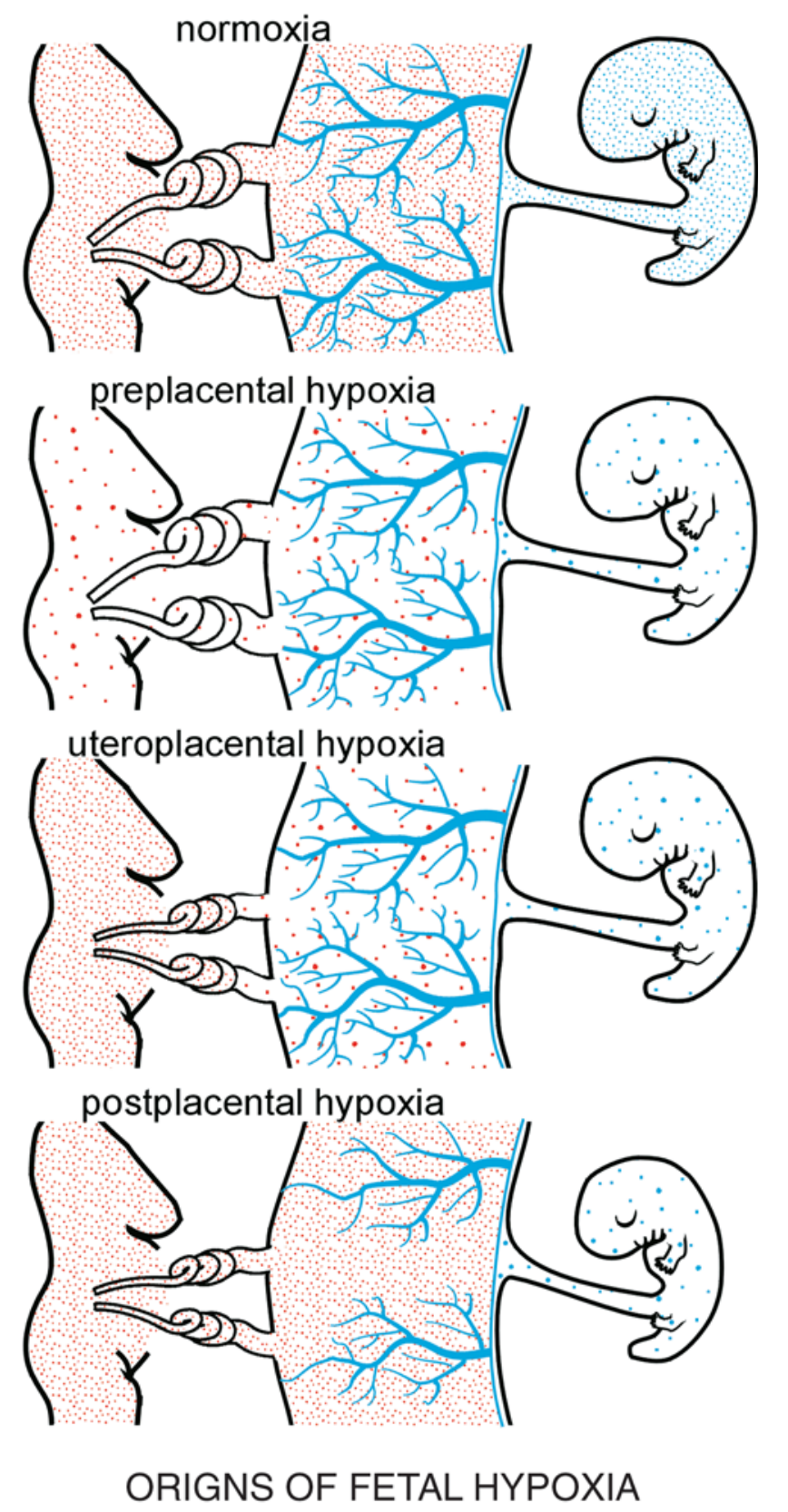

(Fig. 7.23, stage Vc), and fetal blood flow impedance is normal or even reduced (Kiserud et al., 1994; Hitschold et al.,1996). Preliminary Western blot data show increased expression of VEGF and reduced PIGF values in placentas of comparable cases (Ahmed et al., 1997), suggesting that placental VEGF expression was upregulated in vivo and caused the changes in angiogenesis.

3. In postplacental hypoxia (e.g., IUGR with absent umbilical end-diastolic flow), the fetus is hypoxic whereas the mother is normoxic and the placenta may show even higher $\mathrm{pO}_{2}$ levels than normal, a situation described as placental hyperoxia (Fig. 7.25) (Macara et al., 1996; Kingdom \& Kaufmann, 1997; for commentary, see Ahmed \& Kilby, 1997). In this situation, the terminal villus 
capillaries are poorly developed, capillary branching is virtually absent (Fig. 7.23, stage Va), and the resulting fetoplacental flow impedance is considerably increased. Perinatal mortality is more than $40 \%$ in these circumstances, and survivors of neonatal intensive care are at risk of neurodevelopmental handicap. Similar situations occur in locally restricted parts of the placenta as a consequence of fetoplacental vessel obstruction (Panigel \& Myers, 1972; Fox, 1997). Preliminary Western blot data in postplacental hypoxia suggest a pattern of angiogenic growth factor expression in the placenta very different from that of preeclampsia with preserved umbilical enddiastolic flow, namely, a reduction of VEGF expression and relative dominance of PlGF (Ahmed et al., 1997).

Several data support the view that the three variables described above, (1) intraplacental oxygen partial pressure, (2) the balance between VEGF and PIGF expression, and (3) the balance between branching and nonbranching angiogenesis, depend on each other:

- In normal first trimester pregnancy, physiologic intraplacental hypoxia favors VEGF expression and branching angiogenesis.

- In normal third trimester pregnancy, increased intraplacental $\mathrm{pO}_{2}$ results in a slight prevalence of PlGF expression and dominating but not exclusive nonbranching angiogenesis.

- In several pathologic conditions of third trimester pregnancies, severe intraplacental hypoxia results in prevalence of VEGF expression and marked branching angiogenesis.

- Elevated placental oxygen pressures in severe earlyonset IUGR pregnancies (postplacental hypoxia) are combined with the dominance of PlGF expression and complete absence of branching angiogenesis in terminal villi.

\section{Evidence for Oxygen-Controlled Fetoplacental Angiogenesis}

Histopathologic and experimental studies have been employed to study the response of fetal villous endothelium to hypoxia (for review, see Kingdom \& Kaufmann, 1977).

Histopathology: Complicated pregnancies suffering from intrauterine hypoxia show villous "hypercapillarization" (Hölzl et al., 1974); the same is true for placentas obtained in pregnancies from high altitude (Jackson et al., 1987; Reshetnikova et al., 1993) and those from cases of maternal anemia (Kosanke et al., 1998).

Animal experiments: Experimental chronic hypoxia in pregnant guinea pigs resulted in increased fetal capillarization and in elevated $\mathrm{CO}_{2}$ diffusion capacity (Bacon et al., 1984). More detailed studies have revealed that this was caused by stimulated sprouting and branching of capillaries; the mean capillary length and the mean capil- lary diameter were reduced, and the number of parallel capillary loops was considerably increased (Scheffen et al., 1990). As the trophoblastic thickness also decreased, the mean maternofetal diffusion distance was much shorter when compared to normoxic placentas (Bacon et al., 1984). Despite considerable species differences, later repetition of these experiments in sheep revealed a similar reaction pattern (Krebs et al., 1997).

In vitro culture: Using culture of villous explants, the reaction of villous trophoblast to hypoxia was studied in some detail (Tominaga \& Page, 1966; Fox, 1970; Amaladoss \& Burton, 1985; Ong \& Burton, 1991); however, it is difficult to find experimental evidence for an endothelial reactivity in explant culture, because the isolated and unperfused fragments of fetal endothelial tubes tend to disintegrate in culture.

\section{Oxygen-Controlled Angiogenic Growth Factors}

The first evidence for the existence of oxygen-controlled endothelial growth factors was obtained from experiments with endothelial cell cultures (Werb, 1983; Ogawa et al., 1991; Shreeniwas et al., 1991). Surprisingly, endothelial cells showed reduced mitotic rates and reduced motility when cultured under hypoxic conditions (Ogawa et al., 1991; Shreeniwas et al., 1991). The addition of conditioned medium obtained from hypoxic macrophages, however, stimulated endothelial proliferation (Ogawa et al., 1991). Moreover, the same authors showed that an increased production of bFGF (FGF-2) by hypoxic macrophages and enhanced expression of bFGF receptor by the hypoxic endothelium were responsible for the enhanced endothelial proliferation.

Since these pilot studies, the list of angiogenic growth factors under discussion to mediate hypoxic signals in the placenta has grown to include

- the platelet-derived growth factor B (PDGF-B) produced by villous cytotrophoblast or by endothelium (Holmgren et al., 1991),

- acidic and basic fibroblast growth factor (FGF-1 and FGF-2) (Ferriani et al., 1994; Shams \& Ahmed, 1994; Crescimanno et al., 1995),

- vascular endothelial growth factor (VEGF) (Sharkey et al., 1993; Ahmed et al., 1995, 1997; Wheeler et al., 1995; Shore et al., 1997; Vuorela et al., 1997; for review, see Ahmed et al., 2000), and

- placental growth factor (PlGF) (Khaliq et al., 1996; Ahmed et al., 1997; Shore et al., 1997; Vuorela et al., 1997).

From this list, more recently only VEGF and PIGF and their receptors have been studied in more detail regarding their oxygen dependence

The balance between VEGF-A and PIGF secretion may be regulated by oxygen partial pressures. It has been 
shown that the expression of VEGF and its receptors in placental and related chorioallantoic tissues is upregulated under conditions of reduced oxygen (Wheeler et al., 1995; Wilting et al., 1995, 1996; Shore et al., 1997; Khaliq et al., 1999), whereas PIGF expression appears to be downregulated under hypoxic conditions (Shore et al., 1997; Khaliq et al., 1999). These findings raise the question of whether or not the switch (from VEGF-A dominance in early pregnancy to PlGF dominance in the second and third trimesters), together with the concomitant changes in vascular geometry, result from increasing intraplacental oxygenation reported by Rodesch et al. (1992).

Throughout the last decade it was shown that oxygencontrol of growth factors is mediated by hypoxiainducible factor (HIF), which transcriptionally regulates the genes of growth factors that are involved in developmental, physiologic, and pathologic responses to hypoxia (Epstein et al., 2001; Semenza, 2001; Pugh \& Ratcliffe, 2003). The HIF-1 complex is a heterodimer composed of a constitutively expressed HIF-1 $\beta$ subunit (also known as ARNT, aryl-hydrocarbon receptor nuclear translocator) and the hypoxia-dependent HIF- $1 \alpha$ subunit. The level and transcriptional activity of this complex is precisely regulated by the cellular oxygen concentration. In most tissues, the level of the HIF-1 $\alpha$ protein is acutely sensitive to cellular oxygen concentration. Under normal oxygen concentrations, the protein is rapidly destroyed, whereas at low oxygen concentrations HIF- $1 \alpha$ is stabilized and accumulates within the cell. It then dimerizes with HIF$1 \beta$ to form an effective transcriptional activator. The HIF-1 dimer binds to specific DNA sequences of the hypoxia-responsive growth factors and activates transcription of the latter.

So far only HIF action in extravillous trophoblast has raised some interest. Relevant data on HIF action in placental villi, however, are scarce. Among the few available data, those by Caniggia et al. (2000) suggest that HIF-1 $\alpha$ expression is high in the first trimester, as long as intervillous $\mathrm{pO}_{2}$ is low and that it decreases thereafter. Unfortunately, the HIF data available at present are not helpful in explaining the oxygen-controlled balance of VEGF and PIGF secretion or the timing mismatch among the increase in placental oxygenation, changes in growth factor expression, and the switch in fetoplacental angiogenesis.

\section{The Timing Mismatch Between Changes in Oxygenation and Morphologic Changes}

Throughout pregnancy it is necessary to protect the fetus from the potentially harmful effects of high oxygen tensions (Burton, 1997; Burton \& Caniggia, 2001; Hung et al., 2001). Development and remodeling of the fetoplacental vasculature may be part of this protection. As men- tioned above, it is tempting to speculate about causal interactions among changes in placental oxygenation, the switch from VEGF-A dominance to PlGF dominance, and the switch from branching to nonbranching angiogenesis. Interestingly, there is a time lag of about 2 months between the rises in intervillous $\mathrm{pO}_{2}$ levels and perfusion rates (after week 12, Rodesch et al., 1992) and the evidence of morphologic changes (transition from mainly branching to predominantly nonbranching angiogenesis around week 25; Kaufmann \& Kingdom, 2000; Mayhew, 2002). The explanation for this time lag may be that the anatomic changes are considerably more protracted than the rapid in vitro effects of altered oxygen tensions on cultured cells. This situation possibly reflects the difference between the acute (short-term and rapidonset) and chronic (long-term and delayed-onset) responses to oxygen (Semenza, 2001). Sculpting the fetoplacental vascular network takes time and, if the placenta as a whole is to function in a coordinated manner, vascular changes must be integrated with changes in other villous compartments, especially the trophoblast (Mayhew, 2002).

Downregulation of VEGF-A and upregulation of PlGF may occur almost contemporaneously with the oxygen switch, although there is no direct evidence for this at present. The time course of respective vascular adaptation in the placenta is not known, but in the eye and in tumors these events occur within just a few days (Alon et al., 1995; Benjamin \& Keshet, 1997). In the placenta stimulated vascularization may take much more time since the interactions between fetoplacental vascularization and villous development are much more complex. Regression of capillaries in immature intermediate villi, together with establishment of a tunica media around maturing vessels in developing stem villi, may begin at about the time of the oxygen switch. The transition from branching angiogenesis (in mesenchymal and immature intermediate villi) to nonbranching angiogenesis (in mature intermediate and terminal villi), however, involves different generations of villi. Only when the key types of villi for nonbranching angiogenesis (mature intermediate villi) are generated, persistently-high $\mathrm{pO}_{2}$ levels may combine with low VEGF-A and high PIGF levels (and changes in other, as yet unidentified, factors) to facilitate nonbranching angiogenesis.

Intervillous $\mathrm{pO}_{2}$ values seem to peak during the second trimester (about $60 \mathrm{~mm} \mathrm{Hg}$ at 16 weeks, Soothill et al., 1986; Rodesch et al., 1992; Jauniaux et al., 2001). This is in seeming contradiction to the assumption that, as pregnancy advances, also the fetal demand for oxygen will rise further. Possibly the final drop to about $45 \mathrm{~mm} \mathrm{Hg}$ at term (Soothill et al., 1986; Rodesch et al., 1992; Jauniaux et al., 2001) is a consequence of fetoplacental vascular remodeling resulting in increased oxygen extraction from the intervillous space. 


\section{Oxygen and Villous Trophoblast}

Histopathologic reports unanimously describe that the amount of villous cytotrophoblast is increased in all those pathologic conditions that are thought to be related to intrauterine hypoxia (Fox, 1964, 1970; Piotrowicz et al., 1969; Beischer et al., 1970; Kaufmann et al., 1977a; Kosanke et al., 1998). Arnholdt and coworkers (1991) found evidence that this is the result not only of an increased mitotic index but also of a reduction of the length of the cell cycle. In contrast, unusually good oxygenation of villi reduces the rate of proliferation as well as the quantity of villous cytotrophoblast (Panigel \& Myers, 1971, 1972; Myers \& Panigel, 1973; Kaufmann et al., 1977a; Macara et al., 1996; for review, see Kingdom \& Kaufmann, 1997).

In addition, the villous syncytiotrophoblast is affected by hypoxia as was shown experimentally by Tominaga and Page (1966) and Ong and Burton (1991), and in pathologic specimens (Alvarez et al., 1969, 1970). It is reduced in thickness and simultaneously increased numbers of syncytial knots are produced, the nuclei of which show signs of chromatin clumping and partly of apoptosis. Tominaga and Page interpreted this as a sign of adaptation by reducing diffusion distances. More stringent stereologic studies have suggested, however, that the changes are more likely caused by degenerative processes (Ong \& Burton, 1991). Recent experiments by Burton pose the question of whether or not all insults seen after ischemic/hypoxic periods are in fact due to lack of oxygen; the authors found that damage by oxygen radicals in the reoxygenation period may be even more important (Hung et al., 2002a).

Most in vitro studies on the effects of hypoxia have been performed on villous explants rather than on villous cytotrophoblast cultures. For that reason it is still an open question whether cytotrophoblast responds directly to variations of the oxygen partial pressure, or whether this response is mediated by factors released by other hypoxic tissue components such as syncytiotrophoblast or villous macrophages. There are several candidate mediators of hypoxic signals: epidermal growth factor (EGF) may be derived from maternal sources and is additionally produced by syncytiotrophoblast (for review, see Prager et al., 1992); its mitogenic action on trophoblast has been shown by Lysiak and coworkers (1992), and its receptors have been detected on the syncytiotrophoblastic surfaces (Rao et al., 1985) as well as on cytotrophoblastic membranes (Mühlhauser et al., 1993). Transforming growth factor- $\alpha($ TGF- $\alpha)$ (Lysiak et al., 1992) and tumor necrosis factor- $\alpha$ (TNF- $\alpha$ ) (Hung et al., 2002b), the latter produced by macrophages (for review, see Hunt, 1989), and colony-stimulating factor 1 (CSF-1) produced by mesenchymal cells (Jokhi et al., 1992; Shorter et al., 1992) are other candidates. Finally, TGF- $\beta_{1}$ and TGF- $\beta_{2}$, both produced by macrophages (for review, see Hunt, 1989) and by trophoblast (Graham \& Lala, 1991), seem to be involved in the regulation of syncytial fusion of the postproliferative cytotrophoblast to regenerate the hypoxically damaged syncytiotrophoblast. As already mentioned above, oxygen-dependent regulation of most of these cytokines involves HIF as hypoxia-responsive transcriptional factor.

\section{Oxygen and Villous Stroma}

It is a common experience in pathologic studies of the placenta that the villous connective tissue responds to variations in the intrauterine oxygen supply. This is nicely illustrated by the low degree of villous fibrosis throughout the first trimester when intervillous $\mathrm{pO}_{2}$ is low, and the increasing fibrosis, for example, in stem villi at the transition to the second trimester when placental oxygen levels steeply increase. Chronic hypoxia results in minimal fibrosis of the villi (Fox, 1978); in contrast, higher levels of intravillous $\mathrm{pO}_{2}$ increase villous fibrosis (for example following intrauterine death when intraplacental oxygen partial pressure, because of lacking fetal oxygen extraction, approaches maternal arterial values) (Panigel \& Myers, 1971, 1972; Fox, 1978). Related in vitro experiments with placental tissues are still to be done. Possible mediators are macrophage products such as TGF- $\beta$, which stimulates collagen-I transcription (Rossi et al., 1988), or interleukin-1, which, among other functions, regulates fibroblast proliferation (Schmidt et al., 1982).

\section{Oxygen and Intervillous Circulation}

There are few data concerning hypoxic influences on the maternal vascularization of the placenta. In the guinea pig, volume and surface of maternal blood lacunae are reduced under hypoxic conditions (Bacon et al., 1984). In contrast, in human placentas from patients at high altitude, the intervillous space was described to be increased (Jackson et al., 1987). For the cow placenta, Reynolds and coworkers (1992) have demonstrated maternal endothelial mitogens of endometrial origin.

Numerous experimental data have been provided concerning the influence of oxygen on trophoblast invasion (Genbacev et al., 1996, 1997; Graham \& McCrae, 1997; Fitzpatrick \& Graham, 1998; Zhou et al., 1998; Caniggia et al., 2000). Trophoblast invasion triggers adaptation of uteroplacental arteries to pregnancy conditions and thus has an important effect on intervillous blood flow. Unfortunately, these data are controversial. Therefore, no actual conclusions can be drawn as to whether hypoxia affects maternal blood flow to the intervillous space, and if so, in which direction. 


\section{Hormones as Regulators of Villous Development}

Even though it should be expected that villous development is controlled by maternal and fetal hormones, there are only very few relevant clinical indications. Reliable experimental proof is completely missing. Here, we briefly discuss data that look promising for future research.

Ovarian steroids are the most likely group of hormones to be involved in placental development and probably represent the only group of hormones that, in few cases, have been used for the treatment of villous maldevelopment. The following examples may give an idea of how ovarian steroids can influence villous development:

- Placentas from pregnancies complicated by IUGR and combined with decreased or absent end-diastolic blood flow are characterized by very homogeneous features of villous maldevelopment (Macara et al., 1996). These are reduced trophoblastic proliferation rate, reduced numbers of terminal villi, reduced total villous volume, poor branching of terminal villous capillaries, increased terminal villous fibrosis, and increased differentiation of villous myofibroblasts. The functional consequences of these alterations are likely to be responsible for the impaired fetal nutrition, as well as for the increased fetoplacental blood flow impedance. Several groups of investigators have found evidence that third trimester treatment with gestagens (allylestrenol) decreased blood flow impedance and increased fetal birth weight as well as placental weight (Kaneoka et al., 1983; Kurjak \& Pal, 1986; Marzolf et al., 1986). The only histologic study of these placentas provided by Papierowski (1981) described a "stimulated development" of villi. As far as we were able to see from Papierowski's data, a numerical increase in immature, proliferating villous types was responsible for the overall increased villous growth rate.

- In contrast, P. Prahalada (personal communication, 1982) found that treatment of rhesus monkeys with higher doses of estrogens during midpregnancy caused reduced placental and fetal growth rates. To our knowledge, these placentas have not been studied histologically.

- The latter findings were supported by experimental data by Yallampalli and Garfield (1993), Chwalisz et al. (1994), and Garfield et al. (1994). These authors induced symptoms of preeclampsia including IUGR in rats and guinea pigs by blocking nitric oxide synthase by I-NAME, and reversed these effects by treatment with gestagens.

The above data suggest that gestagens and estrogens may have antagonistic effects on villous development and differentiation. Possibly not only the oxygen-controlled balance of VEGF and PIGF (see above) but also both steroid hormones control the switch of mesenchymal villous transformation either into continuously growing immature intermediate villi or into differentiating mature intermediate villi.

Also insulin is under discussion regarding its influence on villous development. The prevailing finding in placentas of diabetic mothers is that of an overall increased proliferation rate of villous trophoblast, villous stromal cells, and villous capillaries, resulting in large placentas that are characterized by large-caliber villi with high cellular density (Widmaier, 1970; Werner \& Schneiderhan, 1972; Fox, 1978).

So far, all attempts have failed to demonstrate classic insulin effects on the maternal side of the placental barrier, such as stimulation of glucose uptake (Challier et al., 1986), of amino acid transport (Montgomery \& Young, 1982), and increase in glycogen levels in trophoblast cells (Schmon et al., 1991). These negative results can be explained by the low levels of insulin receptors on the syncytiotrophoblastic surface during the second half of pregnancy (Jones et al., 1993; Desoye et al., 1994, 1997).

On the other hand, direct growth-promoting effects of insulin (for review, see Strauss, 1984) on the various placental tissues must be considered.
- In the first trimester, insulin receptors available at the maternal/ intervillous surface of villous trophoblast are expressed mainly along the surfaces of sprouting segments of the villous trees (true trophoblastic sprouts, mesenchymal villi) (Desoye et al., 1994, 1997). This finding indicates that maternal insulin might be involved in first-trimester villous growth, which is mainly a result of trophoblastic proliferation (Castellucci et al., 1990, 2000).

- In the last trimester, the highest immunoreactivities for insulin receptors are found in fetal villous endothelium (Jones et al., 1993), in particular in segments with capillary sprouting, such as mature intermediate villi and terminal villus necks (Desoye et al., 1994, 1997). In this period, expansion and differentiation of the villous trees are mainly a result of capillary sprouting (Kaufmann et al., 1988; Castellucci et al., 1990, 2000).

A switch in villous growth control from maternal insulin (with insulin receptors along the maternal trophoblastic surface) in early pregnancy to fetal insulin (with endothelial insulin receptors) in late pregnancy would make sense because it would enable the fetus to control villous differentiation in accordance with its own nutritional needs.

Also thyroid hormones are candidate regulators of villous development. It is now recognized that in pregnancy, maternal thyroid function is mediated by the placenta (Fisher, 1983). The placenta plays a major role in the synthesis and metabolism of the thyroid hormones: the putative trophoblastic thyrotropin (Hershman, 1972) as well as human chorionic gonadotropin ( $\mathrm{hCG}$ ) (Kennedy \& Darne, 1991) stimulate the maternal thyroid hormone production; thyroid-stimulating hormone $(\mathrm{TSH})$, triiodothyronine $\left(\mathrm{T}_{3}\right)$, thyroxine $\left(\mathrm{T}_{4}\right)$, and thyroglobulin cannot pass the placental barrier, while thyroid-releasing hormone (TRH), iodine, and thyroid-stimulating immunoglobulins can (Cappoen, 1989). Placental tissue as well as the decidua has a high nuclear-binding capacity for $T_{3}$. Therefore, Banovac et al. (1986) have suggested the placenta to be a thyroid hormone-dependent tissue. Maruo et al. (1991) have described stimulatory effects of maternal $T_{3}$ and $T_{4}$ on trophoblastic endocrine functions; moreover, they found that $T_{3}$ enhances trophoblastic production of epidermal growth factor (EGF), a potent trophoblastic mitogen, and concluded that thyroid hormone, in synergy with EGF, regulates villous growth (Matsuo et al., 1993).

There are fewer data concerning the correlation of thyroid malfunction with placental function or development. According to experiments in rats (Kumar \& Chaudhuri, 1989), the levels of maternal thyroid hormone secretion are positively correlated with fetal growth. Thorpe Beeston et al. (1991) found significantly reduced maternal $T_{4}$ levels in small-for-gestational-age fetuses combined with fetal hypoxemia and acidemia.

All these data suggest that maternal thyroid hormones are involved in villous development and thus influence placental transfer functions for nutrients and gases. Relevant clinical data, however, are difficult to interpret. We have seen some placentas of hypothyroid mothers medicated with thyroid hormones. The placentas of all of these cases were characterized by stimulated nonbranching angiogenesis and correspondingly reduced branching of terminal villi; partly, the respective cases comprised persisting villous immaturity with predominance of mature intermediate villi (see Chapter 15, Fig. 15.9) as well as IUGR with ARED flow in the umbilical arteries (Fig. 15.17). We found similar features in two cases of untreated hyperthyroid mothers.

\section{Intervillous Space as Related to the Villous Trees}

The human placenta is a hemochorial, villous placental type. After leaving the spiral arteries, the maternal blood circulates through the diffuse intervillous space and flows directly around the villi. The maternal blood is outside 
the confines of the endothelium of the maternal vascular system.

\section{Width of the Intervillous Space}

The anatomical investigations concerning the width of the intervillous space suffer the disadvantage of having been made on delivered placentas, which have lost considerable amount of maternal blood during delivery. They are also usually fixed without the in vivo maternal blood pressure distending the intervillous space. Therefore, the usual appearance of the intervillous space of the delivered placenta is that of a system of narrow intervillous clefts. Hörmann (1951, 1953, 1958a,b) and Lemtis (1955) called it the intervillous cleft system. This view was supported by Becker (1962b), who attempted to reestablish in vivo pressure conditions before fixation and found the same narrow clefts. Becker described neighboring villi as clinging closely to one another, the tips of some fitting into notches of others, as in a jigsaw puzzle. Becker interpreted the occasional appearance of a wider intervillous space (in conventional histologic material) as the result of shrinkage. Freese (1966) also failed to demonstrate an intervillous space of larger than capillary dimensions, except for the subchorial lake. Boyd and Hamilton (1970) contradicted these interpretations. According to their experience from in vivo radioangiographs, the rapid filling of the intervillous space is not compatible with a cleft system of capillary dimensions.

Using the data for postpartal intervillous blood volume ( $23.3 \%$ to $37.9 \%$ of the placental volume) and for the villous surface (11.0 to $13.3 \mathrm{~m}^{2}$ ) (see Tables 28.5 and 28.8 ), we calculate the mean width of the intervillous space (blood volume divided by one half of the villous surface) as ranging from 16.4 to $32 \mu \mathrm{m}$. The villous surface must be divided by 2 because it covers the clefts on both sides. Bouw et al. (1976) demonstrated that late cord clamping is responsible for a loss of intervillous volume, probably owing to the decreasing turgor of the villi that border the intervillous space (see Table 28.8). If we calculate the mean width of the intervillous space with their data from term placentas obtained after early cord clamping, it amounts to $31.6 \mu \mathrm{m}$. One must bear in mind that there is a considerable subchorial lake, and that wide spaces also exist in the arterial inflow area. Thus, the real "intervillous" volume is likely to be lower and the intervillous clefts narrower. On the other hand, when one adds the considerable loss of maternal blood during labor, we consider that these calculations may be near the truth.

Also recent in vivo studies in various stages of pregnancy using color power Doppler ultrasonography with three-dimensional (3D) option did not answer the question as to the in vivo width of the intervillous space at term (Konje et al., 2003). They suggest, however, that the width of the intervillous space becomes considerably reduced in the course of pregnancy: the $3 \mathrm{D}$ reconstruc- tions (Fig. 7.26B) revealed high maternal blood flow velocities in the maternal inflow and outflow areas on the intervillous space throughout the second and third trimesters of pregnancy. In the second trimester even between peripheral ramifications of the villous trees minor maternal flows could be visualized, suggesting wide intervillous clefts $(\gg 100 \mu \mathrm{m})$ with high flow velocities. In the third trimester velocities and width of the intervillous clefts between the peripheral villi were too small for detection.

\section{Organization of Villous Trees}

Wigglesworth (1967) studied corrosion casts of fetal vessels and suggested that most villous trees are arranged "as hollow-centered bud-like structures" around a central cavity. When he injected the spiral arteries, Wigglesworth found the injection mass to collect in the loose centers of the villous trees. This finding is in agreement with most descriptions of the maternal arterial inlets as being located near the centers of the villous trees (Schuhmann \& Wehler, 1971; Schuhmann, 1981), which direct the bloodstreams into these centers (Panigel \& Pascaud, 1968). The 50 to 200 maternal venous outlets of each placenta are thought to be arranged around the periphery of the villous trees. Thus, each fetomaternal circulatory unit is composed of one villous tree with a corresponding, centrifugally perfused portion of the intervillous space (Figs. 4.7, 7.26A, and 7.27A). This unit was called a "placentone" by Schuhmann and Wehler (1971) (for review, see Schuhmann, 1982).

Most placentologists agree that, under in vivo conditions, most of the 40 to 60 placentones are in contact with each other and that they overlap more or less broadly. This supposition is highly probable, as structural borderlines, such as placental septa, are absent (Becker \& Jipp, 1963). It is our experience that the peripheral placentones are more clearly separated from each other and thus exhibit typical structural differences between their central and peripheral zones. In the thicker, more central regions of the placenta, most villous trees overlap (Figs. 7.26A and 7.27A), causing less distinct differences between maternal inflow and outflow areas of the placentone.

According to studies of Schuhmann and Wehler (1971), the centers of typical placentones exhibit loosely arranged villi, mostly of the immature intermediate type, and provide a large intervillous space for the maternal arterial inflow, the central arterial inflow area (Figs. 7.26A and 7.27). It is still uncertain if these large, loosely arranged villi regularly delineate a central cavity as described by Wilkin (1965). Schuhmann (1981) suggested that these cavities are pressure-dependent in vivo structures that rapidly collapse after delivery, and his suggestion is borne out by ultrasonographic findings. If one accepts the considerations of Moll (1981), the existence of such a central cavity makes sense because it guarantees the rapid and 

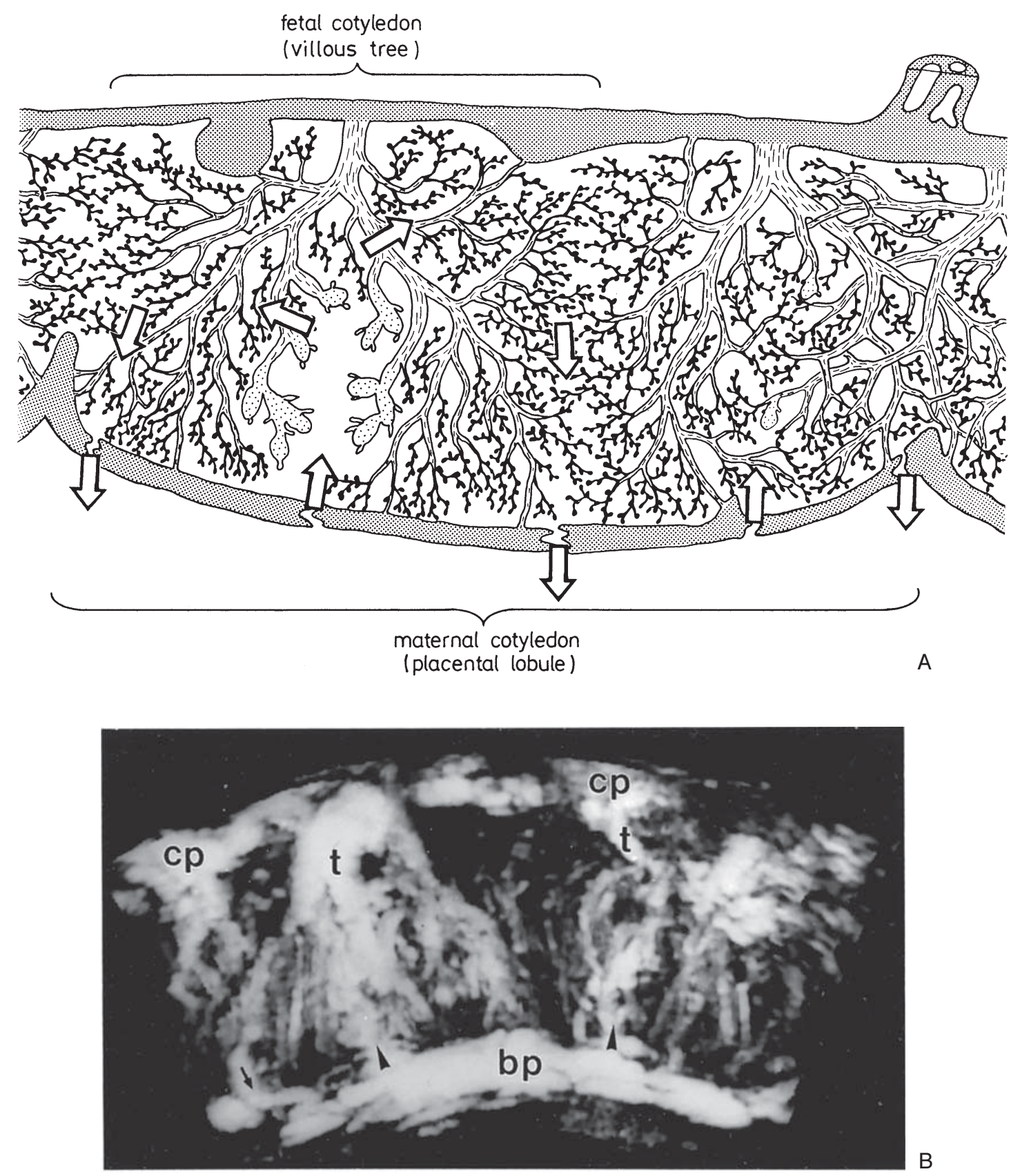

Figure 7.26. A: Typical spatial relations between villous trees, single villous types, and the maternal bloodstream. According to the placentone theory of Schuhmann (1981), a placentone is one villous tree together with the related part of the intervillous space. In the case of typical placentones (left half of the diagram), which prevail in the periphery of the placenta, the maternal blood (arrows) enters the intervillous space near the center of the villous tree and leaves the intervillous space near the clefts between neighboring villous trees. In the term placenta, the larger stem villi (line shaded), the immature intermediate villi (point shaded), and their tiny branches (unshaded) are concentrated in the centers of the villous trees, surrounding a central cavity as maternal blood inflow area. The mature intermediate villi (black) together with their terminal branches (black, grapelike) make up the periphery of the villous trees, near the venous outflow area. One or few villous trees occupy one placental lobule (see Chapter 2, Fig. 2.2), which is delimited by grooves in the basal surface of the placenta (see Fig. 2.1B). In the central parts of the placenta, the villous trees, because of size and nearby location, may partly overlap (right half of the diagram) so that the zonal arrangement of the placentone disappears. (Source: Modified from Kaufmann, 1985, with permission.) B: Corresponding in vivo photograph, generated by powerDoppler ultrasonography with 3D option, shows two villous trees, corresponding to those depicted in part A. The villous trees are derived from villous trunci $(\mathrm{t})$, which are connected to the chorionic plate (cp). As is typical for the power Doppler technique, the picture shows not only the larger vessels in chorionic and basal plates but also the larger stem villi in which the Doppler signals of arteries and veins add to each other. The maternal arterial bloodstreams ("jets") entering the intervillous space (arrowheads), as well as the maternal venous blood (arrow) leaving the intervillous space, are also seen. Since blood flow velocities across the fetal cotyledons are too slow, the remaining parts of the intervillous space are black. Near-term placenta, $\times 2$. (Courtesy of Dr. Justin Konje, Leicester, UK.) 


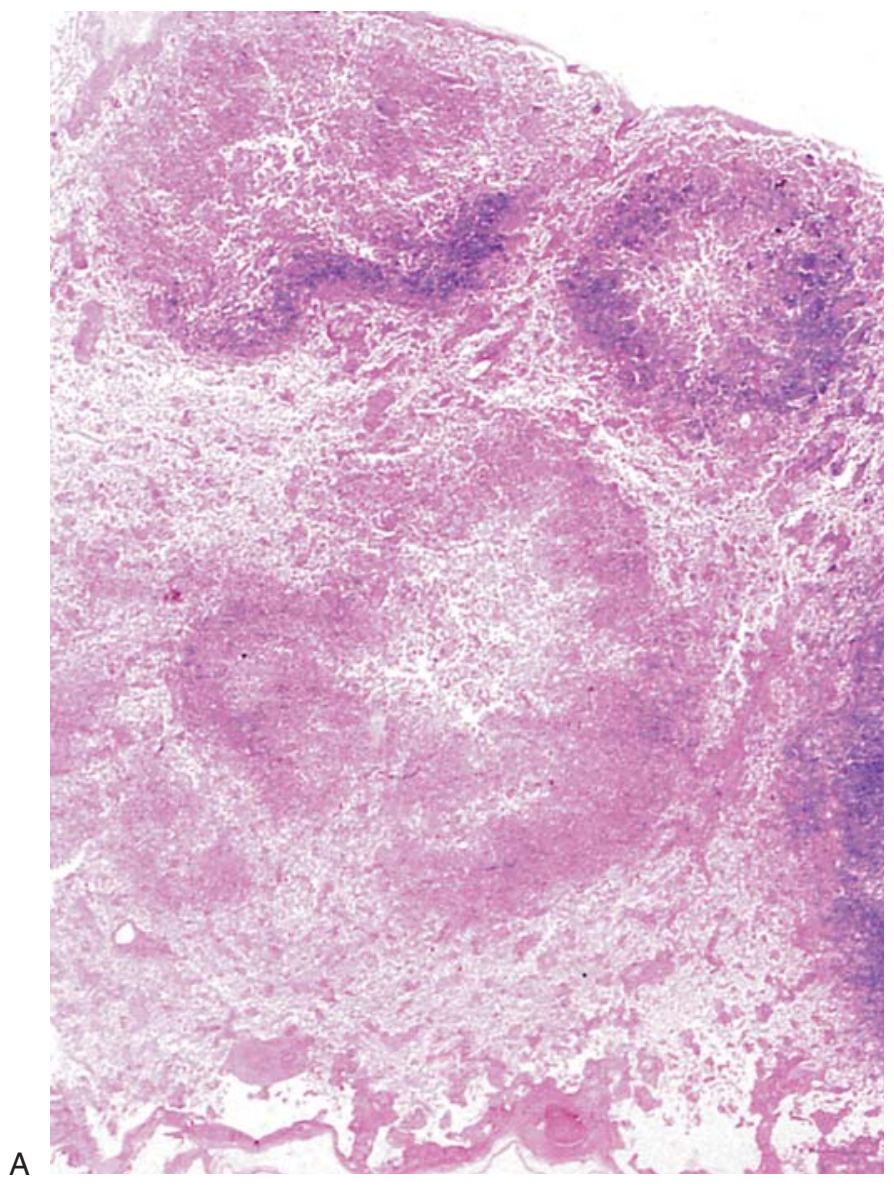

Figure 7.27. Placentone arrangement of villous trees. A: Horizontal paraffin section across the marginal zone of a mature placenta. H\&E stain. Note the existence of three ring-shaped placentones (fetal cotyledons), each single one composed of a loose center (arterial inflow area), surrounded by a dense ring of small peripheral villi (exchange area), and finally surrounded by the loosely structured venous outflow area. $\times 3.6$. B: Higher

homogeneous distribution of blood into the surrounding mantle of small, densely packed villi with little loss of pressure.

The surrounding mantle is composed mostly of small villi of the mature intermediate and terminal types and provides the peripheral exchange area. The villi are densely packed. Schmid-Schönbein (1988) described the intervillous space in this zone as a system of randomly shaped and oriented, interconnected clefts, or "connected voids." With respect to their topology, these clefts lack the regular connectivity seen in dichotomously branching vascular beds. The fixed relations of the latter vessels, which orient pressure gradients, are not found in randomly connected voids as in the intervillous space. This feature may be advantageous under normal conditions, but it may also cause hazards to the intervillous circulation.

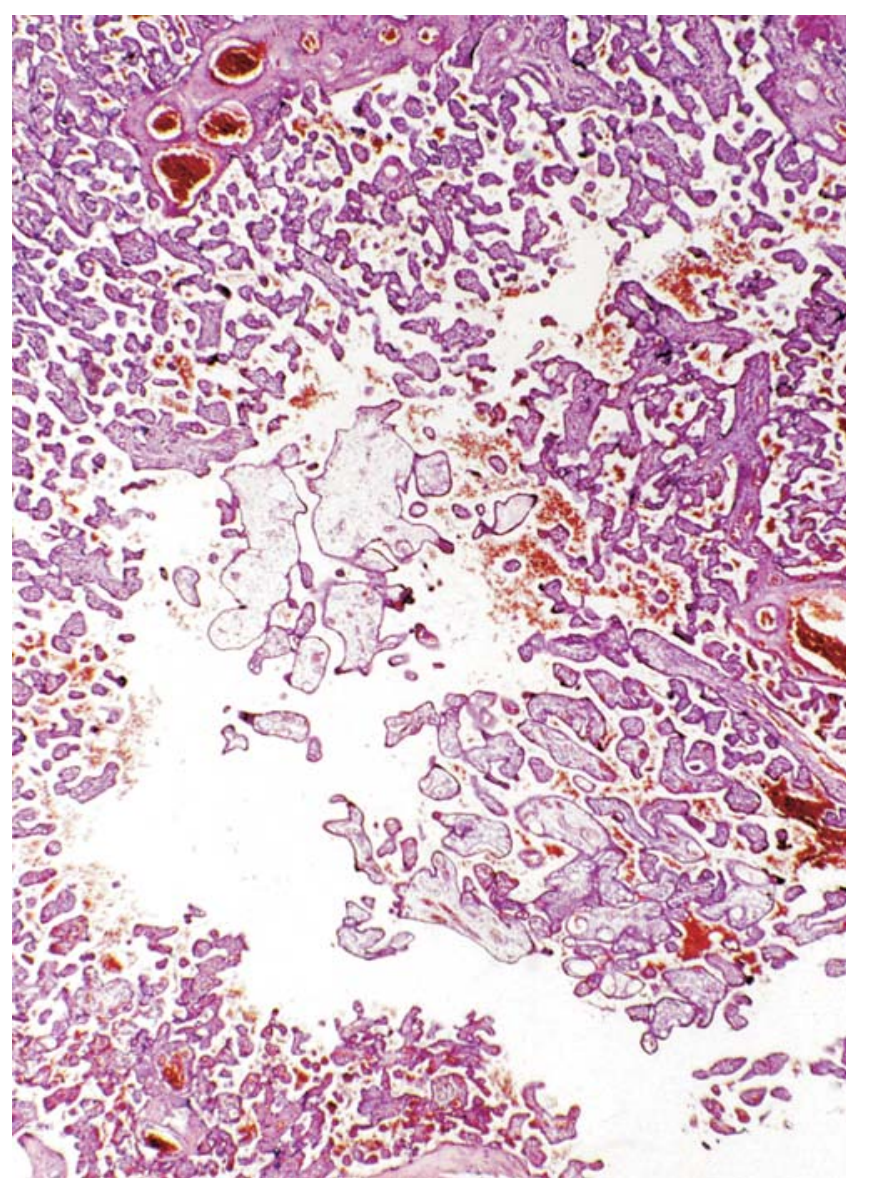

B

magnification of the placentone center of a fetal cotyledon. Note the large empty appearing arterial inflow area, which is bordered by some immature intermediate villi, easily recognizable by their light staining. This immature center of the cotyledon is surrounded by a densely packed mantle of smaller villi which provide the maternofetal exchange area. $\times 20$.

The most peripheral zone of a placentone, the venous outflow area, is the loosely arranged area that separates neighboring villous trees (Fig. 7.27A) and that, subchorially, is connected to the subchorial lake. It collects the maternal venous blood that has left the high impedance area of the fetomaternal exchange zone of the densely packed terminal villi. Moll (1981) called this the perilobular zone, which is functionally comparable to wide venules of other vascular beds. It allows venous backflow under conditions of low blood flow resistance.

The radioangiographic studies of Ramsey et al. (1963) in rhesus monkey placentas, and those of Borell et al. (1958) in human placentas, are consistent with the placentone concept. They demonstrated rapid filling of the centers of the villous trees and called them "jets," or "spurts." More recent physiologic concepts of intervillous circulation (Moll, 1981; Schmid-Schönbein, 1988) do not agree with these terms, 
as the actual filling velocities amount to only a few centimeters per second, which might not be enough to describe the driving force of a fountain as implied by the terms jer or spurt. After passage of the central cavity, a subsequent rather slow centrifugal spreading of the blood toward the subchorial and peripheral zone was observed. Wallenburg et al. (1973) ligated single spiral arteries in rhesus monkeys, which resulted in obliteration of the intervillous space and degeneration of the corresponding villous tree. This experiment demonstrated that each villous tree depends on its own spiral artery. Even though the intervillous space is a widely open, freely communicating system, villous arrangement and pressure gradients are coordinated in such a way that blood perfusion depends strictly on the original flow arrangement. Reversal of the direction is impossible.

If one accepts these considerations, the immature intermediate villi, together with their sprouting mesenchymal side branches (Figs. 7.26A and 7.27B), are concentrated in the placentone center and are thus in the zones of highest $\mathrm{pO}_{2}$ in the intervillous space. Schuhmann's group found that ${ }^{3} \mathrm{H}$-thymidine incorporation, as an index for the mitotic rate, is twice as high in the center of the placentone as at the periphery (Geier et al., 1975). This finding is in seeming contrast to several experimental and histologic findings. The latter authors also suggested that low oxygen concentration serves as a stimulus for trophoblastic proliferation and villous sprouting (Alvarez, 1967; Alvarez et al., 1970; Fox, 1970). The most likely explanation for this discrepancy is that oxygen delivery to the centrally located large villi, those in the central cavity and its close vicinity, is reduced owing to high blood flow velocity and long diffusion distances. The adjacent densely packed zones, although already located nearer the venous pole, probably have a much higher oxygen delivery, as blood flow velocity is reduced in the slender intervillous clefts and diffusion distances are short. This situation results in high mean $\mathrm{pO}_{2}$ values at the villous surfaces, which is a prerequisite for effective maternofetal oxygen transfer. At the same time, it inhibits villous proliferation and stimulates villous differentiation in the placentone periphery.

These relations may be the basis for regulatory mechanisms. Wide intervillous clefts in the periphery of the villous trees of immature placentas, which lack fine and richly branched terminal villi, result in long diffusion distances and high blood flow velocities - and thus in reduced oxygen delivery. The resulting intravillous $\mathrm{pO}_{2}$ in this area is low, which stimulates villous sprouting and especially capillary sprouting (Bacon et al., 1984; Scheffen et al., 1990). Increased capillary sprouting is followed by the production of new terminal villi. The latter narrow the intervillous space, reduce blood flow velocity and diffusion distances, and thus increase oxygen delivery. Finally, the elevated $\mathrm{pO}_{2}$ inhibits further villous branching.

According to this hypothesis, the maternal bloodstream, oxygenation, and villous branching act as limbs of a simple feedback mechanism that regulates growth of the villous trees. As a further consequence, a functional diversity of the placentone is obtained. Whereas the centers act as proliferative zones that guarantee placental growth until term, the periphery is the functionally fully active exchange and secretory area. This situation has also been highlighted by the histochemically and biochemically higher activity of enzymes such as alkaline phosphatase (Schuhmann et al., 1976) and by the higher conversion rate of steroid hormones (Lehmann et al., 1973) in the placentone periphery.

The zonal differences become evident only after the development of mature intermediate villi, at the end of the second trimester. Up to that time, the villous trees are largely homogeneous. In most placentas, the immature placentone centers are present until term, at least in the more peripheral areas of the placenta. Only in cases of preterm maturation of the placenta (hypermaturity, maturitas praecox) do we regularly find mature placentone centers, resulting in a virtually homogeneous structure of the placentones. Thus, such a placenta has lost its capacity to grow, as only the immature intermediate villi and their immediate mesenchymal branches are able to sprout and act as growth zones.

\section{Histopathologic Importance of Inhomogeneity of Villous Trees}

For the histopathologist, the inhomogeneity of the villous trees causes considerable problems of interpretation. Because the average diameter of placentone is 1 to $4 \mathrm{~cm}$, histologic sections often do not cover a representative part of the placentone, which would comprise immature growth zones as well as highly differentiated, mature tissue. The prevalence of one or the other tissue may influence the diagnosis. This danger is even greater when one considers that placentones from various locations may show varying degrees of maturation. Thus, even the careful study of several sections from a given placenta may lead to wrong interpretations. This point is of particular importance when performing morphometric evaluations of the placenta. Burton (1987) remarked that "strict attention must be paid to the sampling regimen if meaningful results are to be obtained. Sadly this has not always been taken into consideration in the past, and so many of the published claims must be qualified accordingly."

This problem is greater still when one uses small tissue samples, such as semithin sections for light microscopy or ultrathin sections for electron microscopy. Neither section type allows a diagnosis concerning the degree of maturation upon which one can rely. The same holds true for samples obtained by aspiration from the intact uterus (Alvarez et al., 1964; Aladjem, 1968), the placenta at cesarean section (Schweikhart \& Kaufmann, 1977), and chorion villus sampling (CVS). While the latter samples are of greatest value for genetic purposes (Hugentobler et al., 1987), one must be careful with a histologic evaluation of such material (Gerl et al., 1973; Ehrhardt et al., 1974), even during early stages of pregnancy. In these situations one does not have the problem of heterogeneity of the placentones but rather the problem of general heterogeneity.

\section{Fetomaternal Flow Interrelations}

The efficiency of diffusional exchange (e.g., oxygen, carbon dioxide, water), among other factors, depends on the arrangement of fetal and maternal blood flows to each other. As early as 1926 Mossman described countercurrent flow conditions in the rabbit placenta; neighboring maternal and fetal bloodstreams were thought to be arranged in parallel but with opposite flow directions. 
Later, Mossman (1965) found the same condition to be valid for the human placenta. This finding, however, is not supported by anatomic or physiologic results. Rather, it has been recognized for many years that the anatomic arrangement of placental vascular pathways differs from one species to another. For the human, we have described three major morphologic objections to the existence of countercurrent flow conditions (Kaufmann, 1985):

1. All villi would have to be oriented in the same direction, parallel to the maternal bloodstream. They are, in fact, arranged at varying angles to each other because of the structure of the villous tree.

2. Only one limb of the hairpin-like fetal capillary loops is allowed to have interchange contact with the maternal blood; in fact, both limbs normally exhibit the same structure and the same diffusion distance to the maternal blood.

3. According to the results of Lemtis (1969), one must consider the possibility that considerable amounts of venous maternal blood are recirculated by the arterial "jet" before leaving the intervillous space. Thus, intraplacental circulatory "orbits" are formed.

The anatomic situation and the physiologic effectiveness of the human placenta are much more in agreement with the concept of a multivillous flow arrangement (Bartels \& Moll, 1964; Moll, 1981). In this condition, the maternal bloodstream crosses subsequent villi with hairpin-like arranged fetal capillaries. It seems to be of minor importance with which angle the maternal bloodstream crosses the individual villi or whether the vessels of the villi are serially connected to each other or arranged in parallel. The multivillous blood flow is less effective for diffusional transfer (Moll, 1981).

This difference may be the reason why $1 \mathrm{~g}$ of human placenta supplies only $6 \mathrm{~g}$ of fetus at term, compared to a relation of 1:20 in the guinea pig with a countercurrent flow placenta (see Chapter 4, Table 4.1) (Dantzer et al., 1988). On the other hand, the multivillous arrangement is structurally more flexible. It allows rearrangement and adaptation to changing developmental conditions and the continuous growth to a much greater extent. In this respect, it is worthy of note that the highly effective guinea pig placenta is small (about $5 \mathrm{~g}$ ) and functions for only 68 days. The capybara (Kaufmann, 2004), which belongs to the same suborder of rodents, has a structurally closely related placenta but a much longer pregnancy (150 days) and a much higher placental weight (150g), but is less effective than the guinea pig placenta ( $1 \mathrm{~g}$ of placenta at term supplies $10 \mathrm{~g}$ of fetus).

\section{References}

Ahmed, A. and Kilby, M.: Commentary: Hypoxia or hyperoxia in placental insufficiency? Lancet 350:826-827, 1997.
Ahmed, A. and Perkins, J.: Angiogenesis and intrauterine growth restriction. Baillieres Best Pract. Res. Clin. Obstet. Gynaecol. 14:981-988, 2000.

Ahmed, A., Li, X.F., Dunk, C., Whittle, M.J., Rushton, D.I. and Rollason, T.: Colocalisation of vascular endothelial growth factor and its flt-1 receptor in human placenta. Growth Factors 12:235-243, 1995.

Ahmed, A., Whittle, M.J. and Khaliq, A.: Differential expression of placenta growth factor (PIGF) and vascular endothelial growth factor (VEGF) in abnormal placentation. J. Soc. Gynecol. Invest. 4:A663, 1997.

Ahmed, A., Dunk, C., Ahmad, S. and Khaliq, A.: Regulation of placental vascular endothelial growth factor (VEGF) and placenta growth factor (PlGF) and soluble Flt-1 by oxygena review. Placenta, 21: suppl. A. Troph. Res. 14:S16-S24, 2000 .

Aladjem, S.: Morphopathology of the human placental villi and the fetal outcome. J. Obstet. Gynaecol. Br. Commonw. 75:1237-1244, 1968.

Alon, T., Hemo, I., Itin, A., Pe'er, J., Stone, J. and Keshet, E.: Vascular endothelial growth factor acts as a survival factor for newly formed retinal vessels and has implications for retinopathy of prematurity. Nature Med. 1:1024-1028, 1995.

Alvarez, H.: Syncytial proliferation in normal and toxemic pregnancies. Obstet. Gynecol. 29:637-643, 1967.

Alvarez, H., De Bejar, R. and Aladjem, S.: La placenta human. Aspectos morfologicos y fisio-patologicos. In, 4th Uruguayan Congress for Obstetrics and Gynecology 1:190-261, 1964.

Alvarez, H., Morel, R.L., Benedetti, W.L. and Scavarelli, M.: Trophoblast hyperplasia and maternal arterial pressure at term. Amer. J. Obstet. Gynecol. 105:1015-1021, 1969.

Alvarez, H., Benedetti, W.L., Morel. R.L. and Scavarelli, M.: Trophoblast development gradient and its relationship to placental hemodynamics. Amer. J. Obstet. Gynecol. 106:416-420, 1970.

Alvarez, H., Medrano, C.V., Sala, M.A. and Benedetti, W.L.: Trophoblast development gradient and its relationship to placental hemodynamics. II. Study of fetal cotyledons from the toxemic placenta. Amer. J. Obstet. Gynecol. 114:873-878, 1972.

Amaladoss, A.S.P. and Burton, G.J.: Organ culture of human placental villi in hypoxic and hyperoxic conditions: a morphometric study. J. Dev. Physiol. 7:13-118, 1985.

Amstutz, E.: Beobachtungen Über die Reifung der Chorionzotten in der menschlichen Placenta mit besonderer Berücksichtigung der Epithelplatten. Acta Anat. (Basel) 42:12-30, 1960.

Ara, G., Bari, M.A. and Siddiquey, A.K.: Effects of age, parity and length of pregnancy on the morphology and histology of human placenta. Bangladesh Med. Res. Counc. Bull. 10:53-58, 1984.

Arnholdt, H., Meisel, F., Fandrey, K. and Löhrs, U.: Proliferation of villous trophoblast of the human placenta in normal and abnormal pregnancies. Virchows Arch. B Cell Pathol. 60:365372, 1991.

Arts, N.F.T.: Investigation on the vascular system of the placenta. I. General introduction and the fetal vascular system. Amer. J. Obstet. Gynecol. 82:147-166, 1961.

Bacon, B.J., Gilbert, R.D., Kaufmann, P., Smith, A.D., Trevino, F.T. and Longo, L.D.: Placental anatomy and diffusing capac- 
ity in guinea pigs following long-term maternal hypoxia. Placenta 5:475-488, 1984.

Baker, P.N., Krasnow, J., Roberts, J.M. and Yeo, K.T.: Elevated serum levels of vascular endothelial growth factor in patients with preeclampsia. Obstet Gynecol 86:815-821, 1995.

Banks, R.E., Forbes, M.A., Searles, J., Pappin, D., Canas, B., Rahman, D., Kaufmann, S., Walters, C.E., Jackson, A., Eves, P., Linton, G., Keen, J., Walker, J.J. and Selby, P.J.: Evidence for the existence of a novel pregnancy-associated soluble variant of the vascular endothelial growth factor receptor, Flt-1. Mol. Human Reprod. 4:377-386, 1998.

Banovac, K., Ryan, E.A. and O'Sullivan, M.J.: Triiodothyronine (T3) nuclear binding sites in human placenta and decidua. Placenta 7:543-549, 1986.

Bär, T., Güldner, F.H. and Wolff, J.R.: "Seamless" endothelial cells of blood capillaries. Cell Tiss. Res. 235:99-106, 1984.

Bartels, H. and Moll, W.: Passage of inert substances and oxygen in the human placenta. Pfluegers Arch. Gesamte Physiol. 280:165, 1964.

Becker, V.: Mechanismus der Reifung fetaler Organe. Verh. Dtsch. Ges. Pathol. 46:309-314, 1962a.

Becker, V.: Funktionelle Morphologie der Plazenta. Arch. Gynäkol. 198:3-28, 1962 b.

Becker, V.: Pathologie der Ausreifung der Plazenta. In, Die Plazenta des Menschen. V. Becker, T.H. Schiebler and F. Kubli, eds., pp. 266-281. Thieme, Stuttgart, 1981.

Becker, V. and Jipp, P.: Über die Trophoblastschale der menschlichen Plazenta. Geburtsh. Frauenheilk. 23:466-474, 1963.

Becker, V. and Seifert, K.: Die Ultrastruktur der Kapillarwand in der menschlichen Placenta zur Zeit der Schwangerschaftsmitte. Z. Zellforsch. 65:380-396, 1965.

Beischer, N.A., Sivasamboo, R., Vohra, S., Silpisornkosal, S. and Reid, S.: Placental hypertrophy in severe pregnancy anaemia. J. Obstet. Gynaecol. Br. Commonw. 77:398-409, 1970.

Benjamin, L.E. and Keshet, E.: Conditional switching of vascular endothelial growth factor (VEGF) expression in tumors: induction of endothelial cell shedding and regression of hemangioblastoma-like vessels by VEGF withdrawal. Proc. Natl. Acad. Sci. USA 94:8761-8766 1997.

Boe, F.: Studies on the vascularization of the human placenta. Acta Obstet. Gynecol. Scand. (Suppl. 5) 32:1-92, 1953.

Boe, F.: Studies on the human placenta. II. Gross morphology of the fetal structures in the young placenta. Acta Obstet. Gynecol. Scand. 47:420-435, 1968.

Boe, F.: Studies on the human placenta. III. Vascularization of the young fetal placenta. A. Vascularization of the chorionic villus. Acta Obstet. Gynecol. Scand. 48:159-166, 1969.

Borell, U., Fernstroem, I. and Westman, A.: Eine arteriographische Studie des Plazentarkreislaufs. Geburtsh. Frauenheilkd. 18:1-9, 1958.

Bouw, G.M., Stolte, L.A.M., Baak, J.P.A. and Oort, J.: Quantitative morphology of the placenta. 1. Standardization of sampling. Eur. J. Obstet. Gynecol. Reprod. Biol. 6:325-331, 1976.

Boyd, J.D. and Hamilton, W.J.: The Human Placenta. Heffer, Cambridge, 1970.

Breier, G.: Angiogenesis in embryonic development-a review. Placenta 21: suppl A. Troph. Res. 14:S11-S15, 2000.

Brosens, I.A.: The uteroplacental vessels at term-the distribution and extent of physiological changes. Trophoblast Res. 3:61-67, 1988.
Bukovsky, A., Caudle, M.R., Keenan, J.A., Wimalasena, J. and McKenzie, P.P.: Thy-1 differentiation protein and monocytederived cells during regeneration and aging of human placental villi. Amer. J. Reprod. Immunol. 42:135-152, 1999.

Burri, P. and Tarek, M.R.: A novel mechanism of capillary growth in the rat pulmonary microcirculation. Anat. Rec. 228:35-45, 1990.

Burton, G.J.: The fine structure of the human placental villus as revealed by scanning electron microscopy. Scanning Electron Microsc. 1:1811-1828, 1987.

Burton, G.J.: On "Oxygen and placental villous development: origins of fetal hypoxia." Placenta 18:625-626, 1997.

Burton, G.J. and Caniggia, I.: Hypoxia: implications for implantation to delivery-a workshop report. Placenta 22: Suppl. A: S63-S65, 2001.

Burton, G.J. and Palmer, M.E.: Eradicating fetomaternal fluid shift during perfusion fixation of the human placenta. Placenta 9:327-332, 1988.

Caniggia, I., Mostachfi, H., Winter, J., Gassmann, M., Lye, S.J., Kuliszewski, M. and Post, M.: Hypoxia-inducible factor-1 mediates the biological effects of oxygen on human trophoblast differentiation through TGFbeta(3). J. Clin. Invest 105:577-587, 2000.

Cantle, S.J., Kaufmann, P., Luckhardt, M. and Schweikhart, G.: Interpretation of syncytial sprouts and bridges in the human placenta. Placenta 8:221-234, 1987.

Cao, Y., Chen, H., Zhou, L., Chiang, M.K., Anand-Apte, B., Weatherbee, J.A., Wang, Y., Fang, F., Flanagan, J.G. and Tsang, M.L.: Heterodimers of placenta growth factor/vascular endothelial growth factor. Endothelial activity, tumor cell expression, and high affinity binding to Flk-1/KDR. J. Biol. Chem. 271:3154-3162, 1996.

Cappoen, J.P.: Physiology of the thyroid during pregnancy. Various exploratory tests. Rev. Fr. Gynecol. Obstet. 84:893897, 1989.

Carmeliet, P.: Angiogenesis in health and disease. Nature Med. 9:653-660, 2003.

Castellucci, M. and Kaufmann, P.: A three-dimensional study of the normal human placental villous core: II. Stromal architecture. Placenta 3:269-286, 1982a.

Castellucci, M. and Kaufmann, P.: Evolution of the stroma in human chorionic villi throughout pregnancy. Bibl. Anat. 22:40-45, 1982b.

Castellucci, M., Schweikhart, G., Kaufmann, P. and Zaccheo, D.: The stromal architecture of the immature intermediate villus of the human placenta. Gynecol. Obstet. Invest. 18:95-99, 1984.

Castellucci, M., Scheper, M., Scheffen, I., Celona, A. and Kaufmann, P.: The development of the human placental villous tree. Anat. Embryol. (Berl.) 181:117-128, 1990.

Castellucci, M. and Kaufmann, P.: A three-dimensional study of the normal human placental villous core: II. Stromal architecture. Placenta 3:269-286, 1982a.

Castellucci, M. and Kaufmann, P.: Evolution of the stroma in human chorionic villi throughout pregnancy. Bibl. Anat. 22:40-45, 1982b.

Castellucci, M., Schweikhart, G., Kaufmann, P. and Zaccheo, D.: The stromal architecture of the immature intermediate villus of the human placenta. Gynecol. Obstet. Invest. 18:95-99, 1984. 
Castellucci, M., Scheper, M., Scheffen, I., Celona, A. and Kaufmann, P.: The development of the human placental villous tree. Anat. Embryol. (Berl.) 181:117-128, 1990.

Castellucci, M., Kosanke, G., Verdenelli, F., Huppertz, B., Kaufmann, P.: Villous sprouting: fundamental mechanisms of human placental development. Hum. Reprod. Update 6:485494, 2000.

Challier, J.C., Hauguel, S. and Desmaizieres, V.: Effect of insulin on glucose uptake and metabolism in the human placenta. J. Clin. Endocrinol. Metab. 62:803-807, 1986.

Challier, J.C., Galtier, M., Kacemi, A. and Guillaumin, D.: Pericytes of term human foeto-placental microvessels: Ultrastructure and visualization. Cell Mol. Biol. 45:89-100, 1999.

Chappell, L.C., Seed, P.T., Briley, A., Kelly, F..J, Hunt, B.J., Charnock-Jones, D.S., Mallet, A.I. and Poston, L.: A longitudinal study of biochemical variables in women at risk of preeclampsia. Amer. J. Obstet. Gynecol. 187:127-136, 2002.

Charnock-Jones, D.S., Kaufmann, P. and Mayhew, T.M.: Aspects of Human fetoplacental vasculogenesis and angiogenesis. I. Molecular regulation. Placenta 25:103-113, 2004.

Chwalisz, K., Ciesla, I. and Garfield, R.E.: Inhibition of nitric oxide (NO) synthesis induces preterm parturition and preeclampsia-like conditions in guinea pigs. Presented at the Society for Gynecological Investigation Meeting, Chicago, IL, 1994.

Clark, D.E., Smith, S.K., Sharkey, A.M. and Charnock-Jones, D.S.: Localization of VEGF and expression of its receptors flt and KDR in human placenta throughout pregnancy. Hum. Reprod. (Oxf.) 11:1090-1098, 1996a.

Clark, D.E., Smith, S.K., Sharkey, A.M., Sowter, H.M. and Charnock-Jones, D.S.: Hepatocyte growth factor scatter factor and its receptor c-met: localization and expression in the human placenta throughout pregnancy. J. Endocrinol. 151:459-467, 1996b.

Clark, D.E., Salvig, J.D., Smith, S.K. and Charnock-Jones, D.S.: Hepatocyte growth factor levels during normal and intrauterine growth-restricted pregnancies. Placenta 19:671-673, 1998a.

Clark, D.E., Smith, S.K., He, Y., Day, K.A., Licence, D.R., Corps, A.C., Lammoglia, R. and Charnock-Jones, D.S.: A vascular endothelial growth factor antagonist is produced by the human placenta and released into the maternal circulation. Biol. Reprod. 59:1540-1548, 1998b.

Clark, D.E., Smith, S.K., Licence, D., Evans, A.L and CharnockJones, D.S.: Comparison of expression patterns for placenta growth factor, vascular endothelial growth factor (VEGF), VEGF-B and VEGF-C in the human placenta throughout gestation. J. Endocrinol. 159:459-467, 1998c.

Cooper, J.C., Sharkey, A.M., Charnock-Jones, D.S., Palmer, C.R. and Smith, S.K.: VEGF mRNA levels in placentae from pregnancies complicated by pre-eclampsia. Br. J. Obstet. Gynaecol. 103:1191-1196, 1996.

Crescimanno, C., Marzioni, D., Persico, M.G., Vuckovic, M., Mühlhauser, J. and Castellucci, M.: Expression of bFGF, PIGF and their receptors in the human placenta. Placenta 16:A13, 1995.

Dantzer, V., Leiser, R., Kaufmann, P. and Luckhardt, M.: Comparative morphological aspects of placental vascularization. Trophoblast Res. 3:235-260, 1988.
Davidoff, M. and Schiebler, T.H.: Über den Feinbau der Meerschweinchenplacenta während der Entwicklung. Z. Anat. Entwicklungsgesch. 130:234-254, 1970.

Demir, R., Kaufmann, P., Castellucci, M., Erbengi, T. and Kotowski, A.: Fetal vasculogenesis and angiogenesis in human placental villi. Acta Anat. (Basel) 136:190-203, 1989.

Demir, R., Demir, N., Kohnen, G., Kosanke, G., Mironov, V., Üstünel, I. and Kocamaz, E.: Ultrastructure and distribution of myofibroblast-like cells in human placental stem villi. Electron Microsc. 3:509-510, 1992.

Demir, R., Kosanke, G., Kohnen, G., Kertschanska, S. and Kaufmann, P.: Classification of human placental stem villi: review of structural and functional aspects. Microsc. Res. Tech. 38:29-41, 1997.

Demir, R., Kayisli, U.A., Seval, Y., Celik-Ozenci, C., Korgun, E.T., Demir Weusten, A.Y. and Huppertz, B.: Sequential expression of VEGF and its receptors in human placental villi during very early pregnancy: Differences between placental vasculogenesis and angiogenesis. Placenta 25:560-572, 2004.

Dempsey, E.W.: The development of capillaries in the villi of early human placentas. Am. J. Anat. 134:221-238, 1972.

Desoye, G., Hartmann, M., Blaschitz, A., Dohr, G., Kohnen, G. and Kaufmann, P.: Insulin receptors in syncytiotrophoblast and fetal endothelium of human placenta. Immunohistochemical evidence for developmental changes in distribution pattern. Histochemistry 101:277-285, 1994.

Desoye G., Hartmann, M., Jones, C.J.P., Wolf, H.J., Kohnen, G., Kosanke, G. and Kaufmann, P.: Location of insulin receptors in the placenta and its progenitor tissues. Microsc. Res. Tech. 38:63-75, 1997.

Di Blasio, A.M., Carniti, C., Vigano, P., Florio, P., Petraglia, F. and Vignali, M.: Basic fibroblast growth factor messenger ribonucleic acid levels in human placentas from normal and pathological pregnancies. Mol. Hum. Reprod. 3:1119-1123, 1997.

Downs, K.M., Gifford, S., Blahnik, M. and Gardner, R.L.: Vascularization in the murine allantois occurs by vasculogenesis without accompanying erythropoiesis. Development 125:4507-4520, 1998.

Dunk, C., Shams, M., Nijjar, S., Rhaman, M., Qiu, Y., Bussolati, B. and Ahmed, A.: Angiopoietin-1 and angiopoietin-2 activate trophoblast Tie-2 to promote growth and migration during placental development. Amer J Pathol 156:2185-2199, 2000.

Ehrhardt, G., Gerl, D., Estel, C., Kadner, J. and Günther, M.: Morphologische Auswertbarkeit von in vitro gewonnenen Punktionszylindern der Plazenta. Zentralbl. Gynäkol. 96:705711, 1974.

Enders, A.C. and King, B.F.: The cytology of Hofbauer cells. Anat. Rec. 167:231-252, 1970.

Epstein, A.C., Gleadle, J.M., McNeill, L.A., Hewitson, K.S., O’Rourke, J., Mole, D.R., Mukherji, M., Metzen, E., Wilson, M.I., Dhanda, A., Tian, Y.M., Masson, N., Hamilton, D.L., Jaakkola, P., Barstead, R., Hodgkin, J., Maxwell, P.H., Pugh, C.W., Schofield, C.J. and Ratcliffe, P.J.: C elegans EGL-9 and mammalian homologs define a family of dioxygenases that regulate HIF by prolyl hydroxylation. Cell 107:43-54, 2001.

Evans, P.W., Wheeler, T., Anthony, F.W. and Osmond, C.: A longitudinal study of maternal serum vascular endothelial growth factor in early pregnancy. Human Reprod. 13:1057-1062, 1998. 
Farley, A.E., Graham, C.H. and Smith, G.N.: Contractile properties of human placental anchoring villi. Amer. J. Physiol. Regul. Integr. Comp. Physiol. 287:R680-R685, 2004.

Feneley, M.R. and Burton, G.J.: Villous composition and membrane thickness in the human placenta at term: a stereological study using unbiased estimators and optimal fixation techniques. Placenta 12:131-142, 1991.

Ferriani, R.A., Ahmed, A., Sharkey, A.M. and Smith, S.K.: Colocalization of acidic and basic fibroblast growth factor (FGF) in human placenta and the cellular effects of bFGF in trophoblast cell line JEG-3. Growth Factors 10:259, 1994.

Fisher, D.A.: Maternal-fetal thyroid function in pregnancy. Clin. Perinatol. 10:615-626, 1983.

Fitzpatrick, T.E. and Graham, C.H.: Stimulation of plasminogen activator inhibitor-1 expression in immortalized human trophoblast cells cultured under low levels of oxygen. Exp. Cell Res. 245:155-162, 1998.

Folkman, J. and Haudenschild, C.: Angiogenesis in vitro. Nature (Lond.) 288:551-556, 1980.

Folkman, J. and Shing, Y.: Angiogenesis. J. Biol. Chem. 267: 10931-10934, 1992.

Fong, G.-H., Rossant, J., Gertsenstein, M. and Breitman, M.L.: Role of the Flt-1 receptor tyrosine kinase in regulating the assembly of vascular endothelium. Nature (Lond.) 376:66-70, 1995.

Fong, G.-H., Zhang, L., Bryce, D.M. and Peng, J.: Increased hemangioblast commitment, not vascular disorganization, is the primary defect in flt-1 knock-out mice. Development 126:3015-3025, 1999.

Fox, H.: The villous cytotrophoblast as an index of placental ischaemia. J. Obstet. Gynaecol. Br. Commonw. 71:885-893, 1964.

Fox, H.: Effect of hypoxia on trophoblast in organ culture. A morphologic and autoradiographic study. Amer. J. Obstet. Gynecol. 107:1058-1064, 1970.

Fox, H.: Pathology of the Placenta. 1st Ed. Saunders, London, 1978.

Fox, H.: Pathology of the Placenta. 2nd Ed. Saunders, London, 1997.

Freese, U.E.: The fetal-maternal circulation of the placenta. I. Histomorphologic, plastoid injection, and X-ray cinematographic studies on human placentas. Amer. J. Obstet. Gynecol. 94:354-360, 1966.

Garfield, R.E., Yallampalli, C., Buhimschi, I. and Chwalisz, K.: Reversal of preeclampsia symptoms induced in rats by nitric oxide inhibition with L-arginine, steroid hormones and an endothelin antagonist. Presented at the Society for Gynecologic Investigation Meeting, 1994.

Geier, G., Schuhmann, R. and Kraus, H.: Regional unterschiedliche Zellproliferation innerhalb der Plazentone reifer menschlicher Plazenten: autoradiographische Untersuchungen. Arch. Gynäkol. 218:31-37, 1975.

Genbacev, O., Joslin, R., Damsky, C.H., Polliotti, B.M. and Fisher, S.J.: Hypoxia alters early gestation human cytotrophoblast differentiation invasion in vitro and models the placental defects that occur in preeclampsia. J. Clin. Invest. 97:540-550, 1996.

Genbacev, O., Zhou, Y., Ludlow, J.W. and Fisher, S.J.: Regulation of human placental development by oxygen tension. Science. 277:1669-1672, 1997.
Gerl, D., Eichhorn, H., Eichhorn, K.-H. and Franke, H.: Quantitative Messungen synzytialer Zellkernkonzentrationen der menschlichen Plazenta bei normalen und pathologischen Schwangerschaften. Zentralbl. Gynäkol. 95:263-266, 1973.

Geva, E., Ginzinger, D.G., Zaloudek, C.J., Moore, D.H., Byrne, A. and Jaffe, R.B.: Human placental vascular development: vasculogenic and angiogenic (branching and nonbranching) transformation is regulated by vascular endothelial growth factor-A, angiopoietin-1, and angiopoietin-2. J. Clin. Endocrinol. Metab. 87:4213-4224, 2002.

Graf, R., Langer, J.U., Schönfelder, G., Öney, T., Hartel-Schenk, S., Reutter, W. and Schmidt, H.H.H.W.: The extravascular contractile system in the human placenta. Morphological and immunocytochemical investigations. Anat. Embryol. 190:541$548,1994$.

Graf, R., Schönfelder, G., Mühlberger, M. and Gutsmann, M.: The perivascular contractile sheath of human placental stem villi; its isolation and characterization. Placenta 16:57-66, 1995.

Graf, R., Matejevic, D., Schuppan, D., Neudeck, H., Shakibaei, M. and Vetter, K.: Molecular anatomy of the perivascular sheath in human placental stem villi: the contractile apparatus and its association to the extracellular matrix. Cell Tissue Res. 290:601-607, 1997.

Graham, C.H. and Lala, P.K.: Mechanism of control of trophoblast invasion in situ. J. Cell Physiol. 148:228-234, 1991.

Graham, C. H. and McCrae, K. R. Hypoxia stimulates expression of the urokinase receptor and invasion of extracellular matrix by trophoblast cells through a heme proteindependent pathway. Placenta 18:A24, 1997.

Habashi, S., Burton, G.J. and Steven, D.H.: Morphological study of the fetal vasculature of the human placenta: scanning electron microscopy of corrosion casts. Placenta 4:41-56, 1983.

Hanahan, D.: Signaling vascular morphogenesis and maintenance. Science 277:48-50, 1997.

He, Y., Smith, S.K., Day, K.A., Clark, D.E., Licence, D.R. and Charnock-Jones, D.S.: Alternative splicing of vascular endothelial growth factor (VEGF)-R1 (FLT-1) pre-mRNA is important for the regulation of VEGF activity. Mol. Endocrinol. 13:537-545, 1999.

Helske, S., Vuorela, P., Carpen, O., Hornig, C., Weich, H. and Halmesmaki, E.: Expression of vascular endothelial growth factor receptors 1,2 and 3 in placentas from normal and complicated pregnancies. Mol. Hum. Reprod. 7:205-210, 2001.

Hershman, J.M.: Hyperthyroidism induced by trophoblastic thyrotropin. Mayo Clin. Proc. 47:913-918, 1972.

Hertig, A.T.: Angiogenesis in the early human chorion and in the primary placenta of the macaque monkey. Contrib. Embryol. Carnegie Inst. 25:37-81, 1935.

Highison, G.J. and Tibbitts, F.D.: Ultrasonic microdissection of immature intermediate human placental villi as studied by scanning electron microscopy. Scanning Electron Microsc. 2:679-685, 1986.

Hiratsuka, S., Minowa, O., Kuno, J., Noda, T. and Shibuya, M.: Flt-1 lacking the tyrosine kinase domain is sufficient for normal development and angiogenesis in mice. Proc. Natl. Acad. Sci. USA 95:9349-9354, 1998.

Hitschold, T., Müntefering, H., Ulrich, S. and Berle, P.: Does extremely low fetoplacental impedance as estimated by umbilical artery Doppler velocimetry also indicate fetuses at risk? Ultrasound Gynecol. 8:39A, 1996. 
Holmgren, L., Glaser, A., Pfeifer-Ohlsson, N.S. and Ohlsson, R.: Angiogenesis during human extraembryonic development involves the spatiotemporal control of PDGF ligand and receptor gene expression. Development (Camb.) 113:749754, 1991.

Hölzl, M., Lüthje, D. and Seck-Ebersbach, K.: Placentaveränderungen bei EPH-Gestose. Arch. Gynäkol. 217:315-334, 1974.

Hörmann, G.: Lebenskurven normaler und entwicklungsfähiger Chorionzotten; Ergebnisse systematischer Zottenmessungen. Arch. Gynäkol. 181:29-43, 1951.

Hörmann, G.: Ein Beitrag zur funktionellen Morphologie der menschlichen Placenta. Arch. Gynäkol. 184:109-123, 1953.

Hörmann, G.: Versuch einer Systematik plazentarer Entwicklungsstörungen. Geburtsh. Frauenheilkd. 18:345-349, 1958a.

Hörmann, G.: Zur Systematik einer Pathologie der menschlichen Placenta. Arch. Gynäkol. 191:297-344, 1958 b.

Hornig, C., Barleon, B., Ahmad, S., Vuorela, P., Ahmed, A. and Weich, H.A.: Release and complex formation of soluble VEGFR-1 from endothelial cells and biological fluids. Lab. Invest. 80:443-454, 2000.

Hugentobler, W., Binkert, F., Haenel, A.F. and Schaetti, D.: Die Chorionzotten-(Plazenta-) Biopsie im II. und III. Trimenon: Neue Perspektiven der Pränataldiagnostik. Geburtsh. Frauenheilkd. 47:729-732, 1987.

Hung, T.H., Skepper, J.N. and Burton, G.J.: In vitro ischemiareperfusion injury in term human placenta as a model for oxidative stress in pathological pregnancies. Amer. J. Pathol. 159:1031-1043, 2001.

Hung, T.H., Skepper, J.N., Charnock-Jones, D.S. and Burton, G.J.: Hypoxia-reoxygenation: a potent inducer of apoptotic changes in the human placenta and possible etiological factor in preeclampsia. Circ. Res. 90:1274-1281, 2002a.

Hung, T., Charnock-Jones, D. S. and Burton, G. J. Hypoxia/reoxygenation is a potent stimulus for placental production of tumour necrosis factor-alpha. Placenta 23:Suppl. A, A.9. 2002 b.

Hunt, J.S.: Macrophages in human uteroplacental tissues: a review. Amer. J. Reprod. Immunol. 21:119-122, 1989.

Jackson, M.R., Mayhew, T.M. and Haas, J.D.: Morphometric studies on villi in human term placentae and the effects of altitude, ethnic grouping and sex of newborn. Placenta 8:487495, 1987.

Jackson, M.R., Carney, E.W., Lye, S.J. and Ritchie, J.W.K. Localization of two angiogenic growth factors (PDECGF and VEGF) in human placentae throughout gestation. Placenta 15:341-353, 1994.

Jauniaux, E., Watson, A. and Burton, G.: Evaluation of respiratory gases and acid-base gradients in human fetal fluids and uteroplacental tissue between 7 and 16 weeks gestation. Amer. J. Obstet. Gynecol. 184:998-1003, 2001.

Jirkovska, M., Kubinova, L., Krekule, I. and Hach, P.: Spatial arrangement of fetal placental capillaries in terminal villi: a study using confocal microscopy. Anat. Embryol. 197:263-272, 1998.

Jokhi, P., Chumbley, G., King, A., Gardner, L. and Loke, W.: Expression of the colony stimulating factor-1 receptor by cells at the uteroplacental interface. Placenta 13:A29, 1992.

Jones, C.J.P., Hartmann, M., Blaschitz, A. and Desoye, G.: Ultrastructural localization of insulin receptors in human placenta. Amer. J. Reprod. Immunol. 30:136-145, 1993.
Kadyrov, M.K., Kosanke, G., Kingdom, J.C.P. and Kaufmann, P. Increased fetoplacental angiogenesis during first trimester in anaemic women. Lancet 352:1747-1749, 1998.

Kaneoka, T., Taguchi, S., Shimizu, H. and Shirakawa, K.: Prenatal diagnosis and treatment of intrauterine growth retardation. J. Perinat. Med. 11:204-212, 1983.

Karimu, A.L. and Burton, G.J.: The effects of maternal vascular pressure on the dimensions of the placental capillaries. Br. J. Obstet. Gynaecol. 101:57-63, 1994.

Kaufmann, P.: Entwicklung der Plazenta. In, Die Plazenta des Menschen. V. Becker, T.H. Schiebler and F. Kubli, eds., pp. 13-50. Thieme Verlag, Stuttgart, 1981.

Kaufmann, P.: Development and differentiation of the human placental villous tree. Bibl. Anat. 22:29-39, 1982.

Kaufmann, P.: Basic morphology of the fetal and maternal circuits in the human placenta. Contrib. Gynecol. Obstet. 13:517, 1985.

Kaufmann, P.: Capybara. In: Kurt Benirschke: Comparative Placentation. http://medicine.ucsd.edu/cpa/indxfs.html 2004.

Kaufmann, P. and Davidoff, M.: The guinea pig placenta. Adv. Anat. Embryol. Cell Biol. 53:1-91, 1977.

Kaufmann, P. and Kingdom, J.C.P.: Development of the vascular system in the placenta. In, Morphogenesis of Endothelium. W. Risau and G. M. Rubanyi, pp 255-275. Amsterdam, Harwood Academic Publishers. 2000.

Kaufmann, P. and Scheffen, I.: Placental development. In, Neonatal and Fetal Medicine-Physiology and Pathophysiology, Vol. I. R.A. Polin and W.W. Fox, eds., pp. 47-55. Saunders, Orlando, 1992.

Kaufmann, P., Schiebler, T.H., Ciobotaru, C. and Stark, J.: Enzymhistochemische Untersuchungen an reifen menschlichen Placentazotten. II. Zur Gliederung des Syncytiotrophoblasten. Histochemistry 40:191-207, 1974.

Kaufmann, P., Gentzen, D.M. and Davidoff, M.: Die Ultrastruktur von Langhanszellen in pathologischen menschlichen Placenten. Arch. Gynaekol 222:319-332, 1977a.

Kaufmann, P., Stark, J. and Stegner, H.-E.: The villous stroma of the human placenta. I. The ultrastructure of fixed connective tissue cells. Cell Tissue Res. 177:105-121, 1977b.

Kaufmann, P., Sen, D.K. and Schweikhart, G.: Classification of human placental villi. I. Histology and scanning electron microscopy. Cell Tissue Res. 200:409-423, 1979.

Kaufmann, P., Nagl, W. and Fuhrmann, B.: Die funktionelle Bedeutung der Langhanszellen der menschlichen Plazenta. Ann. Anat. 77:435-436, 1983.

Kaufmann, P., Bruns, U., Leiser, R., Luckhardt, M. and Winterhager, E.: The fetal vascularization of term human placental villi. II. Intermediate and terminal villi. Anat. Embryol. (Berl.) 173:203-214, 1985.

Kaufmann, P., Luckhardt, M., Schweikhart, G. and Cantle, S.J.: Cross-sectional features and three-dimensional structure of human placental villi. Placenta 8:235-247, 1987.

Kaufmann, P., Luckhardt, M. and Leiser, R.: Three-dimensional representation of the fetal vessel system in the human placenta. Trophoblast Res. 3:113-137, 1988.

Kaufmann, P., Mayhew, T.M. and Charnock-Jones, D.S.: Aspects of human fetoplacental vasculogenesis and angiogenesis. II. Changes during normal pregnancy. Placenta 25:114-126, 2004. 
Kennedy, R.L. and Darne, J.: The role of hCG in regulation of the thyroid gland in normal and abnormal pregnancy. Obstet. Gynecol. 78:298-307, 1991.

Khaliq, A., Li, X.F., Shams, M., Sisi, P., Acevedo, C.A., Whittle, M.J., Weich, H. and Ahmed, A.: Localisation of placenta growth factor PlGF in human term placenta. Growth Factors 13:243-250, 1996.

Khaliq, A., Dunk, C., Jiang, J., Shams, M., Li, X.F., Acevedo, C., Weich, H., Whittle, M. and Ahmed, A.: Hypoxia down-regulates placenta growth factor, whereas fetal growth restriction up-regulates placenta growth factor expression: molecular evidence for "placental hyperoxia" in intrauterine growth restriction. Lab. Invest. 79:151-170, 1999.

Kilby, M.D., Afford, S., Li, X.F., Strain, A.J., Ahmed, A. and Whittle, M.J.: Localisation of hepatocyte growth factor and its receptor (c-met) protein and mRNA in human term placenta. Growth Factors 13:133-139, 1996.

King, B.F.: Ultrastructural differentiation of stromal and vascular components in early macaque placental villi. Amer. J. Anat. 178:30-44, 1987.

Kingdom, J.C.P. and Kaufmann, P.: Oxygen and placental villous development: origins of fetal hypoxia. Placenta 18:613-621, 1997.

Kingdom, J.C.P., Burrell, S.J. and Kaufmann, P.: Pathology and clinical implications of abnormal umbilical artery Doppler waveforms. Ultrasound Obstet. Gynecol. 9:271-286, 1997a.

Kingdom, J.C.P., Macara, L.M., Krebs, C., Leiser, R. and Kaufmann, P.: Pathological basis for abnormal umbilical artery Doppler waveforms in pregnancies complicated by intrauterine growth restriction. Trophoblast Res. 10:291-309, 1997b.

Kiserud, T., Hellevik, L.R., Eik-Nes, S.H., Angelsen, B.A. and Blaas, H.G.: Estimation of the pressure gradient across the fetal ductus venosus based on Doppler velocimetry. Ultrasound Med. Biol. 20:225-232, 1994.

Knoth, M.: Ultrastructure of chorionic villi from a four-somite human embryo. J. Ultrastruct. Res. 25:423-440, 1968.

Kohnen, G., Kosanke, G., Korr, H. and Kaufmann, P.: Comparison of various proliferation markers applied to human placental tissue. Placenta 14:A38, 1993.

Kohnen, G., Castellucci, M., Hsi, B.L., Yeh, C.J.G. and Kaufmann, P.: The monoclonal antibody GB42-a useful marker for the differentiation of myofibroblasts. Cell Tissue Res. 281:231242, 1995.

Kohnen, G., Kertschanska, S., Demir, R. and Kaufmann, P.: Placental villous stroma as a model system for myofibroblast differentiation. Histochem. Cell Biol. 101:415-429, 1996.

Konje, J.C., Huppertz, B., Bell, S.C., Taylor, D. and Kaufmann, P.: 3-dimensional colour power angiography for staging human placental development. Lancet 362:1199-2101, 2003.

Kosanke, G., Castellucci, M., Kaufmann, P. and Mironov, V.A.: Branching patterns of human placental villous trees: perspectives of topological analysis. Placenta 14:591-604, 1993.

Kosanke, G., Kadyrov, M., Korr, H. and Kaufmann, P.: Maternal anemia results in increased proliferation in human placental villi. Trophoblast Res. 11:339-357, 1998.

Krantz, K.E. and Parker, J.C.: Contractile properties of the smooth muscle in the human placenta. Clin. Obstet. Gynecol. 6:26-38, 1963.

Krebs, C., Macara, L.M., Leiser, R., Bowman, A.W., Greer, I.A. and Kingdom, J.C.P.: Intrauterine growth restriction with absent end-diastolic flow velocity in the umbilical artery is associated with maldevelopment of the placental terminal villous tree. Amer. J. Obstet. Gynecol. 175:1534-1542, 1996.

Krebs, C., Longo, L.D. and Leiser, R.: Term ovine placental vasculature: comparison of sea level and high altitude conditions by corrosion cast and histomorphometry. Placenta 18:43-51, 1997.

Kumar, R. and Chaudhuri, B.N.: Altered maternal thyroid function: fetal and neonatal development of rat. Indian J. Physiol. Pharmacol. 33:233-238, 1989.

Kumazaki, K., Nakayama, M., Suehara, N. and Wada, Y.: Expression of vascular endothelial growth factor, placental growth factor, and their receptors Flt-1 and KDR in human placenta under pathologic conditions. Human Pathol. 33:1069-1077, 2002.

Kupferminc, M.J., Daniel, Y., Englender, T., Baram, A., Many, A., Jaffa, A.J., Gull, I. and Lessing, J.B.: Vascular endothelial growth factor is increased in patients with preeclampsia. Amer. J. Reprod. Immunol. 38:302-306, 1997.

Kurjak, A. and Pal, A.: The effect of Gestanon on the fetal and uteroplacental blood flow. Acta Med. Jugosl. 40:121-131, 1986.

Lang, I., Pabst, M.A., Hiden, U., Blaschitz, A., Dohr, G., Hahn, T. and Desoye, G: Heterogeneity of microvascular endothelial cells isolated from human term placenta and macrovascular umbilical vein endothelial cells. Eur. J. Cell Biol. 82:163-173, 2003.

Larsen, L.G., Clausen, H.V., Andersen, B. and Graem, N.: A stereologic study of postmature placentas fixed by dual perfusion. Amer. J. Obstet. Gynecol. 172:500-507, 1995.

Lehmann, W.D., Schuhmann, R. and Kraus, H.: Regionally different steroid biosynthesis within materno-fetal circulation units (placentones) of mature human placentas. J. Perinat. Med. 1:198-204, 1973.

Leiser, R.: Microvascularisation der Ziegenplazenta dargestellt mit rasterelektronisch untersuchten Gefäßausgüssen. Schweiz. Arch. Tierheilkd. 129:59-74, 1987.

Leiser, R., Luckhardt, M., Kaufmann, P., Winterhager, E. and Bruns, U.: The fetal vascularisation of term human placental villi. I. Peripheral stem villi. Anat. Embryol. 173:71-80, 1985.

Leiser, R., Kosanke, G. and Kaufmann, P.: Human placental vascularization. In, Placenta: Basic Research for Clinical Application. H. Soma, ed., pp. 32-45. Karger, Basel, 1991.

Lemtis, H.: Über die Architektonik des Zottengefäßapparates der menschlichen Plazenta. Anat. Anz. 102:106-133, 1955.

Lemtis, H.: New insights into the maternal circulatory system of the human placenta. In, The Foetoplacental Unit. A. Pecile and D. Finzi, eds. Excerpta Medica, Amsterdam, 1969.

Li, X.F., Charnock-Jones, D.S., Zhang, E., Hiby, S., Malik, S., Day, K., Licence, D., Bowen, J.M., Gardner, L., King, A., Loke, Y. W. and Smith, S.K.: Angiogenic growth factor messenger ribonucleic acids in uterine natural killer cells. J. Clin. Endocrinol. Metab. 86:1823-1834, 2001.

Luckett, W.P.: Origin and differentiation of the yolk sac and extraembryonic mesoderm in presomite human and rhesus monkey embryos. Amer. J. Anat. 152:59-97, 1978.

Luttun, A., Tjwa, M., Moons, L., Wu, Y., Angelillo-Scherrer, A., Liao, F., Nagy, J.A., Hooper, A., Priller, J., De Klerck, B., Compernolle, V., Daci, E., Bohlen, P., Dewerchin, M., Herbert, J.M., Fava, R., Matthys, P., Carmeliet, G., Collen, D., Dvorak, H.F., Hicklin, D.J. and Carmeliet, P.: Revascularization of ischemic tissues by PIGF treatment, and inhibition of tumor 
angiogenesis, arthritis and atherosclerosis by anti-Flt1. Nature Med. 8:831-840, 2002.

Lyall, F., Greer, I.A., Boswell, F. and Fleming, R.: Suppression of serum vascular endothelial growth factor immunoreactivity in normal pregnancy and in pre-eclampsia. Br. J. Obstet. Gynecol. 104:223-228, 1997.

Lysiak, J., Khoo, N., Conelly, I., Stettler-Stevenson, W. and Lala, P.: Role of transforming growth factor (TGF) and epidermal growth factor (EGF) on proliferation, invasion, and hCG production by normal and malignant trophoblast. Placenta 13:A41, 1992.

Macara, L., Kingdom, J.C.P., Kaufmann, P., Kohnen, G., Hair, J., More, I.A.R., Lyall, F. and Greer, I.A.: Structural analysis of placental terminal villi from growth-restricted pregnancies with abnormal umbilical artery Doppler waveforms. Placenta 17:37-48, 1996.

Maruo, T., Matsuo, H. and Mochizuki, M.: Thyroid hormone as a biological amplifier of differentiated trophoblast function in early pregnancy. Acta Endocrinol. (Copenh.) 125:58-66, 1991.

Marzolf, G., Lobstein, J.F., Dillmann, J.C., Spizzo, M., Eberst, B. and Gandar, R.: Double blind comparison of the effects of Gestanon versus placebo in intra-uterine growth retardation. Presented at the 4th Asia Oceanic Congress on Perinatology, Tokyo, 1986.

Matsuo, H., Maruo, T., Murata, K. and Mochizuki, M.: Human early placental trophoblasts produce an epidermal growth factor-like substance in synergy with thyroid hormone. Acta Endocrinol. (Copenh.) 128:225-229, 1993.

Mayhew, T.M.: Fetoplacental angiogenesis during gestation is biphasic, longitudinal and occurs by proliferation and remodeling of vascular endothelial cells. Placenta 23:742-750, 2002.

Mayhew, T.M., Charnock-Jones, D.S. and Kaufmann, P.: Aspects of human fetoplacental vasculogenesis and angiogenesis. III. Changes in complicated pregnancies. Placenta 25:127-139, 2004.

Moe, N.: Mitotic activity in the syncytiotrophoblast of the human chorionic villi. Amer. J. Obstet. Gynecol. 110:431, 1971.

Moll, W.: Physiologie der maternen plazentaren Durchblutung. In, Die Plazenta des Menschen. V. Becker, T.H. Schiebler and F. Kubli, eds., pp. 172-194. Thieme, Stuttgart, 1981.

Montgomery, D. and Young, M.: The uptake of naturally occurring amino acids by the plasma membrane of the human placenta. Placenta 3:13-20, 1982.

Mossman, H.W.: The rabbit placenta and the problem of placental transmission. Amer. J. Anat. 37:433-497, 1926.

Mossman, H.W.: The principal interchange vessels of the chorioallantoic placenta of mammals. In, Organogenesis. R.L. DeHann and H. Ursprung, eds., pp. 771-786. Holt Rinehart \& Winston, New York, 1965.

Mühlhauser, J., Crescimanno, C., Kaufmann, P., Höfler, H., Zaccheo, D. and Castellucci, M.: Differentiation and proliferation patterns in human trophoblast revealed by c-erbB-2 oncogene product and EGF-R. J. Histochem. Cytochem. 41:165-173, 1993.

Myers, R.E. and Panigel, M.: Experimental placental detachment in the rhesus monkey: changes in villous ultrastructure. J. Med. Primatol. 2:170-189, 1973.

Naeye, R.L., Maisels, J., Lorenz, R.P. and Botti, J.J.: The clinical significance of placental villous edema. Pediatrics 71:588-594, 1983.
Nikolov, S.D. and Schiebler, T.H.: Über das fetale Gefäßsystem der reifen menschlichen Plazenta. Z. Zellforsch. 139:333-350, 1973.

Nikolov, S.D. and Schiebler, T.H.: Über Endothelzellen in Zottengefäßen der reifen menschlichen Plazenta. Acta Anat. (Basel) 110:338-344, 1981.

Odorisio, T., Schietroma, C., Zaccaria, M.L., Cianfarani, F., Tiveron, C., Tatangelo, L., Failla, C.M. and Zambruno, G.: Mice overexpressing placenta growth factor exhibit increased vascularization and vessel permeability. J. Cell Sci. 115:25592567, 2002.

Ogawa, S., Leavy, J., Clauss, M., Koga, S., Shreeniwas, R., JosephSilverstein, J., Furie, M. and Stern, D.: Modulation of endothelial cell (EC) function in hypoxia: alterations in cell growth and the response to monocyte-derived mitogenic factors. J. Cell. Biochem. Suppl. 15F:213, 1991.

O'Neill, J.E.G.: Vascularizacao da placenta humana. Thesis, Universidade Nova de Lisboa, Portugal, 1983.

Ong, P.J. and Burton, G.J.: Thinning of the placental villous membrane during maintenance in hypoxic organ culture: structural adaptation or syncytial degeneration? Eur. J. Obstet. Gynecol. Reprod. Biol. 39:103-110, 1991.

Panigel, M. and Myers, R.E.: The effect of fetectomy and ligature of the interplacental fetal vessels on the ultrastructure of placental villosities in Macaca mulatta. C.R. Acad. Sci. Hebd. Seances Acad. Sci. Ser. D 272:315-318, 1971.

Panigel, M. and Myers, R.E.: Histological and ultrastructural changes in rhesus monkey placenta following interruption of fetal placental circulation by fetectomy or interplacental umbilical vessel ligation. Acta Anat. (Basel) 81:481-506, 1972.

Panigel, M. and Pascaud, M.: Les orifices artériels d'entrée du sang maternel dans la chambre intervilleuse du placenta humain. Bull. Assoc. Anat. 142:1287-1298, 1968.

Papierowski, Z.: Effects of selected progestogens used for the protection of high-risk pregnancy on the clinical course, morphological changes and proliferative activity of the trophoblast. Ginekol. Pol. 52:298-303, 1981.

Paprocki, M.: Morphologie und Morphometrie der Zottengefässe der reifen menschlichen Plazenta nach vorzeitigem Blasensprung. Med. Thesis, University of Technology Aachen, 1992.

Penfold, P., Wootton, R. and Hytten, P.E.: Studies of a single placental cotyledon in vitro. III. The dimensions of the villous capillaries. Placenta 2:161-168, 1981.

Pilz, I., Schweikhart, G. and Kaufmann, P.: Zur Abgrenzung normaler, artefizieller und pathologischer Strukturen in reifen menschlichen Plazentazotten. III. Morphometrische Untersuchungen bei Rh-Inkompatibilität. Arch. Gynecol. Obstet. 229:137-154, 1980.

Piotrowicz, B., Niebroj, T.K. and Sieron, G.: The morphology and histochemistry of the full term placenta in anaemic patients. Folia Histochem. Cytochem. 7:436-444, 1969.

Prager, D., Weber, M.M. and Herman-Bonert, V.: Placental growth factors and releasing/inhibiting peptides. Semin. Reprod. Endocrinol. 10:83-94, 1992.

Pugh, C.W. and Ratcliffe, P.J.: Regulation of angiogenesis by hypoxia: role of the HIF system. Nature Med. 9:677-684, 2003.

Rafii, S., Meeus, S., Dias, S., Hattori, K., Heissig, B., Shmelkov, S., Rafii, D. and Lyden, D.: Contribution of marrow-derived progenitors to vascular and cardiac regeneration. Semin. Cell Dev. Biol. 13:61-67, 2002. 
Ramsey, E.M., Corner, G.W. and Donner, M.W.: Serial and cineradioangiographic visualization of maternal circulation in the primate (hemochorial) placenta. Amer. J. Obstet. Gynecol. 86:213-225, 1963.

Rao, C.V., Ramani, N., Chegini, N., Stadig, B.K., Carman, F.R., Jr., Woost, P.G., Schultz, G.S. and Cook, C.L.: Topography of human placental receptors for epidermal growth factor. J. Biol. Chem. 260:1705-1710, 1985.

Reshetnikova, O.S., Burton, G.J. and Milovanov, A.P.:The effects of hypobaric hypoxia on the terminal villi of the human placenta. J. Physiol. 459:308P, 1993.

Reuvekamp, A., Velsing-Aarts, F.V., Poulina, I.E., Capello, J.J. and Duits, A.J.: Selective deficit of angiogenic growth factors characterises pregnancies complicated by pre-eclampsia. Br. J. Obstet. Gynaecol. 106:1019-1022, 1999.

Reynolds, L.P., Killilea, S.D. and Redmer, D.A.: Angiogenesis in the female reproductive system. FASEB J. 6:886-892, 1992.

Rhodin, J.A.G.: The ultrastructure of mammalian arterioles and precapillary sphincters. J. Ultrastruct. Res. 18:181-223, 1967.

Rhodin, J.A.G.: Ultrastructure of mammalian venous capillaries, venules and small collecting veins. J. Ultrastruct. Res. 25:452-500, 1968.

Risau, W.: Mechanisms of angiogenesis. Nature 386:671-674, 1997.

Risau, W. and Flamme, I.: Vasculogenesis. Ann. Rev. Cell Dev. Biol. 11:73-91, 1995.

Rodesch, F., Simon, P., Donner, C. and Jauniaux, E.: Oxygen measurements in endometrial and trophoblastic tissues during early pregnancy. Obstet. Gynecol. 80:283-285, 1992.

Rossi, P., Karsenty, G., Roberts, A.B., Roche, N.S., Sporn, M.B. and De Crombrugghe, B.: A nuclear factor 1 binding site mediates the transcriptional activation of a type I collagen promoter by transforming growth factor- $\beta$. Cell 52:405-414, 1988.

Salvatore, C.A.: The placenta in acute toxemia. Amer. J. Obstet. Gynecol. 102:347-352, 1968.

Scheffen, I., Kaufmann, P., Philippens, L., Leiser, R., Geisen, C. and Mottaghy, K.: Alterations of the fetal capillary bed in the guinea pig placenta following long-term hypoxia. In, Oxygen Transfer to Tissue, XII. J. Piiper, T.K. Goldstick and D. Meyer, eds., pp. 779-790. Plenum Press, New York, 1990.

Schiebler, T.H. and Kaufmann, P.: Reife Plazenta. In, Die Plazenta des Menschen. V. Becker, T.H. Schiebler and F. Kubli, eds., pp. 51-111. Thieme, Stuttgart, 1981.

Schmid-Schönbein, H.: Conceptional proposition for a specific microcirculatory problem: maternal blood flow in hemochorial multivillous placentae as percolation of a "porous medium.” Trophoblast Res. 3:17-38, 1988.

Schmidt, J.A., Mizel, S.B., Cohen, D. and Green, I.: Interleukin 1: a potential regulator of fibroblast proliferation. J. Immunol. 128:2177-2182, 1982.

Schmon, B., Hartmann, M., Jones, C.J. and Desoye, G.: Insulin and glucose do not affect the glycogen content in isolated and cultured trophoblast cells of human term placenta. J. Clin. Endocrinol. Metab. 73:888-893, 1991.

Schuhmann, R.: Plazenton: Begriff, Entstehung, funktionelle Anatomie. In, Die Plazenta des Menschen. V. Becker, T.H. Schiebler and F. Kubli, eds., pp. 199-207. Thieme Verlag, Stuttgart, 1981.
Schuhmann, R.A.: Placentone structure of the human placenta. Bibl. Anat. 22:46-57, 1982.

Schuhmann, R. and Wehler, V.: Histologische Unterschiede an Plazentazotten innerhalb der materno-fetalen Strömungseinheit. Ein Beitrag zur funktionellen Morphologie der Plazenta. Arch. Gynäkol. 210:425-439, 1971.

Schuhmann, R., Kraus, H., Borst, R. and Geier, G.: Regional unterschiedliche Enzymaktivität innerhalb der Placentone reifer menschlicher Placenten. Histochemische und biochemische Untersuchungen. Arch. Gynäkol. 220:209-226, 1976.

Schweikhart, G. and Kaufmann, P.: Zur Abgrenzung normaler, artefizieller und pathologischer Strukturen in reifen menschlichen Plazentazotten. I. Ultrastruktur des Syncytiotrophoblasten. Arch. Gynäkol. 222:213-230, 1977.

Scott, W.A. and Cohn, Z.A.: Secretory products of mononuclear phagocytes. In, Pathobiology of the Endothelial Cell. H.L. Nossel and H.J. Vogel, eds., pp. 240-258. Raven Press, New York, 1982.

Semenza, G.L.: HIF-1, $\mathrm{O}_{2}$ and the 3 PHDs: How animal cells signal hypoxia to the nucleus. Cell 107:1-3, 2001.

Sen, D.K., Kaufmann, P. and Schweikhart, G.: Classification of human placental villi. II. Morphometry. Cell Tissue Res. 200:425-434, 1979.

Shalaby, F., Rossant, J., Yamaguchi, T.P., Gertsenstein, M., Wu, X.-F., Breitman, M. and Schuh, A.C.: Failure of blood island formation and vasculogenesis in Flk-1-deficient mice. Nature (Lond.) 376:62-66, 1995.

Shams, M. and Ahmed, A.: Localization of mRNA for basic fibroblast growth factor in human placenta. Growth Factors 11:105-111, 1994.

Sharkey, A.M., Charnock-Jones, D.S., Boocock, C.A., Brown, K.D. and Smith, S.K.: Expression of mRNA for vascular endothelial growth factor in human placenta. J. Reprod. Fertil. 99:609-615, 1993.

Sharkey, A.M., Cooper, J.C., Balmforth, J.R., McLaren, J., Clark, D.E., Charnock-Jones, D.S., Morris, N.H. and Smith, S.K.: Maternal plasma levels of vascular endothelial growth factor in normotensive pregnancies and in pregnancies complicated by pre-eclampsia. Eur. J. Clin. Invest. 26:1182-1185, 1996.

Shiraishi, S., Nakagawa, K., Kinukawa, N., Nakano, H. and Sueishi, K.: Immunohistochemical localization of vascular endothelial growth factor in the human placenta. Placenta 17:111-121, 1996.

Shore, V.H., Wang, T.H., Wang, C.L., Torry, R.J., Caudle, M.R. and Torry, D.S.: Vascular endothelial growth factor, placenta growth factor and their receptors in isolated human trophoblast. Placenta 18:657-665, 1997.

Shorter, S., Clover, L. and Starkey, P.: Evidence for both an autocrine and paracrine role for the colony-stimulating factors in regulating placental growth and development. Placenta 13:A58, 1992.

Shreeniwas, R., Ogawa, S., Cozzolino, F., Torcia, G., Braunstein, N., Butura, C., Brett, J., Lieberman, H.B., Furie, M.B. and Joseph-Silverstein, J.: Macrovascular and microvascular endothelium during long-term hypoxia: alterations in cell growth, monolayer permeability, and cell surface coagulant properties. J. Cell. Physiol. 146:8-17, 1991.

Sibley, C.P., Pardi, G., Cetin, I., Todros, T., Piccoli, E., Kaufmann, P., Huppertz, B., Bulfamente, G., Cribiu, F.M., Ayuk, P., Glazier, J. and Radaelli, T.: Pathogenesis of intrauterine growth restric- 
tion (IUGR)—conclusions derived from a European Union Biomed 2 Concerted Action Project 'Importance of Oxygen Supply in Intrauterine Growth Restricted Pregnancies'-A Workshop Report. Placenta 16:S75-S79, 2002.

Somerset, D.A., Li, X.F., Afford, S., Strain, A., Ahmed, A., Sangha, R.K., Whittle, M.J. and Kilby, M.D.: Ontogeny of hepatocyte growth factor (HGF) and its receptor (c-met) in human placenta-reduced HGF expression in intrauterine growth restriction. Amer. J. Pathol. 153:1139-1147, 1998.

Soothill, P.W., Nicolaides, K.H., Rodeck, C.H. and Campbell, S.: Effects of gestational age on fetal and intervillous blood gas and acid-base values in human pregnancy. Fetal Therapy 1:168-175, 1986.

Strauss, D.S.: Growth-stimulatory actions of insulin in vitro and in vivo. Endocr. Rev. 5:356-369, 1984.

Takemura, R. and Werb, Z.: Secretory products of macrophages and their physiological functions. Amer. J. Physiol. 246:C1C9, 1984.

Tedde, G. and Tedde-Piras, A.: Mitotic index of the Langhans' cells in the normal human placenta from the early stages of pregnancy to the term. Acta Anat. (Basel) 100:114-119, 1978.

Thiriot, M. and Panigel, M.: Microcirculation. La microvascularisation des villosites placentaires humaines. C.R. Acad. Sci. D 287:709-712, 1978.

Thorpe Beeston, J.G., Nicolaides, K.H., Snijders, R.J., Felton, C.V. and McGregor, A.M.: Thyroid function in small for gestational age fetuses. Obstet. Gynecol. 77:701-706, 1991.

Todros, T., Sciarrone, A., Piccoli, E., Guiot, C., Kaufmann, P., and Kingdom, J.: Umbilical Doppler waveforms and placental villous angiogenesis in pregnancies complicated by fetal growth restriction. Obstet. Gynecol. 93:499-503, 1999.

Tominaga, T. and Page, E.W.: Accommodation of the human placenta to hypoxia. Amer. J. Obstet. Gynecol. 94:679-691, 1966.

Torry, D.S., Wang, H.S., Wang, T.H., Caudle, M.R. and Torry, R.J.: Preeclampsia is associated with reduced serum levels of placenta growth factor. Amer. J. Obstet. Gynecol. 179:1539-1544, 1998.

Uehara, Y., Minowa, O., Mori, C., Shiota, K., Kuno, J., Noda, T. and Kitamura, N.: Placental defect and embryonic lethality in mice lacking hepatocyte growth factor/scatter factor. Nature 373:702-705, 1995.

Voigt, S., Kaufmann, P. and Schweikhart, G.: Zur Abgrenzung normaler, artefizieller und pathologischer Strukturen in reifen menschlichen Plazentazotten. II. Morphometrische Untersuchungen zum Einfluss des Fixationsmodus. Arch. Gynäkol. 226:347-362, 1978.

Vuckovic, M., Ponting, J., Terman, B.I., Niketic, V., Seif, M.W. and Kumar, S.: Expression of the vascular endothelial growth factor receptor, KDR, in human placenta. J. Anat. 188:361366, 1996.

Vuorela, P., Hatva, E., Lymboussaki, A., Kaipainen, A., Joukov, V. and Persico, M.G.: Expression of vascular endothelial growth factor and placenta growth factor in human placenta. Biol. Reprod. 56:489-494, 1997.

Wallenburg, H.C.S., Hutchinson, D.L., Schuler, H.M., Stolte, L.A.M. and Janssens, J.: The pathogenesis of placental infarc- tion. II. An experimental study in the rhesus monkey. Amer. J. Obstet. Gynecol. 116:841-846, 1973.

Werb, Z.: How the macrophage regulates its extracellular environment. Amer. J. Anat. 166:237-256, 1983.

Werner, C. and Schneiderhan, W.: Plazentamorphologie und Plazentafunktion in Abhängigkeit von der diabetischen Stoffwechselführung. Geburtsh. Frauenheilkd. 32:959-966, 1972.

Wheeler, T., Elcock, C.L. and Anthony, F.W.: Angiogenesis and the placental environment. Placenta 16:289-296, 1995.

Widmaier, G.: Zur Ultrastruktur menschlicher Placentazotten beim Diabetes mellitus. Arch. Gynäkol. 208:396-409, 1970.

Wigglesworth, J.S.: Vascular organization of the human placenta. Nature 216:1120-1121, 1967.

Wilkin, P.: Pathologie du Placenta. Masson, Paris, 1965.

Wilting, J., Birkenhäger, R., Martiny-Baron, G., Marmé, D., Christ, B., Eichmann, A. and Weich, H.A.: Vascular endothelial growth factor (VEGF) and placenta growth factor (PIGF): homologous factors specifically affecting endothelial cells. Ann. Anat. 178:331A, 1995.

Wilting, J., Birkenhäger, R., Eichmann, A., Kurs, H., MartinyBaron, G., Marme, D., McCarthy, J.E.G., Christ, B. and Weich, H.A.: VEGF(121) induces proliferation of vascular endothelial cells and expression of flk-1 without affecting lymphatic vessels of the chorioallantoic membrane. Dev. Biol. 176:7685, 1996.

Wulff, C., Wilson, H., Dickson, S.E., Wiegand, S.J. and Fraser, H.M.: Hemochorial placentation in the primate: expression of vascular endothelial growth factor, angiopoietins, and their receptors throughout pregnancy. Biol. Reprod. 66:802-812, 2002.

Yallampalli, C. and Garfield, R.E.: Inhibition of nitric oxide synthesis in rats during pregnancy produces signs similar to those of preeclampsia. Amer. J. Obstet. Gynecol. 169:13161320, 1993.

Zeek, P.M. and Assali, N.S.: Vascular changes in the decidua associated with eclamptogenic toxemia of pregnancy. Amer. J. Clin. Pathol. 20:1099-1109, 1950.

Zhang, E.G., Smith, S.K., Baker P.N. and Charnock-Jones, D.S.: The regulation and localization of angiopoietin-1, -2, and their receptor Tie-2 in normal and pathologic human placentae. Mol. Med. 7:624-635, 2001.

Zhou, Y., Genbacev, O., Damsky, C.H. and Fisher, S.J.: Oxygen regulates human cytotrophoblast differentiation and invasion: implications for endovascular invasion in normal pregnancy and in pre-eclampsia. J. Reprod. Immunol. 39:197-213, 1998.

Zhou, Y., McMaster, M., Woo, K., Janatpour, M., Perry, J., Karpanen, T., Alitalo, K., Damsky, C. and Fisher, S.J.: Vascular endothelial growth factor ligands and receptors that regulate cytotrophoblast survival are dysregulated in severe preeclampsia and hemolysis, elevated liver enzymes, and low platelets syndrome. Amer. J. Pathol. 160:1405-1423, 2002.

Ziche, M., Maglione, D., Ribatti, D., Morbidelli, L., Lago, C.T., Battisti, M., Paoletti, I., Barra, A., Tucci, M., Parise, G., Vincenti, V., Granger, H.J., Viglietto, G. and Persico, M.G.: Placenta growth factor- 1 is chemotactic, mitogenic, and angiogenic. Lab. Invest. 76:517-531, 1997. 